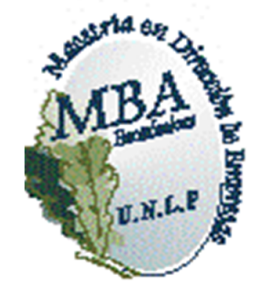

Universidad Nacional de La Plata

Facultad de Ciencias Económicas

MBA - Maestría en Dirección de Empresas

\title{
Satisfacción de los empleadores con los egresados de la carrera de Contador Público de la Facultad de Ciencias Económicas de la UNLP
}

Trabajo final para optar al título de Magister

Autora: Cra. Silvina Anabel Masci

Director: Cr. Rubén Galle

La Plata

Octubre de 2015 


\section{Indice}

Resumen Ejecutivo _ 1

2.- Objetivos de la Investigación __ 3

3.- Evaluación del Problema ___ 3

4.- Alcances de la Presente Investigación __ 4

5.- Marco Teórico de Referencia __ 5

Calidad: Concepto

Aportes Destacables de Expertos en Calidad:

$>$ Edwards Deming___ 9

$>$ Joseph M. Juran _ 11

$>$ Philip B. Crosby _ _ 14

$>$ Armand V. Feigenbaum _ 19

$>$ Kaoru Ishikawa ___ 21

$>$ Taichi Ohno__ 24

$>$ Masaaki Imai___ 24

$>$ Genichi Taguchi _ 25

$>$ Kiyoshi Suzaki __ 25

Evolución de la Calidad __ 25

Calidad en Educación ___ 27

6.- Metodología de la investigación __ 36

Población y muestra___ 36

Tipo de Investigación ___ 37

Técnicas de recolección de datos __ 38

Técnicas de análisis _ـ 39

Comprobando las competencias de los graduados ___ 39

Estableciendo las expectativas de los “clientes" __ 40 
Estableciendo las brechas

Medición de las variables

7.- Análisis de los Datos 47

Estadística descriptiva univariada 47

Percepción y expectativas sobre conocimientos 52

1) Principios básicos y conceptos relacionados con su carrera___ 52

2) Fundamentos económicos de su carrera ___ 53

3) Procesos técnicos en al menos una disciplina de su carrera___ 53

4) Identificación de problemas, formulación y desarrollo de la solución___ _ 54

5) Utilización de un enfoque de sistema__ 55

6) Desarrollo económico sostenible __ 55

7) Leyes, reglamentos y normas ___ 56

8) Principios de gestión y negocios ___ 56

9) Relación con otras disciplinas ___ 57

Percepción y expectativas sobre habilidades _ـ 59

1) Principios básicos y conceptos relacionados con su carrera___ 59

2) Tecnologías disponibles___ 59

3) Acceder, evaluar y sintetizar información __ 60

4) Comunicación con profesionales de otras disciplinas y la sociedad en general ___ _ _ 61

5) Funcionar eficazmente como individuo ___ 61

6) Funcionar eficazmente en equipos multidisciplinarios___ 62

7) Funcionar eficazmente en equipos con capacidad de ser miembro ___ 63

8) Funcionar eficazmente en equipos con capacidad de ser director ___ 63

9) Funcionar eficazmente en equipos con capacidad de ser líder ___ 64

Percepción y expectativas sobre actitudes ___ 66

1) Pensar crítica, creativa y reflexivamente ___ 66

2) Compromiso al aprendizaje permanente___ 66

3) Compromiso a cumplir con responsabilidades éticas ___ 67

4) Compromiso a cumplir con responsabilidades ambientales___ 67

5) Compromiso a trabajar con perspectivas internacionales ___ 68

6) Desarrollo de habilidades profesionales __ 68

7) Compromiso a trabajar con diferentes grupos culturales___ 69

8) Compromiso a utilizar habilidades grupales __ 69

9) Compromiso a desarrollar habilidades interpersonales __ 70

Nivel de satisfacción __ 71

Nivel de desempeño 
Análisis de correlación 72

Significación del coeficiente de correlación 74

Correlación Satisfacción - Competencias 75

8. Conclusiones 77

Percepción de los empleadores 77

Expectativas de los empleadores 78

Brecha entre expectativas y percepciones de los empleadores 78

9. Recomendaciones 80

10. Anexo A: Coeficiente de correlación y prueba de hipótesis 81

11. Anexo B: Encuesta para empleadores 84

12.- Bibliografía 91 


\section{Resumen ejecutivo}

Los estudiantes son el activo más importante con el que cuenta cualquier universidad del mundo y son éstos, los estudiantes, los que permiten además que una universidad perdure en el tiempo.

Por otro lado, un aspecto más que importante en la vida de cualquier egresado es su desarrollo profesional, para lo cual necesita que la demanda laboral se interese en sus servicios.

El presente trabajo intentará determinar el nivel de calidad de los egresados de contador público de la Universidad Nacional de La Plata, desde la óptica de aquellos agentes económicos que demandan los servicios de los egresados.

A tales efectos se recolectaron datos sobre una muestra poblacional de egresados de Contador Público, que desempeñan sus funciones tanto en el sector público como en el sector privado. Luego, se elaboraron deferentes indicadores para determinar el nivel de calidad de los egresados.

El objetivo del mismo es, por lo tanto, identificar las fortalezas y debilidades de los egresados respecto de las expectativas y necesidades de los empleadores para que, en última instancia, las expectativas no satisfechas sirvan como guía para establecer acciones que permitan mejorar la calidad de los empleados.

\section{1.- Formulación del problema}

El concepto de calidad implica la relación entre lo que el consumidor percibe del producto o servicio recibido comparado con las expectativas que tenía del mismo. Tradicionalmente en educación, se ha puesto énfasis en definir a los estudiantes como aquellos individuos que deben hacer la evaluación de calidad. Es 
decir que se identifica a los estudiantes como el cliente final del servicio que ofrece una Facultad determinada.

La calidad como eficacia interna de los sistemas e instituciones de educación universitaria aparece como reacción a la insuficiencia de los indicadores cuantitativos de eficacia y productividad, y se vincula con las características, consideradas cualitativas, de los procesos y productos de la Universidad. La educación superior no sólo preocupa a los participantes en el proceso educativo (profesores, alumnos, investigadores y rectores universitarios) y, a los gobiernos y sus agencias, sino también a los empresarios y empleadores que consideran a las instituciones universitarias como centros de capacitación de profesionales de alto nivel y de producción de conocimiento y tecnología esenciales para mantener el ritmo de desarrollo económico.

En este trabajo se intenta evaluar la calidad de la educación desde una óptica diferente. En particular se define al egresado como el "producto" generado por la Facultad de Ciencias Económicas y a los empleadores como aquel destinatario final de dicho "producto", es decir, el "cliente". Estos últimos son los que harán uso de la demanda laboral formada por los egresados. $Y$ en última instancia, evaluarán si continúan o no adquiriendo sus servicios. Por lo tanto, son los empleadores los que establecerán la calidad de los graduados en este caso de la Facultad de Ciencias Económicas.

Esta información es estratégica y actualmente se desconoce, es decir no existe información que le permita evaluar a la Facultad de Ciencias Económicas su calidad "produciendo" profesionales de las distintas carreras bajo su ámbito.

El proceso de calidad total se inicia con la detección de problemas y deficiencias y la propuesta de determinadas soluciones. La gestión de la calidad se fundamenta en el desarrollo continuo de planes integrales y en la toma de decisiones como consecuencia de datos y evidencias. Por lo tanto es preciso evaluar. Es por ello que el trabajo propone evaluar dicha calidad investigando la misma desde la óptica de los clientes: los empleadores.

La calidad desde el punto de vista del cliente está relacionada con el grado en que sus expectativas son satisfechas teniendo en cuenta el precio que está dispuesto a pagar o pagó. Cuanto más supere el producto o servicio las expectativas 
del cliente mayor será su satisfacción. Pero para esto es fundamental conocer esas expectativas. Carecer de esta información es un problema estratégico ya que no se tienen las herramientas para evaluar la calidad del "producto" ofrecido y por lo tanto es difícil tomar medidas acertadas para mejorarla si es necesario.

\section{2.- Objetivos de la investigación}

El trabajo plantea los siguientes objetivos:

a) Identificar los aspectos críticos del desempeño profesional de los egresados de Contador Público de la Facultad de Ciencias Económicas de la Universidad Nacional de La Plata desde el punto de vista de los usuarios de sus servicios, es decir, los empleadores.

b) Identificar los estándares de satisfacción de los empleadores respecto de los profesionales para cada uno de los aspectos críticos encontrados en el punto anterior.

c) Medir cada una de las variables identificadas y determinar la "brecha" entre las expectativas de los empleadores y su percepción de la realidad.

d) Retroalimentar a la Facultad de Ciencias Económicas de la UNLP con los resultados de la investigación.

\section{3.- Evaluación del problema}

Las empresas se desarrollan y operan en mercados globalizados, por lo tanto para que puedan crecer y perdurar en el tiempo deben generar bienes y servicios con ventajas comparativas respecto de sus competidores. Un elemento clave para generar éstas ventajas comparativas viene dado por el aporte de los profesionales que 
forman cada una de las empresas. Los recursos humanos son los que incorporarán el valor agregado que necesitan las empresas para poder diferenciarse, y las distintas Facultades son las encargadas de formar estos recursos más allá de las capacidades innatas con que cuente cada uno de ellos.

Para que el país alcance un nivel competitivo las Universidades deben enfocar el objetivo de la mayor calidad, conocimiento y competencias para sus graduados. Como se hizo mención anteriormente, uno de los objetivos de la Facultad de Ciencias Económicas de la UNLP es proveer graduados calificados, por lo tanto la calidad de los graduados es un aspecto clave que debe ser estudiado. Pero al mismo tiempo, el estándar de calidad debe estar relacionado con las exigencias o demandas de los agentes que harán uso de los graduados.

Por lo tanto, todos los sectores deben contribuir para tener una respuesta coherente a la demanda (actual y futura) de trabajo, con un modelo que integre rendimiento y expectativas respecto de las habilidades y conocimiento de los graduados.

Por la necesidad de acotar el campo de estudio, ésta investigación pondrá particular énfasis en la calidad de los graduados de Contador Público de la UNLP.

\section{4.- Alcances de la investigación}

Los resultados que se presentan son el producto de un proyecto de investigación del MBA cuyo título es "Satisfacción de los empleadores con los egresados de la Facultad de Ciencias Económicas de la UNLP", con un tronco común que luego se divide en cada una de las carreras integrantes de la Facultad de Ciencias Económicas de la Universidad Nacional de La Plata (UNLP).

La presente investigación comprende aquellos graduados que no posean más de 5 años de experiencia al momento de haberse realizado la encuesta de calidad a los respectivos empleadores / supervisores. El motivo de esta restricción es intentar que la opinión de los empleadores no esté influenciada por las aptitudes y 
habilidades adquiridas en el ámbito laboral, siendo las conseguidas durante el aprendizaje las que definan la calidad de los graduados.

El trabajo expuesto a continuación servirá como base para futuras comparaciones a partir de la recolección de una nueva muestra de graduados.

\section{5.- Marco teórico de referencia}

El marco teórico del presente estudio está conformado por las bases teóricas y antecedentes relacionados con lo que se entiende por calidad. Luego se avanzará sobre la aplicación de dicho concepto a la educación.

\section{Calidad: Concepto}

La calidad puede ser un concepto confuso debido en parte a que la gente considera a la calidad de acuerdo con diversos criterios basados en sus preferencias y necesidades individuales. Es un término abstracto y subjetivo, es decir, depende de la "mirada" de quien esté juzgando. Además el significado de calidad sigue evolucionando conforme pasa el tiempo y las necesidades y preferencias cambian en el tiempo.

A principios de la década de 1900, aparecen los principios y postulados de la administración científica de Frederick Taylor y dan lugar a una nueva filosofía de producción. La administración científica separa la planeación de la ejecución, a los ingenieros y administradores se le hizo responsable de la planeación y a los supervisores y obreros se les responsabilizó de la ejecución. Esta teoría establece la división del trabajo y el aseguramiento de que la calidad queda en manos de los supervisores pero se hace necesario la medición e inspección para lograr la calidad del producto deseada y a la vez controlar los costos de la producción. La medición e inspección es el medio principal del control de la calidad.

Después de la segunda guerra mundial, los escases de bienes de consumo en Estados Unidos, hizo que la producción se convirtiera en una prioridad. 
En la mayoría de las empresas, la calidad siguió siendo dominio de un especialista, no era una prioridad de la alta gerencia.

Fue durante la época de los años 50, cuando el Dr. Joseph Juran y el Dr. W. Edward Deming, presentaron a los japoneses, técnicas de control de calidad estadística que les ayudarían en sus esfuerzos de reconstrucción de Japón. Una parte importante de su actividad educativa estaba enfocada en la alta administración. Con el apoyo de los directivos, los japoneses integraron la calidad en todas sus organizaciones y desarrollaron una cultura de mejoramiento continuo (que en ocasiones los japoneses llaman KAIZEN).

Para la década de los años 70 , debido sobre todo a la mayor calidad de sus productos, la penetración de las compañías japonesas en los mercados occidentales fue significativa. No fue sino hasta 1980 que Estados Unidos, en medio de una crisis de calidad provocada por el dominio de los productos japoneses, inició un movimiento sobre la calidad basado en los conceptos de W. Edwards Deming.

Aunque en un principio las iniciativas para la calidad se enfocaban en reducir defectos y errores en los productos y servicios mediante el uso de la medición, la estadística y otras herramientas para la solución de problemas, las organizaciones empezaron a reconocer que no era posible lograr mejoras duraderas sin una atención significativa hacia la calidad de las prácticas administrativas que se aplican cotidianamente.

Los administradores empezaron a darse cuenta que los enfoques que emplean como:

- Escuchar al cliente

- Establecer relaciones con el cliente a largo plazo

- Crear estrategias

- Medir el desempeño y analizar la información

- Premiar y capacitar a los empleados

- Diseñar productos y servicios conforme a las expectativas del cliente

- Ofrecer productos y servicios de calidad.

Son los factores que dan lugar a la calidad y satisfacción del cliente. 
Así nace la filosofía de la administración de la calidad total. La calidad adquirió un nuevo significado de excelencia en toda la empresa. La Calidad Total se basa en tres principios fundamentales:

1) Un enfoque en los clientes y accionistas

2) La participación y el trabajo en equipo en toda la organización

3) Un enfoque del proceso que cuenta con el apoyo del mejoramiento y el aprendizaje continuo.

Por tanto, es importante entender las diferentes perspectivas desde las cuales se ve la calidad, a fin de apreciar por completo el papel que desempeña en las distintas partes de una organización de negocios.

\section{Enfoque basado en el juicio}

Una noción común sobre la calidad, que los consumidores utilizan a menudo, es que es sinónimo de superioridad o excelencia. En 1931, Walter Shewhart definió primero la calidad como la bondad o conformidad de un producto. Este punto de vista se conoce como la definición trascendente (trascender: elevarse o extenderse más allá de los límites ordinarios). En este sentido, la calidad "se puede conocer en forma absoluta y universal, una marca de normas inflexibles y altos logros". Como tal, no se puede definir con precisión, sólo se la reconoce cuando se la ve. A menudo se relaciona con una comparación de rasgos y características de los productos promulgados mediante esfuerzos de mercadotecnia dirigidos a desarrollar la calidad como una imagen variable en la mente de los consumidores. Algunos ejemplos comunes de los productos a los que se atribuye esta imagen son los relojes Rolex y los automóviles BMW.

Sin embargo, la excelencia es abstracta y subjetiva, y los estándares de excelencia pueden variar de manera considerable entre los individuos. De ahí que la definición trascendente tenga poco valor práctico para los gerentes, pues no ofrece medios para medir ni evaluar la calidad, como base para la toma de decisiones. 


\section{Enfoque hacia los productos}

Esta definición identifica a la calidad como una función para una variable de manera específica, de forma tal que las diferencias en la calidad reflejan las diferencias en la cantidad de algún atributo del producto.

Esta evaluación implica que niveles o cantidades superiores de estos atributos en un producto equivalen a una mejor calidad.

Como resultado de lo anterior a menudo se supone que la calidad se relaciona más con el precio: cuanto más alto es el precio, más alto será la calidad. Esto es un concepto erróneo.

\section{Enfoque hacia el usuario}

La calidad se determina de acuerdo con lo que el cliente quiere. Las personas tienen distintos deseos y necesidades, lo que lleva a una definición basada en el usuario: "la calidad es la adaptación al uso para el cual el producto se compra", o la manera en que el producto cubre la función para la que está destinado. Por lo tanto, La calidad es cubrir o exceder las expectativas del cliente.

\section{Enfoque hacia el valor}

Calidad es la relación entre el uso o la satisfacción con el precio. Desde este punto de vista, un producto de calidad es aquel que es tan útil como los productos con los que compite y se vende a un precio más bajo, o bien aquel que ofrece mejor uso o satisfacción a un precio comparable

\section{Enfoque hacia la manufactura}

Calidad es la conformidad con las especificaciones. Las especificaciones son el objetivo y tolerancias que determinan los diseñadores de los productos y servicios. El objetivo es el conjunto de valores ideales que la producción debe buscar, 
las tolerancias se especifican porque los diseñadores reconocen que es imposible alcanzar el objetivo en todo momento de la fabricación.

\section{Aportes destacables de expertos en calidad}

\section{Edwards Deming}

El concepto de calidad tomo mayor importancia por los años 50's donde aparece Edwards Deming quien fue el más importante en el estudio de la calidad, se le reconoce que logró cambiar la mentalidad de los japoneses al hacerles entender que la calidad es un "arma estratégica".

Demostró los altos costos que una empresa genera cuando no tiene un proceso planeado para administrar su calidad, es decir el desperdicio de materiales y productos rechazados, el costo de trabajar dos o más veces los productos para eliminar defectos, o la reposición y compensación pagada a los clientes por las fallas en los mismos.

Deming mejoró el círculo de calidad propuesto por Shewhart, el cual consiste en localizar el problema y atacarlo de raíz, a través de 4 etapas las cuales son "Planear, Hacer, Verificar y Actuar".

El Círculo de Calidad se transforma en un proceso de mejora continua, ya que se analiza cada parte del proceso para ver cuál es la problemática y esto ayuda a conocerlo mejor y evitar futuros errores, y una vez que se logren los objetivos del primer esfuerzo hay que seguirlo estableciendo, y no dejar de seguir el proceso.

Deming aporto una serie de puntos los cuales deben adoptarse como una filosofía de vida para una empresa, ya sea pequeña, mediana o grande. Los 14 puntos que Deming ofrece son los siguientes:

1) Crear constancia de propósito: Esto es para mejorar productos 0 servicios. Significa crear un plan para permanecer dentro del negocio ya sea a corto, mediano o largo plazo. 
2) Adoptar la nueva filosofía: Para poder entrar a la nueva era económica, estableciendo un liderazgo dirigido al cambio. Esto hace que las empresas que vivan con la cultura del error, no le pueden asegurar a la compañía su permanencia en el mercado. Los artículos con defectos no son gratis, y puede ser más costoso corregir un error, que producir un artículo nuevo. El cambio de cultura no es fácil, y se lleva tiempo, pero solo la alta gerencia puede lograrlo.

3) Terminar con la dependencia de la inspección: La inspección siempre es tardía, ineficaz y costosa. El nuevo objetivo de la inspección es la auditoría para poder detectar cambios en el proceso y comprobar medidas preventivas.

4) Terminar con la práctica de decidir negocios con base en los precios: No se puede permitir que la competitividad de un producto este basada únicamente en su precio, menos ahora que las necesidades del cliente se basan en la confiabilidad de los productos.

5) Mejorar el sistema de producción y de servicios: Esto debe hacerse de una forma constante y permanente para poder mejorar la calidad y productividad, y así mismo reducir los costos y de la misma manera reducir los errores y desperdicios en los productos.

6) Entrenamiento del trabajo: Uno de los principales problemas en entrenamiento, y la supervisión, es que no se han fijado estándares para poder medir cuál es un trabajo aceptable y cuál no lo es. Porque este estándar sólo se ligaba con la necesidad del supervisor de obtener determinada cantidad de producción sin importar la calidad de éstos.

7) Adoptar e instituir el liderazgo: La supervisión es responsabilidad de la administración y debe de eliminar las barreras que le impidan al trabajador desarrollar sus actividades con orgullo.

8) Eliminar temores: El miedo irá desapareciendo en la medida en que la administración, incluso los gerentes se vuelva un apoyo para sus trabajadores e inspiren confianza en ellos.

9) Romper las barreras entre los departamentos: Entre departamentos deben de conocerse muy ampliamente y saber qué es lo que afecta a cada uno de los departamentos. 
10) Eliminar slogan: Es muy importante eliminar todo tipo de slogan que impliquen la perfección o un nuevo nivel de producción, sin proponer cómo lograrlo.

El proponer metas, sin un método para llegar a ellas, va a producir más efectos negativos que positivos.

11) Eliminar estándares: Normalmente estos estándares y metas numéricas vienen a sustituir al liderazgo.

12) Eliminar barreras que impidan alcanzar el orgullo al trabajador: Un trabajador no podrá sentirse orgulloso de su trabajo, sino está enterado cuando está bien y cuando no.

13) Instituir un activo programa de educación: Es necesario capacitar al personal en cuanto al uso de las estadísticas, para poder incorporar algunos sencillos métodos para que los empleados puedan llevar el control diario. El proceso de capacitación es sencillo, y puede hacerse en todos los niveles.

14) Implicar a todo el personal en la transformación: La administración necesitará la orientación de algún experto, pero este no asumirá la responsabilidad que le compete a la administración.

Para concluir se puede decir que Deming se refería como calidad a todo aquello que le hiciera ahorrar a la empresa y a su vez cumplir a tiempo con la entrega del producto al cliente. Esto cambió totalmente la manera de pensar de los gerentes al decirles que era más barato hacer un producto nuevo que corregirlo ya que esto conlleva a la pérdida de tiempo y esfuerzo. DEMING también recalcó observar las líneas de producción para observar dónde se estaba dando el problema y por qué y así eliminar lo que estaba fallando de raíz y esto ayuda a conocer cada vez mejor el sistema y aplicarlo a una forma de mejora continua y contribuir a la satisfacción del cliente.

\section{Joseph M. Juran}

Abogado de profesión orientado a la estadística de costos de la "no calidad". La filosofía de Juran, así como de los demás filósofos de la calidad, está enfocada a que las empresas consigan y mantengan, por consiguiente, el liderazgo en la calidad, definir los papeles de los altos directivos para conducir sus empresas hacia ese objetivo y disponer los medios que han de utilizar los directivos para ese liderazgo. 
Juran basa su teoría acerca de la calidad a partir de las observaciones hechas a los japoneses y sus estrategias utilizadas, las cuales incluían:

- Ocupación de la alta dirección

- Formación para todas las funciones y en todos los niveles

- Mejora de la calidad a un ritmo continuo y revolucionario

- Participación de la mano de obra a través de los círculos de control de calidad

Para Juran la calidad incluye ciertos elementos que conviene definir:

- Producto: Salida de cualquier proceso el cual consiste en bienes y servicios.

- Cliente: Cualquier persona que recibe el producto o proceso o es afectado por él. Los clientes externos son afectados por el producto pero no son miembros de la empresa que los produce; los clientes internos son afectados por el producto y son miembros de la empresa que los produce.

- Satisfacción del producto: es el resultado que se obtiene cuando las características del producto responden a las necesidades del cliente, generalmente, es sinónimo de satisfacción del cliente.

- Deficiencia del producto: es un fallo que tiene como consecuencia la insatisfacción con el producto; el mayor impacto lo ejercen sobre los costos, al rehacer el trabajo previo y responder a las reclamaciones del cliente.

Juran desarrolló un modelo para la administración de la calidad que fue llamada la Trilogía de Juran: Planeación, Control, Mejora.

a) Planeamiento de la calidad

Esta es la actividad de desarrollo de los productos y procesos requeridos para satisfacer las necesidades de los clientes e implica los siguientes pasos:

- Determinar quiénes son los clientes

- Determinar las necesidades de los clientes 
- Desarrollar las características del producto que responden a las necesidades de los clientes

- Desarrollar los procesos que sean capaces de producir aquellas características del producto

- Transferir los planes resultantes a las fuerzas operativas

b) Control de calidad

Este proceso consta de los siguientes pasos:

- Evaluar el comportamiento real de la calidad

- Comparar el comportamiento real con los objetivos de calidad

- Actuar sobre diferencias

c) Mejora de la calidad

Es el medio de elevar la calidad. La metodología consta de los siguientes Pasos Universales:

- Establecer la infraestructura necesaria para conseguir una mejora de la calidad anualmente

- Identificar las necesidades concretas para mejorar los proyectos de mejora

- Establecer un equipo de personas para cada proyecto con una responsabilidad clara de llevar el proyecto a buen fin

- Proporcionar los recursos, la motivación y la formación necesaria para que los equipos diagnostiquen las causas, fomenten el establecimiento de un remedio y establezcan los controles para mantenerlos beneficios 


\section{Philip B. Crosby}

La idea esencial del movimiento de calidad de Crosby es la prevención. Sostiene que la calidad es gratis. Sus costos sólo están relacionados con los diversos obstáculos que impiden que los operarios la tengan desde a la primera vez.

El principal objetivo de las empresas al implantar un sistema de calidad total debe ser, de acuerdo con Crosby, cero defectos. Luego, los niveles aceptables de calidad deben prohibirse porque comprometen el objetivo de cero defectos.

Existen dos grandes problemas causantes de la mala calidad en la industria: los que se deben a la falta de conocimientos de los empleados y los que se originan en los descuidos y las faltas de atención. Los primeros pueden identificarse con gran facilidad, medirse y resolverse, pero los segundos requieren de un esfuerzo gerencial a largo plazo para modificar la cultura y las actitudes.

Para Philip B. Crosby, el proceso de mejoramiento de calidad debe partir de un compromiso de la alta dirección, y de una filosofía en la que todos los miembros de la organización comprenden sus propósitos. Lograr calidad sólo es posible a través de un cambio de cultura de la empresa en donde se le concede al personal la oportunidad de vivir con dignidad, brindándole un trabajo significativo y un ingreso suficiente.

Crosby destaca que los círculos de calidad y las estadísticas representan una mínima parte de la tarea encaminada a lograr la calidad. Las fases del cambio para lograr la calidad son: convicción de la dirección, compromiso de la alta gerencia y de todo el personal y conversión de la cultura organizacional. Por otra parte, Crosby señala que "la empresa que desee evitar conflictos, eliminar el incumplimiento de los requisitos, ahorrar dinero, y mantener satisfechos a sus clientes debe vacunarse". Esta vacuna comprende tres estrategias administrativas que son: Determinación, educación e implantación.

\section{a) Determinación}

Surge cuando los miembros de un equipo de trabajo deciden que no están dispuestos a tolerar por más tiempo una situación inconveniente y reconocen que sus propias acciones constituyen el único instrumento que permitirá cambiar las 
características de la organización. Toman conciencia de los cuatro principios absolutos, que son el fundamento conceptual del proceso de mejoramiento de la calidad:

\section{1) La calidad implica cumplir con los requerimientos}

Este principio establece que para mejorar la calidad todo personal debe estar consciente de que deben hacer las cosas bien desde la primera vez. Pero para que esto se lleve a cabo, los directivos tienen que establecer claramente los requerimientos que deben de cumplir los empleados; suministrar los medios necesarios para que el personal cumpla con los mismos y dedicar todo su tiempo a estudiar y ayudar al personal.

\section{2) La calidad proviene de la prevención}

Este principio señala que es más fácil y menos costoso prevenir las cosas que corregirlas. La prevención se basa en la comprensión del proceso, por lo tanto hay que observar el proceso y determinar las posibles causas de error.

\section{3) El estándar de calidad es cero defectos}

Crosby creó el concepto de cero defectos, por que afirma que el personal debe saber precisamente lo que se espera de ellos. Por lo que no deben establecerse niveles de calidad o estándares de trabajo, sino más bien un estado ideal del trabajo. Cero defectos es hacer lo acordado en el momento acordado, es hacer bien las cosas desde la primera vez, es tomar en serio los requisitos

\section{4) La medición de la calidad es el precio de la inconformidad}

Aquí se menciona una forma de evaluar la calidad dentro de la empresa, costeando las actividades que se tengan que realizar por haber hecho las cosas mal (incumplimiento de requisitos). Desde correcciones hasta el pago de garantías y reclamaciones e incluso la entrega de nuevos productos por defectuosos. 


\section{b) Educación}

Una vez que en la empresa haya la determinación de conseguir la calidad de sus productos y terminar con sus problemas, se requiere de un programa de educación continuo para todo el personal. La educación tiene que ser un proceso cotidiano para que todos comprendan los cuatro principios absolutos del proceso de mejoramiento de calidad y lo que implica propiciar la calidad total dentro de la organización. Los cursos de capacitación se impartirán a los siguientes niveles: Ejecutivos, gerentes y personal. De esta manera similar a las afirmaciones de Deming y Juran, Crosby piensa que el desempeño de las compañías es el reflejo de la actitud gerencial con respecto a la calidad.

Para lograr grandes mejoras, la gerencia tiene que estar convencida de los siguientes pasos:

- Que tienen un problema de calidad y que esta debe usarse para operar con ventaja

- Que tendrán que comprometerse a comprender y aplicar los cuatro principios absolutos de la administración de calidad

- Que deben cambiar la manera de pensar y abandonar los criterios convencionales que causan los problemas.

Crosby sostiene que se requiere un tiempo largo para pasar de la convicción a la conversión pero que, tan pronto como empieza el proceso de transferencia, se inician las mejoras.

\section{c) Implantación}

La implantación consiste en establecer el proceso de mejoramiento dentro de la organización en forma metódica, para lo cual Crosby propone los siguientes principios:

\section{1) Compromiso gerencial}

La alta dirección debe elaborar una política de calidad; el tema principal de discusión en sus reuniones debe ser la calidad. 


\section{2) Equipo de mejoras de calidad}

Para formar este equipo deben conjuntarse participantes de cada departamento. Deberá tener alguien que tenga fácil comunicación con la alta gerencia para establecer la estrategia general a seguir.

3) Medición de la calidad

Todo personal debe pensar en su trabajo y cómo medirlo, pues así conocerán como y hacia dónde va. A través de la medición, los requisitos de cada actividad o trabajo se van consolidando 0 definiendo específicamente.

4) Costo de la evaluación de la calidad

Se establece el costo de calidad para indicar de dónde se deben aplicar acciones correctivas que sean rentables para la compañía.

\section{5) Percepción de calidad}

Se debe concientizar al personal por medio de información, de lo que cuesta hacer las cosas mal y los resultados que se obtienen con el mejoramiento de la calidad.

\section{6) Acciones correctivas}

Se refiere a establecer un sistema de corrección, el cual se basará en información relevante del problema y análisis detallado que muestren las causas que lo originan, para eliminarlo.

7) Formación de un comité adecuado para el programa cero defectos

Elaborar un plan y/o programa de desarrollo de una convivencia social de la empresa, en el cual participaran oradores que representen a los clientes, los sindicatos, las comunidades, los empleados y todos aquellos que estén interesados en la calidad. 


\section{8) Entrenamiento de supervisores}

Después que los directivos han comprendido y se han comprometido con los cuatro principios absolutos, se debe educar al personal para concientizarlo, para que sea menos tolerante a los defectos y errores, lo que dará como resultado el mejoramiento deseado.

9) Celebración del día cero defectos

Debe implantarse un programa formal de orientación para cero defectos, que debe desarrollarse antes de poner en acción las medidas pertinentes.

10) Establecimiento de las metas

Las reuniones periódicas entre los supervisores y los empleados, ayudan a que el personal piense en términos de alcanzar las metas y desarrollar las tareas específicas en equipo.

11) Eliminación de las causas de errores

Se solicita al personal que señale los problemas existentes dentro de sus actividades o relación laboral, para de esta manera resolver las causas de error.

12) Reconocimientos

Se establecen programas de recompensas para premiar a los que cumplen sus metas o desarrollan labores extraordinarias. No es necesario que las recompensas sean económicas; lo importante es el reconocimiento público. 
13) Consejos de calidad

Consiste en reunir a todos los profesionales de la calidad, con el objetivo de que exista retroalimentación y comenten sus experiencias en la eliminación de problemas, para que se estimule entre ellos y los empleados la certeza de alcanzar cero defectos.

14) Hacerlo nuevamente

En el momento en que se ha alcanzado cierta madurez en el proceso, el equipo de mejoramiento de la calidad, debe transferir todas sus responsabilidades a uno nuevo que revitalice el proceso e inicie innovaciones para obtener aún mayores mejoras.

\section{Armand V. Feigenbaum}

Feigenbaum tiene tres contribuciones en lo que respecta a la calidad: la promoción internacional de la ética de la calidad, la formulación del concepto de calidad total, y la elaboración de la clasificación de costos de calidad.

Sus contribuciones fueron presentadas en su libro Total Quality Control, publicado por primera vez en 1951 con el título "Quality Control: Principles, Practice and Administration". Este concepto fue recogido por los japoneses y llegó a ser el cimiento de su práctica de control de calidad.

Feigenbaum es uno de los pioneros del movimiento hacia la calidad y productividad. Fue conocido por los Japoneses casi al mismo tiempo que Deming y Juran ya que como jefe de calidad de General Electric, tuvo muchos contactos con compañías japonesas tales como, Hitachi y Toshiba.

Fue el primero en afirmar que la calidad debe considerarse en todas las diferentes etapas del proceso y no sólo en la función de manufactura. Sostiene que la contribución de la función de manufactura considerada de manera aislada, no es suficiente para obtener productos de alta calidad, expresó lo siguiente:

"El principio fundamental del concepto de calidad total, así como su diferencia con otros conceptos, es que, para que sea de una efectividad genuina, el 
control debe iniciar por la identificación de los requerimientos de la calidad del cliente y termine solamente cuando el producto que llega a sus manos produzca un cliente satisfecho. El control de calidad total guía las acciones coordinadas de personas, máquinas e información, para alcanzar este objetivo. El primer principio que debe tomarse en cuenta es que la calidad es responsabilidad de todos".

Feigenbaum sostiene que el curso de los nuevos productos en una fábrica pasa por etapas similares a lo que él llama el ciclo industrial. Considera tres categorías de etapas:

- Control de nuevos diseños

- Control de materiales de insumo

- Control del producto o del proceso

Introdujo grandes avances al estudiar los costos de la calidad, identifica a los diversos costos en lo que designa como la fábrica oculta, esto es la proporción de la capacidad total que se dedica de manera específica a los reproceso y correcciones. Considera que el tamaño de la fábrica oculta puede llegar a $15-40 \%$ de la capacidad total de la fábrica.

Define el concepto de Control Total de la Calidad como el conjunto de esfuerzos efectivos de los diferentes grupos de una organización para la integración del desarrollo, del mantenimiento y de la superación de la calidad de un producto, con el fin de hacer posibles fabricación y servicio, a satisfacción completa del consumidor y al nivel más económico.

La totalidad implica tener o dar calidad a partir de todos los elementos de la organización, es decir, las especificaciones del producto son importantes, pero no son suficientes, ya que es indispensable el servicio que se ofrece dentro y fuera de la empresa hacia los clientes, esto es lo que le da el carácter de total y lo que propicia la "satisfacción total del consumidor", que es el gran cambio en el concepto de calidad, anteriormente cuando se hablaba si un producto tenía o no calidad se verificaban sus dimensiones contra un plano y si cumplía con las normas se consideraba que tenía calidad; Feigenbaum al introducir el concepto de la satisfacción total provoca que ya no sea suficiente cumplir con las especificaciones de un producto, sino que hay que buscar la satisfacción total del cliente a fin de permanecer en el mercado. 
Cuando este autor se refiere "al nivel más económico", está considerando hacerlo bien en la primera vez, sin errores. Hacer el trabajo solamente una vez y hacerlo bien, este es el compromiso.

\section{Kaoru Ishikawa}

Ishikawa se graduó en la Universidad de Tokio en marzo de 1939, año en que se vincula a una empresa dedicada a la licuefacción del carbón, que era una de las prioridades nacionales por aquella época, y adquirió experiencia en los campos de diseño, construcción y operaciones de investigación, entre mayo de 1939 y mayo de 1941, estuvo comisionado como oficial técnico naval en el área de la pólvora. Los ocho años que paso en la industria y en la armada lo prepararon para dedicarse al control de calidad.

En 1947, regresa a la Universidad de Tokio, y comenzó a estudiar métodos estadísticos en 1948. En 1949 acudió a la Unión de Científicos e Ingenieros Japoneses (JUSE).

Los pasos que siguió y las razones que lo guiaron fueron las siguientes:

1) Los ingenieros que juzgan con base en sus datos experimentales tienen que conocer los métodos estadísticos de memoria. Creó un curso titulado "Cómo utilizar datos experimentales" y lo hizo obligatorio para el primer semestre del último año en la Facultad de Ingeniería de Tokio.

2) Japón no tiene abundancia de recursos naturales sino que debe importarlos del exterior. Por lo tanto, es necesario ampliar las exportaciones. La época de los productos baratos y de mala calidad para la exportación se ha acabado. Japón tiene que esforzarse por manufacturar productos de alta calidad y bajo costo, Por esta razón, el control de calidad estadístico y el control de calidad requieren un máximo de cuidado.

3) Los ocho años que pasó en el mundo no académico, después de graduarse, le enseñaron que la industria y la sociedad japonesas se 
comportaban de manera muy irracional. Empezó a creer que estudiando el control de calidad y aplicándolo correctamente, se podría corregir este comportamiento irracional de la industria y la sociedad. En otras palabras le pareció que la aplicación del control de calidad podría lograr la revitalización de la industria y efectuar una revolución conceptual en la gerencia.

En Japón, Ishikawa es considerado como el principal precursor de la Administración de la Calidad Total. Se inspiró en los trabajos de Deming y Juran y, en menor grado de Feigenbaum. Es muy admirado por las siguientes contribuciones:

- Círculos de Control de Calidad, fue el primero en introducir este concepto y ponerlo en práctica con éxito.

- Fue el originador de los diagramas de espinas pescado, de causa-efecto o de Ishikawa, que se usan actualmente en todo el mundo en las mejoras continuas, para representar los análisis de los efectos y sus posibles causas.

Nacimiento de los Círculos de Calidad de Ishikawa, ¿Qué un Círculo de Calidad?

Un Círculo de Calidad es un grupo pequeño que desarrolla actividades de calidad voluntariamente dentro de un mismo taller. Este grupo lleva a cabo continuamente como parte de las actividades de control de calidad en toda la empresa, autodesarrollo y desarrollo mutuo, control y mejoramiento dentro del taller utilizando técnicas de control de calidad con participación de todos sus miembros.

Las ideas básicas subyacentes en los círculos de control de calidad en toda empresa son las siguientes:

- Contribuir al mejoramiento y desarrollo de la empresa

- Respetar a la humanidad y crear un lugar de trabajo amable y diáfano donde valga la pena estar

- Ejercer las capacidades humanas plenamente, y con el tiempo aprovechar capacidades infinitas

En la fabricación de productos de alta calidad con garantía plena de calidad no hay que olvidar el papel de los trabajadores. Los trabajadores son los que 
producen, y sin ellos y si sus supervisores no lo hacen bien, el Círculo de Calidad no podrá progresar.

En este sentido, la educación de los trabajadores en materia de Círculos de Calidad es sumamente importante. En los años 50 esa educación se consideraba prácticamente imposible, si bien no era difícil educar a los ingenieros y empleados directivos mediante seminarios y conferencias, resultaba imposible manejar al gran número de supervisores y dirigentes de grupo. Además éstos estaban dispersos por todo el país. No era fácil empezar a educarlos.

Se resolvió el problema utilizando los medios de comunicación masiva; en 1956 se empezó un curso de Círculo de Calidad por correspondencia para supervisores, valiéndose de la radiodifusora Japonesa de onda corta. En 1957 la radiodifusora Japonesa NHK empezó a difundir dichos programas dentro de su programación educativa. El programa fue bien recibido por el público y se vendieron 110.000 ejemplares del texto, mucho más de lo previsto. Después de este éxito, en 1960 la JUSE publicó una monografía titulada "A text on Quality Control for the Foreman ( $A$ y $B)$ ", que continuó vendiéndose muy bien.

En aquella época se hizo hincapié en lo siguiente: Los círculos han de crearse voluntariamente, no por órdenes de superiores. Comenzar las actividades de círculos con personas que deseen participar.

Ishikawa ha hecho críticas respecto del enfoque de Feigenbaum del Control de Calidad Total ya que incluye muchas personas que no son especialistas y, por consiguiente, tienen limitaciones en cuanto a su contribución a la resolución de problemas. Sostiene que el control de calidad en toda la compañía, tiene que basarse en el uso generalizado de técnicas estadísticas. Clasifica las técnicas en tres categorías, Ishikawa piensa que el $90-95 \%$ de los problemas pueden resolverse usando técnicas estadísticas elementales, que no requieren conocimientos especializados.

Técnicas Estadísticas de Ishikawa para los Círculos de Control de Calidad:

a) Técnicas estadísticas elementales

i) Análisis de Pareto (lo poco vital contra lo mucho trivial)

ii) Estratificación Lista de comprobación (bitácora) 
iii) Histograma

iv) Diagrama de dispersión

v) Controles y gráficas de Shewart

b) Método estadístico intermedio

i) Análisis teórico y de muestreo

ii) Diversos métodos de estimación estadística y comprobación de hipótesis

iii) Métodos basados en pruebas censoras

iv) Métodos de diseño experimental

c) Métodos estadísticos avanzados

i) Diseño experimental avanzado

ii) Análisis multivariados

iii) Métodos de investigación de operaciones

\section{Diagrama de Causa-Efecto}

Este diagrama muestra una relación entre las características y los factores causales, por lo cual se ha denominado de causa-efecto. Es necesario entender qué es el control de procesos, adueñarse del proceso (que es un conjunto de factores causales) e incorporar dentro del proceso maneras de hacer mejores productos, fijar mejores metas y lograr efectos.

\section{$>$ Taichi Ohno}

"Just in time" Sistema de gestión de producción que permite entregar al cliente el producto de la calidad exigida, en la cantidad precisa y el momento exacto.

\section{Masaaki Imai}

Kaizen: Significa mejora continua en japonés. Es el espíritu y práctica de la mejora continua en la organización. 


\section{Genichi Taguchi}

Ingeniería de la Calidad: Métodos para el diseño y desarrollo de procesos de industrialización con el máximo de eficiencia.

\section{Kiyoshi Suzaki}

Gestión visual: es un sistema donde la información necesaria para la gestión operativa está presente allí donde trabajan las personas.

\section{Evolución de la Calidad}

Hay muchas empresas que aunque reconocen la importancia de la calidad, no están lo suficientemente preparadas para llevar a cabo los principios y las técnicas que lleva consigo el concepto de calidad total.

Por esto existen otras empresas que su función es ayudar a otras a implantar sistemas de mejora de la calidad.

Una de estas empresas es Juran Institute, y una de las metodologías que utilizan es la metodología Lean Seis sigma.

\section{Lean Seis Sigma}

Es la unión de dos métodos:

\section{Metodología LEAN}

2. Metodología SEIS SIGMA

Lean: Es una metodología que permite trabajar sobre la cadena de valor del producto. Busca sistemáticamente conocer aquello que el cliente reconoce como valor añadido y por lo que está dispuesto a pagar.

Eliminar los pasos del proceso que no generan valor.

Los principios de operaciones en Lean se basan en tres pilares fundamentales: 1.- Producción: mediante la aplicación de las técnicas japonesas de JIT (Just in Time). Tamaño de lote pequeño, cambios rápidos y sistemas sencillos.

2.-Cadena de suministro: reduciendo el número de proveedores siguiendo un proceso de selección con base en su habilidad para adaptarse a los requerimientos del cliente.

3.- Cultural: menos personal, pero este personal mejor preparado y con capacidad de realizar varias tareas.

Objetivo: Emplear el tiempo en actividades que realmente generen valor. 
Elaborando un mapa de proceso, tal y como es este, y medir el tiempo que no añade Valor y eliminarlo.

\section{Seis Sigma:}

Más que un programa es una filosofía de trabajo.

El objetivo a lograr por Seis Sigma, es alcanzar no más de 3,4 defectos o errores por cada millón de oportunidades.

Por tanto Seis Sigma centra el trabajo en identificar y controlar la variabilidad del proceso con el fin de tener un producto más fiable y predecible.

\section{La metodología consiste en 5 fases:}

1. Definir: Identificar, evaluar y seleccionar proyectos, preparar la misión, seleccionar y lanzar el equipo.

2. Medir: Consiste en la caracterización del proceso o procesos afectados, estudiando su funcionamiento/capacidad actual para satisfacer los requerimientos clave de los clientes de dicho proceso. En esta fase, se documentan los posibles modos de fallo y sus efectos al tiempo que se elaboran las primeras teorías sobre las causas de mal funcionamiento.

3. Analizar: Se realiza el plan de recogida de datos y a continuación se procede al análisis de los mismos con el ánimo de establecer y determinar las pocas causas vitales del fallo del proceso.

4. Mejorar: Es esta la fase en la que se determinan e implantan las soluciones para que el proceso alcance los resultados esperados.

5. Controlar: Consiste en diseñar y documentar los mecanismos necesarios para asegurar que lo conseguido se mantenga una vez que el equipo del proyecto Seis Sigma haya implantado los cambios.

Lean Seis Sigma supone integrar dos aspectos fundamentales: 1. Eliminación de defectos-reducción de la variabilidad 2. Aumentar la velocidad del proceso, eliminando las trampas de tiempo y generando más valor para el cliente.

\section{Interacción Lean Seis Sigma}

En la siguiente tabla se puede ver la interacción existente entre Lean y Seis Sigma. Se observa cómo un proceso con 20 pasos que trabaja a niveles de rendimiento de 3 sigma tan sólo tiene un $25 \%$ libre de error a la primera. 


\section{Relación entre Lean y 6 Sigmas}

El rendimiento decrece cuando la complejidad aumenta.

Dónde atacar los problemas y qué objetivos persiguen los proyectos Lean Seis Sigma: 1. Reducir inventarios hasta un $90 \% 2$. Mejorar la entrega a tiempo en $>80 \% 3$. Reducir el tiempo de ciclo de meses a días 4 . Reducir exponencialmente el número de defectos y la variabilidad que genera el proceso.

Así se consigue más valor para el cliente y que se pague más por el producto.

Los productos de calidad se consiguen a lo largo de todo el proceso y depende de todas las personas que participan en ese proceso.

El objetivo de los Sistemas de Gestión de la Calidad es generar confianza en el cliente, para esto es necesario también contar con entidades que acrediten esa calidad.

\section{Calidad en educación}

Las empresas de servicios no enfrentan una competencia extranjera como las empresas manufactureras. Sin embargo, la importancia de la calidad en los servicios no puede subestimarse.

Las definiciones de calidad que se aplican a los productos de manufactura también se aplican en el caso de los servicios. El servicio debe responder a las necesidades del cliente. Las expectativas del cliente se deben convertir en estándares de desempeño y especificaciones similares a las normas que rigen las actividades de manufactura.

Esta tarea no es para nada sencilla, a menudo es difícil identificar las necesidades de servicios de los clientes y los estándares de desempeño, sobre todo porque los clientes definen cuales son éstos y cada cliente es diferente.

La OCDE (1995) la Organización para la Cooperación y el Desarrollo Económicos, define la educación de calidad como aquella que "asegura a todos los jóvenes la adquisición de los conocimientos, capacidades, destrezas y actitudes necesarias para equiparlos para la vida adulta". 
Otra definición sería: "La educación de calidad es la que promueve el progreso de sus estudiantes en una amplia gama de logros intelectuales, sociales, morales y emocionales, teniendo en cuenta su nivel socioeconómico, su medio familiar y su aprendizaje previo. Un sistema educativo eficaz es el que maximiza la capacidad de las escuelas para alcanzar esos resultados". (J. Mortimore)

La calidad de las instituciones educativas se debe definir y visualizar en un sentido integral, adoptando un enfoque de totalidad y globalidad de las mismas; en donde todos y cada uno de los elementos que conforman un centro educativo son considerados como susceptibles de estudio y análisis bajo criterios definidos de calidad.

En el análisis de la calidad deben considerarse, por lo tanto, todos los componentes que intervienen en el proceso educativo y sus mutuas relaciones y abarcar tanto los procesos como los resultados de la educación.

En el mismo se evaluarán las competencias, consideradas como las aptitudes, habilidades de los graduados para desarrollar una tarea determinada, desagregándolas en 3 grupos: conocimientos, habilidades y actitudes, priorizando el ámbito privado para dicha evaluación, por ser más competitivo y exigente que el sector público.La calidad del proceso incluye la calidad de la enseñanza, el aprendizaje y plan de estudios y la calidad de los resultados es la calidad de las competencias logradas por los graduados.Los clientes de las instituciones de formación esperan, cada día más que la formación recibida se corresponda con las habilidades y competencias demandas en el trabajo.

La calidad está determinada por la conjunción de los elementos que participan en la educación de un modo dinámico y por entender que el todo es más que la suma de las partes. En este orden de ideas, la calidad es la búsqueda de un equilibrio dinámico entre dos vertientes. Por un lado, las necesidades de los sectores sociales y exigencias de los actores individualmente involucrados con las Instituciones de Educación Superior, y por otro, los objetivos y funciones de éstas. Es decir, la calidad se refiere no sólo a la mejora en la eficiencia y/o la eficacia en el logro de los productos deseados, sino también a la definición cualitativa de éstos. 


\section{Introducción}

El éxito de toda organización está íntimamente ligado a su capacidad para mejorar y optimizar los procesos desde un punto de vista transversal, que rompa la individualidad departamental y que logre una mejora integral en el flujo de sus procesos. Para esto se hace importante y a la vez complicado la gestión de las operaciones, y por tanto la gestión de la calidad.

En las Instituciones de Educación Superior (IES) se presenta una barrera departamental que dificulta el flujo de los proceso en busca de un objetivo global, es decir, la atención de un estudiante en las distintas áreas y departamentos de una IES es tan independiente como defectuosa para el nivel de servicio ofrecido.

Por ello, las IES y numerosas entidades educativas están realizando importantes avances en la aplicación de metodologías que permitan mejorar la calidad en el servicio educativo ofrecido, más sin embargo, los intentos para estos avances ha estado encaminada a certificar algunos procesos y de forma individual (como es el caso de las bibliotecas, modelo educativo, etc.), o para acreditar algunos programas de formación. Pero teniendo en cuenta los grandes cambios en el mundo y en el ámbito laboral, se hace cada vez más necesario la agilización de los procesos estudiantiles y del desarrollo de los programas académicos, por medio de una gestión global de los procesos de la institución.

Por medio del "Lean Thinking" se puede apelar a una gestión global de los procesos, por medio de una estrategia enfocada en proveer el servicio de la manera más eficaz, mejorando el flujo y eliminando los desperdicios de los procesos.

Con esta investigación se presenta las bases de una metodología para evolucionar, desde un modelo clásico de gestión de proceso, a una implantación Lean, Se toma como estudio de caso el proceso de matrícula de la Universidad Tecnológica De Bolívar, para poder contextualizar la propuesta, teniendo en cuenta los cinco principios del Lean Thinking dando las primeras pautas para la implantación de estos principios en el proceso seleccionado y de allí proponer recomendaciones futuras para aplicar en otros procesos en una institución de educación superior.

\section{El problema de investigación}

Los 7 desperdicios (sobreproducción, tiempo de espera, transporte, exceso de procesado, inventario, movimiento y defectos) no solo se presentan en la empresas de manufactura, de alguna manera u otra también se encuentran en el sector servicio afectando los procesos de atención y satisfacción de las necesidades de los clientes. Si bien, la presencia de fallos y errores en los procesos administrativos, institucionales y actividades académicas perjudican la productividad y por ende la calidad de lo 
ofrecido por una institución, para ello existen modelos o metodologías que se están adoptando para lograr una mejora en las operaciones de forma que se pueda mejorar la calidad y el servicio al cliente.

Uno de los principales problemas encontrados en las instituciones de educación superior radica en la carencia de integración y de ejecución transversal de los procesos, debido a:

- Los procesos no son integrados, existe una individualidad y fronteras entre los departamentos, se desarrollan muchas actividades que no agregan valor al servicio y se desvían de los objetivos.

- Existe individualidad entre los productos o servicios ofrecidos por la institución. Ya que no hay integración entre programas.

- No cuentan con un sistema que lleve una funcionalidad y normalización en los procesos, la individualidad de los procesos administrativos, los procesos académicos, y los procesos de apoyo, no asegura la calidad de la institución y la satisfacción de los clientes.

Una de las principales estrategias para lograr la satisfacción de los clientes, mejorar la calidad y lograr una ventaja competitiva que mantenga a una institución en el mercado es el establecimiento de un sistema de gestión de calidad, donde el énfasis está en el enfoque al cliente, la gestión de los procesos, el mejoramiento continuo y el bienestar institucional.

Por esta razón, se hace necesario buscar nuevas formas para gestionar los procesos, mejorar continuamente el sistema, asegurar la calidad y la satisfacción de los clientes, ya con ello las instituciones podrán prescindir de lo que se conoce hoy en día como acreditación de programas de pregrado, vista en forma individual, y pasar a obtener una certificación global y/o una acreditación institucional.

De tal forma, se busca proponer una guía para mejorar la calidad y mejorar el flujo del proceso, reduciendo el gasto y el ciclo de tiempo. Para ello, se adopta la metodología de gestión conocida hoy en día como "Lean Thinking", la cual permitirá eliminar los despilfarros y crear valor en la empresa, esto llevara a mejorar la calidad, el coste y la velocidad de respuesta.

\section{El Lean thinking y su aparición}

Lean Thinking es una metodología de gestión que surge a partir del Lean Manufacturing o Lean Production, la cual es "un conjunto de técnicas desarrolladas por la compañía Toyota a partir del decenio de 1950 para mejorar y optimizar sus procesos operativos" (Grupo Kaizen, 2007); de tal forma que permita ofrecer bienes y 
servicios más ajustados a los deseos de los clientes, con mayor rapidez, con un costo más bajo y sin desperdicios.

Estas técnicas conocidas simplemente como "Lean" se han vuelto una filosofía que busca la eliminación de mudas de los procesos con la meta de crear valor. Así, se define Lean Thinking como una "filosofía de gestión" (Tony J Connell, 2008) que se enfoca en la en la provisión de servicio de la manera más eficaz, mejorando el flujo y eliminando los desperdicios en los procesos.

La evolución hacia el Lean Manufacturing (Lean Manufacturing, 2008): Desde finales de 1890, Frederick W. Taylor innova estudiando y difundiendo el management científico del trabajo, cuyas consecuencias son la formalización del estudio de los tiempos y del establecimiento de estándares. Frank Gilbreth añade el desglose del trabajo en tiempos elementales. Entonces aparecen los primeros conceptos de eliminación del despilfarro y los estudios del movimiento.

Después de la Segunda Guerra Mundial, Taiichi Ohno y Shigeo Shingeo crean para Toyota los conceptos de "justo a tiempo", "waste reduction", "pull system" que, añadidos a otras técnicas de puesta en flujo, crean el Toyota Production System (TPS).

Desde entonces, el TPS no ha dejado de evolucionar y de mejorar. En 1990, James Womack sintetiza estos conceptos para formar el Lean Manufacturing, mientras que el saber hacer japonés se difunde en occidente a medida que se observa la evidencia del éxito de las empresas que aplican estos principios y estas técnicas.

Con la creación del TPS, la poderosa firma de automóviles TOYOTA podía ofrecer bienes y servicios más ajustados a los deseos del cliente, con mayor rapidez, a un costo más bajo y con la calidad asegurada. Aunque TOYOTA fue el pionero e impulsor de este nuevo enfoque de gestión desde el Japón, la difusión de estos conceptos y su aplicación a toda clase de empresas y sectores se deben a James P. Womack \& Daniel T. Jones, dos investigadores del Massachussets Institute of Tecnology (MIT), autores de "La Máquina que cambio el mundo" y "Lean Thinking".

En 1990, luego de varios años de recopilar datos alrededor de todo el mundo, Womack y Jones analizaron y divulgaron la evolución de los sistemas de gestión de la producción. El último y más novedoso de estos enfoques, el sistema de producción de Toyota, lo denominaron Lean Production en su primera publicación sobre esta temática, "La Máquina que Cambio el Mundo". Según decían, con el Lean Production se podía obtener "más y más con menos y menos" recursos.

Durante esta misma década Womack \& Jones consideraron importante desarrollar y aplicar los principios de este nuevo enfoque en las empresas industriales y de servicio de Estados Unidos y del resto del mundo, de esta forma surgió lo que se 
conoce hoy en día como Lean Management. En 1996, publicaron la primera edición del libro que contiene los principios para que cualquier tipo de organización y de cualquier sector de la economía, realice la transición a este novedoso enfoque de gestión lean, que ellos denominaron Lean Thinking.

La gestión lean según varios autores ofrecerá en el corto plazo "la bonificación kaikaku" (mejoras radicales) obtenida por el replanteamiento radical del flujo de valor. Lo que sigue son mejoras continuas por medio del "kaizen" en ruta hacia la perfección. Pero además, gracias al pensamiento lean se podrá combinar el kaikaku y el kaizen, lo cual producirá mejoras ilimitadas. Pero el interrogante es: ¿cómo funcionaría si se aplica en una institución universitaria?

\section{Evolución concepto de calidad vs Lean}

A través de la historia el concepto de calidad ha tenido muchas interpretaciones, dependiendo de los diferentes aportes de los diferentes autores, de las actividades de todo tipo de organización, e incluso de las tecnologías para la mejora de los procesos. Entonces, debido a las distintas orientaciones que se le dio a la calidad, se presentó un gran número de formas de administrarla, controlarla y de evaluarla. Por ello, en 1946, delegados de 25 países se reunieron en Londres con el fin de crear una nueva organización internacional, la cual tendría como objetivo "facilitar la coordinación internacional y la unificación de los estándares y normas internacionales", para esto surgió la Organización Internacional de Estandarización ISO la cual pretende normalizar la labor de gestión de la calidad en cualquier tipo de organización.

Hoy en día muchas organizaciones requieren probar su conformidad con las especificaciones y requisitos del cliente, los de seguridad, y otras regulaciones con el fin de aumentar su participación en el mercado. Además, el grado de calidad y el nivel de servicio dependerá del "valor agregado"1 que se le crea al producto o al servicio.

De tal forma las organizaciones de todos los sectores en su intención por mejorar continuamente, han adoptado nuevas formas de gestionar las operaciones y la calidad. Una de las formas que se ha adoptado para gestionar los procesos y mejorar continuamente la calidad, ha sido por medio de la Técnica de Gestión Lean, desarrollada en un principio por la firma de automóviles Toyota y difundida a los largo de los años como Lean Management.

En el nuevo milenio se tuvo un interés especial al seguir trabajando en la difusión de los conceptos lean, más allá de su aplicación en la gestión industrial. Un ejemplo de ello se evidencio con el Encuentro Internacional de Lean Management que se celebró en Holanda en Junio del año 2004, y el cual se denominó Lean Service 
Summit, donde el sector de los servicios se vería beneficiado por el progreso que tendrían sus programas de gestión gracias a los aportes que se lograron con el Lean Management y han sido analizados por Brokline, (2003) y James P. Womack \& Daniel T. Jones, (2000).

Uno de los mayores logros que debe alcanzar una organización para mejorar su competitividad y rentabilidad es la satisfacción de los clientes. ¿Pero cómo se satisface al cliente?, la mayoría de los clientes busca calidad al mejor precio, sin embargo lo que puede ser excelente para algunos, no lo es para otros. Las personas como clientes o consumidores adquieren un producto o servicio con el fin de satisfacer unas necesidades, algunas veces hasta deseos, y siempre esperan que lo adquirido cumpla a cabalidad con sus requerimientos y expectativas, de lo contrario se sentirán engañados y esto debilita al agente que ofrece el producto o servicio. De tal forma se debe buscar la forma de establecer la calidad de un producto a partir del cliente y que se dice de la educación en este sentido.

\section{La calidad en las instituciones de educación superior (IES) vs Lean}

Las Instituciones de Formación Profesional, Patiño (2008) (IFP) y numerosas entidades educativas están realizando importantes avances en el desarrollo de sistemas de gestión de la calidad, enmarcados en prácticas que corresponden, básicamente, a tres modelos con alto reconocimiento internacional: el de las Normas ISO, (especialmente las de la familia ISO 9000), el de los Sistemas de Acreditación de Programas e Instituciones, que se han desarrollado particularmente en el ámbito de la educación superior, y el de los Premios (nacionales e internacionales) de Calidad (que en algunos casos incluyen Galardones de Excelencia para la gestión escolar).

La gestión de la calidad en las universidades implica diseñar, estandarizar, e implementar todas las tareas y procedimientos que garanticen el desarrollo efectivo de las funciones básicas de la institución. Así mismo, comprende el diseño y aplicación de los mecanismos de seguimiento evaluación y mejoramiento a los procesos establecidos, que brinden al sistema de gestión de calidad el dinamismo y adaptabilidad requeridos para asegurar que su funcionamiento logre el nivel de excelencia demandado por la sociedad.

Como se ha mencionado, uno de los mejores caminos hacia el éxito para una organización lo encuentra en las estrategias empleadas para mejorar, la gestión de la calidad y por procesos analizado por varios autores como Juran (1993), Huete, (2006) y Camison (2007) entre otros y optimizar los procesos administrativos, productivos y de servicios, puesto que aumenta su productividad y mejora su competitividad analizados por otros autores en diversas perspectivas como son: Góngora (1992), 
Schargel, (1996), Nava, (2005) y Riveros, (2007). De acuerdo con ello definir una estrategia enfocada hacia la forma de proveer el servicio de la manera más eficaz, mejorando el flujo y eliminando los desperdicios de los procesos es la metodología de gestión Lean.

Para la conceptualización del Lean Thinking, es importante poder conocer el constante avance que ha tenido dicha metodología de gestión, además de sus rasgos a la hora de su implementación. De esta forma, es más fácil entender los lineamientos que siguen los principios y herramientas para su aplicación en una Institución de Educación Superior.

Se espera que el interesado identifique y conozca los dos aspectos claves para emprender una "Iniciativa Lean"; determinar y eliminar las mudas e identificar lo que es valor. Para luego lograr esto se puede contextualizar la investigación y aplicación en una IES, como es el caso de la Universidad Tecnológica de Bolívar (UTB), donde se realizara detalladamente la situación actual, de los procesos o el proceso seleccionado y las actividades de la institución, de modo que se podrá identificar los posibles problemas en la gestión de la calidad, y los procesos esenciales y su trazabilidad para la operatividad de la institución. De esta forma se logra establecer la conexión entre la eliminación de la muda, y la creación de valor.

Por esto, el marco teórico-referencial aplicado en otras empresas sobre esta temática, es la base para la implantación de la metodología de gestión Lean en la UTB o en cualquier IES, ya que muestra los criterios para aplicar las herramientas Lean ,durante la adopción de cada uno de los principios de gestión. Siendo el Lean Thinking una metodología para mejorar la gestión de la calidad en las IES en Colombia y otros lugares.

\section{Discusión}

Si se utilizan los principios del Lean Thinking en una linstitución de Educación Superior, como es el caso de la UTB, el interrogante sería ver si es viable implantar esta filosofía, como metodología de gestión para la mejora continua. La presente ponencia presenta algunos resultados relativos a la aplicación de Lean Thinking en educación y la novedad que traería esta aplicación en este tipo de servicio.

\section{Conclusiones}

Las Instituciones de Educación Superior no cuentan en la actualidad con procedimientos científicamente argumentados que permitan gestionar proactivamente la mejora de la calidad de sus procesos, lo cual dificulta la aplicación de metodologías con esta concepción. 
Es necesario analizar propuestas metodológicas que hagan posible gestionar efectiva y eficazmente los procesos que inciden directamente en la mejora de la calidad institucional, lo cual requiere de una investigación profunda y un riesgo de las IES hacia la aplicación de herramientas teórica-practicas no convencionales , así como definir claramente las condiciones concretas en donde van a ser aplicadas y el tiempo de su aplicación.

El éxito del Lean Manufacturing o en su defecto el lean service y su demostrada superioridad como modelo de gestión ha impulsado la transferencia de sus técnicas desde la fábrica hacia la las empresas de servicios y demás sectores, entornos actualmente muy necesitados de mejoras en la calidad, de costos o la velocidad de respuesta, razones estas que justificarían el riesgo a probar estos nuevos enfoques de gestión

De acuerdo con la investigación realizada se puede establecer que el Lean Thinking es una metodología de gestión para ir evolucionando en la implantación por etapas, desde una ejecución tradicional de procesos a una gestionada de acuerdo con los principios lean, con procesos altamente eficientes y competitivos, donde se lograra establecer la conexión entre la eliminación de muda y la creación de valor.

También, se logró establecer que a través de los años las IES en el país han estado buscando nuevas formas de gestionar los procesos de formación académica, así como los demás procesos institucionales (estratégicos y misionales), para ello se han establecido regulaciones y normas para certificar que los procesos y programas de una IES son de alta calidad.

Las IES tienden a inclinarse más a la gestión por procesos, y tomen esto como punto de partida para lograr una certificación de calidad, por ello se puede afirmar que la implantación de la metodología Lean Thinking como una alternativa más para lograr las Acreditaciones Institucionales y certificar los Sistemas de Gestión de Calidad en las Instituciones Educativas de Educación Superior.

Aunque, es necesario contar con un equipo de trabajo que se comprometa con la institución en la implantación de la metodología, y que tenga en cuenta las otras técnicas ya existentes en las instituciones y que se aseguren de que estas no se opongan al Lean Thinking. Además, el personal clave para la gestión deberá estar familiarizado con los conceptos Lean y que sean conscientes de que es un proceso de transformación lento, que puede tardar en culminarse entre cinco y hasta 10 años.

Así mismo, se puede establecer según la metodología Lean Thinking que en cualquier IES se podrá reducir hasta los despilfarros en un $50 \%$, y en ocasiones mucho más, esto de acuerdo con los problemas encontrados en los procesos y según las herramientas lean que se utilicen para la mejora, siempre y cuando se sigan 
aplicando y manteniendo los principios Lean en los procesos, vale la pena que las instituciones de educación superior se atrevan al cambio y al uso de las bondades de este tipo de metodologías.

\section{6.- Metodología de la investigación}

La metodología incluye la elección del método de recolección de datos y la selección de las fuentes de información.

La elección del método de recolección de datos es la forma de obtener información sobre los conocimientos y el desempeño de los graduados y en definitiva de la satisfacción de los "clientes". La fuente de información serán aquellas personas que posean el conocimiento necesario sobre los graduados para poder ser consultados acerca de ellos. Ocupando los mismos puestos de supervisores 44 , empleadores jefes de áreas 24 y coordinadores 5 , siendo 75 el total de la muestra sobre un universo de 141 de la Facultad de Ciencias Económicas.. Entre las empresas que realizaron las encuestas se destacan YPF, Sinopec Exploration y Production, Pluspetrol, Chevron, Total , Federación Patronal, Ernst \&Young, Accenture, Enarsa , , Austral, Copertei, Osde, Ministerio de Economía, Tribunal de Cuentas, Ministerio de Salud.

\section{Población y muestra}

La muestra es la unidad de análisis sobre la cual se recolectarán los datos, siendo la misma representativa del universo y/ o población que se estudia.

Se define como población a los graduados de la Facultad de Ciencias Económicas de la UNLP en el período 2007-2011.

El tamaño de la población (N) surgió de los registros aportados por la Facultad de Ciencias Económicas respecto de la cantidad de graduados entre los años de referencia 
El tamaño de la muestra se calculó a través de la fórmula de muestreo de proporciones con «N» conocido:

$$
n=\frac{Z_{\alpha}^{2} \cdot N \cdot p \cdot q}{e^{2} \cdot(N-1)+Z_{\alpha}^{2} \cdot p \cdot q}
$$

Donde:

$$
\begin{aligned}
& \mathrm{N}=2.244 \text { graduados (tamaño de la población) } \\
& \mathrm{p}=\text { prevalencia esperada del parámetro a evaluar. En caso de } \\
& \text { desconocerse, se aplica la opción más desfavorable }(p=0,5) \text {, que } \\
& \text { hace mayor el tamaño muestral. } \\
& q=\text { complemento de la prevalencia esperada del parámetro a evaluar, } \\
& \text { es decir } 1-p=0,5 \\
& Z=1,96 \text { para } \alpha=5 \% \text {, es decir, un nivel de confianza del } 95 \% \\
& \mathrm{e}=8 \% \text {, error de muestreo } \\
& \mathrm{n}=141 \text {, tamaño de la muestra }
\end{aligned}
$$

Con el objetivo de lograr una mejor representatividad de cada una de las carreras que forman parte de la Facultad de Ciencias Económicas de la UNLP, la muestra fue ponderada según la participación de cada una de ellas en la cantidad total de egresados. Luego, la muestra para la Carrera de Contador Público es igual a 75 (n $=75$ ), equivalente al $53,19 \%$ de los egresados de ésta carrera sobre el total de graduados para el período de referencia.

\section{Tipo de Investigación}

La investigación a realizarse será exploratoria. Los estudios exploratorios se efectúan, normalmente, cuando el objetivo es examinar un tema o problema de investigación poco estudiado o que no ha sido abordado antes. Es decir, cuando la revisión de la literatura reveló que únicamente hay guías no investigadas e ideas vagamente relacionadas con el problema de estudio. 
Los estudios exploratorios son de utilidad para aumentar el grado de familiaridad con fenómenos relativamente desconocidos, obtener información sobre la posibilidad de llevar a cabo una investigación más completa sobre un contexto particular de la vida real, investigar problemas del comportamiento humano que consideren cruciales los profesionales de determinada área, identificar conceptos o variables promisorias, establecer prioridades para investigaciones posteriores o sugerir afirmaciones (postulados) verificables. Los estudios exploratorios en pocas ocasiones constituyen un fin en sí mismos, por lo general determinan tendencias, identifican relaciones potenciales entre variables y establecen el 'tono' de investigaciones posteriores más rigurosas" (Dankhe, 1986, p. 412).

\section{Técnicas de recolección de datos}

Recolectar los datos implica tres actividades estrechamente vinculadas entre sí:

i) Seleccionar un instrumento de medición de los disponibles en el estudio del comportamiento o desarrollar uno (el instrumento de recolección de los datos). Este instrumento debe ser válido y confiable, de lo contrario los datos obtenidos a partir de éste no servirán para realizar el análisis.

ii) Aplicar ese instrumento de medición. Es decir, obtener las observaciones y mediciones de las variables que son de interés para el estudio (medir variables).

iii) Preparar las mediciones obtenidas para que puedan analizarse correctamente (codificación de los datos).

Aquí la medición es algo diferente de las ciencias físicas y exactas y requiere de una definición para saber que representará, se la define como "el proceso de vincular conceptos abstractos con indicadores empíricos", proceso que se realiza mediante un plan explícito y organizado para clasificar (y frecuentemente cuantificar) los datos disponibles (los indicadores) en términos del concepto que el investigador tiene en mente (Carmines y Zeller, 1979, p. 10). Y en este proceso, el instrumento de medición o de recolección de los datos juega un papel central. Sin él no hay observaciones clasificadas. 
La medición de las variables es efectiva cuando el instrumento de recolección de los datos realmente representa a las variables que se pretenden estudiar. Si bien no hay medición perfecta, hay que acercar lo más posible a la representación fiel de las variables a observar. Por lo tanto, el instrumento de medición a elegir debe cumplir con dos requisitos fundamentales: confiabilidad y validez.

Será confiable si las respuestas son repetibles y válido cuando se está midiendo lo que se desea medir.

\section{Técnicas de análisis}

\section{Comprobando las competencias de los graduados}

Uno de los objetivos de este estudio es investigar las "aptitudes" de los graduados. Los graduados han sido definidos como aquellos individuos que han aprobado todas las materias del Plan de Estudios de alguna de las carreras de la Facultad de Ciencias Económicas de la UNLP, en este caso en particular la Carrera de Contador Público, dentro del período de análisis. Las aptitudes, por su parte, se definen como la habilidad del graduado para realizar una tarea específica. Las mismas han sido divididas en 3 grupos: conocimiento, habilidades y actitudes.

Las competencias fueron estudiadas utilizando la información obtenida a partir de las encuestas realizadas a los "clientes", es decir que los resultados muestran las competencias actuales de los graduados en su lugar de trabajo.

El objetivo fue determinar el nivel alcanzado por la muestra para cada una de las aptitudes evaluadas. Luego, de acuerdo con la teoría, las aptitudes o competencias de los graduados fueron relacionadas con la satisfacción del "cliente". Al realizar un orden jerárquico de las aptitudes, se determinaron aquellas en la que los graduados son más idóneos y cuáles son en las que deberían mejorar y por ende poner énfasis la Facultad durante el proceso de aprendizaje.

Se priorizó la evaluación de las competencias dentro del ámbito privado por ser más competitivo y exigente que el sector público. 


\section{Estableciendo las expectativas de los "clientes"}

Un segundo objetivo planteado fue establecer los estándares de satisfacción de los "clientes" sobre las aptitudes de los graduados. La satisfacción está determinada por el desempeño de los graduados respecto de las expectativas del "cliente" sobre cada una de las aptitudes evaluadas. Por lo tanto, para realizar esta tarea primero se deben conocer las expectativas de los "clientes" ya que las mismas son, en última instancia, las que determinarán el nivel de satisfacción.

Para facilitar la investigación, se ha acotado la evaluación de las expectativas sólo a aquellos atributos que se evaluarán dentro del punto anterior. Una vez determinado el nivel de expectativas para cada uno de los atributos se podrá establecer "ranking de prioridades", las cuales también servirán de guía durante el proceso de aprendizaje. Esto se debe a que se conocerán qué aptitudes de los graduados son más valoradas.

\section{Estableciendo las brechas}

Al tener tanto las competencias de los graduados como las expectativas de los "clientes" valoradas de acuerdo con los mismos parámetros, se cumplió con el tercer objetivo de este trabajo, es decir, conocer la "brecha entre competencias y expectativas" y, por lo tanto, el nivel de satisfacción de los "clientes".

Prestando atención a las brechas encontradas, las autoridades educativas podrán establecer prioridades sobre las competencias a desarrollar para aumentar la satisfacción de los "clientes". Es decir, cuanto más grande sea la brecha mayor será la diferencia entre la expectativa del cliente y la competencia del graduado respecto de un atributo determinado. Aún más grave será la situación si el atributo analizado es muy valorado por el "cliente". Luego, cerrar la brecha permitirá aumentar la satisfacción del "cliente". 


\section{Medición de las variables}

Habiendo establecido las variables, se debe pasar a la medición de las mismas. En particular hay cuatro grupos de variables susceptibles de medición: competencias, desempeño, satisfacción y expectativas.

\section{Competencias}

Las competencias de los graduados han sido medidas a partir de la confección de una serie de afirmaciones divididas en 3 categorías: conocimiento, habilidades y actitudes.

Se les solicitó a las personas encuestadas que evalúen y elijan una única respuesta para cada una de las afirmaciones realizadas respecto de las competencias de los graduados teniendo en cuenta la siguiente escala de medición:

\begin{tabular}{|c|c|c|c|c|}
\hline $\begin{array}{c}1=\text { Totalmente } \\
\text { en desacuerdo }\end{array}$ & $\begin{array}{c}2=\text { En } \\
\text { desacuerdo }\end{array}$ & $\begin{array}{c}3=\text { No está } \\
\text { seguro }\end{array}$ & $4=$ De acuerdo & $\begin{array}{c}5=\text { Muy de } \\
\text { acuerdo }\end{array}$ \\
\hline
\end{tabular}

(en páginas siguientes: cuadros de Evaluación de conocimientos, Evaluación de habilidades $y$ Evaluación sobre actitudes) 


\subsection{Evaluación de conocimientos}

\begin{tabular}{|c|c|c|c|c|c|}
\hline Creo que el graduado: & 1 & 2 & 3 & 4 & 5 \\
\hline $\begin{array}{l}\text { 1.1.1) Entiende los principios básicos y conceptos relacionados } \\
\text { con su carrera }\end{array}$ & & & & & \\
\hline 1.1.2) Entiende los fundamentos económicos su carrera & & & & & \\
\hline $\begin{array}{l}\text { 1.1.3) Entiende en profundidad los procedimientos técnicos en } \\
\text { al menos una disciplina de su carrera }\end{array}$ & & & & & \\
\hline $\begin{array}{l}\text { 1.1.4) Entiende la identificación de problemas, su formulación y } \\
\text { el desarrollo de soluciones }\end{array}$ & & & & & \\
\hline 1.1.5) Entiende cómo utilizar un enfoque de sistema & & & & & \\
\hline $\begin{array}{l}\text { 1.1.6) Entiende los principios de diseño y desarrollo económico } \\
\text { sostenibles }\end{array}$ & & & & & \\
\hline $\begin{array}{l}\text { 1.1.7) Entiende las leyes, reglamentos y normas relacionadas } \\
\text { con su carrera }\end{array}$ & & & & & \\
\hline 1.1.8) Entiende los principios de gestión y negocios & & & & & \\
\hline $\begin{array}{l}\text { 1.1.9) Comprende otras disciplinas relacionadas con su carrera } \\
\text { (lógico-matemáticas, humanas y sociales) }\end{array}$ & & & & & \\
\hline
\end{tabular}

\subsection{Evaluación de habilidades}

\begin{tabular}{|c|c|c|c|c|c|}
\hline Creo que el egresado es capaz de: & 1 & 2 & 3 & 4 & 5 \\
\hline $\begin{array}{l}\text { 1.2.1) Aplicar perfectamente los conocimientos técnicos en al } \\
\text { menos una disciplina de su carrera }\end{array}$ & & & & & \\
\hline 1.2.2) Usar apropiadamente las tecnologías disponibles & & & & & \\
\hline 1.2.3) Acceder, evaluar y sintetizar información & & & & & \\
\hline $\begin{array}{l}\text { 1.2.4) Comunicarse efectivamente con profesionales de otras } \\
\text { disciplinas y la comunidad en general. }\end{array}$ & & & & & \\
\hline 1.2.5) Funcionar eficazmente como un individuo & & & & & \\
\hline $\begin{array}{l}\text { 1.2.6) Funcionar eficazmente en equipos multidisciplinarios o } \\
\text { multiculturales }\end{array}$ & & & & & \\
\hline $\begin{array}{l}\text { 1.2.7) Funcionar eficazmente en equipos con capacidad de ser } \\
\text { miembro }\end{array}$ & & & & & \\
\hline $\begin{array}{l}\text { 1.2.8) Funcionar eficazmente en equipos con la capacidad de } \\
\text { ser un director }\end{array}$ & & & & & \\
\hline $\begin{array}{l}\text { 1.2.9) Funcionar eficazmente en equipos con la capacidad para } \\
\text { ser un líder }\end{array}$ & & & & & \\
\hline
\end{tabular}




\subsection{Evaluación sobre actitudes}

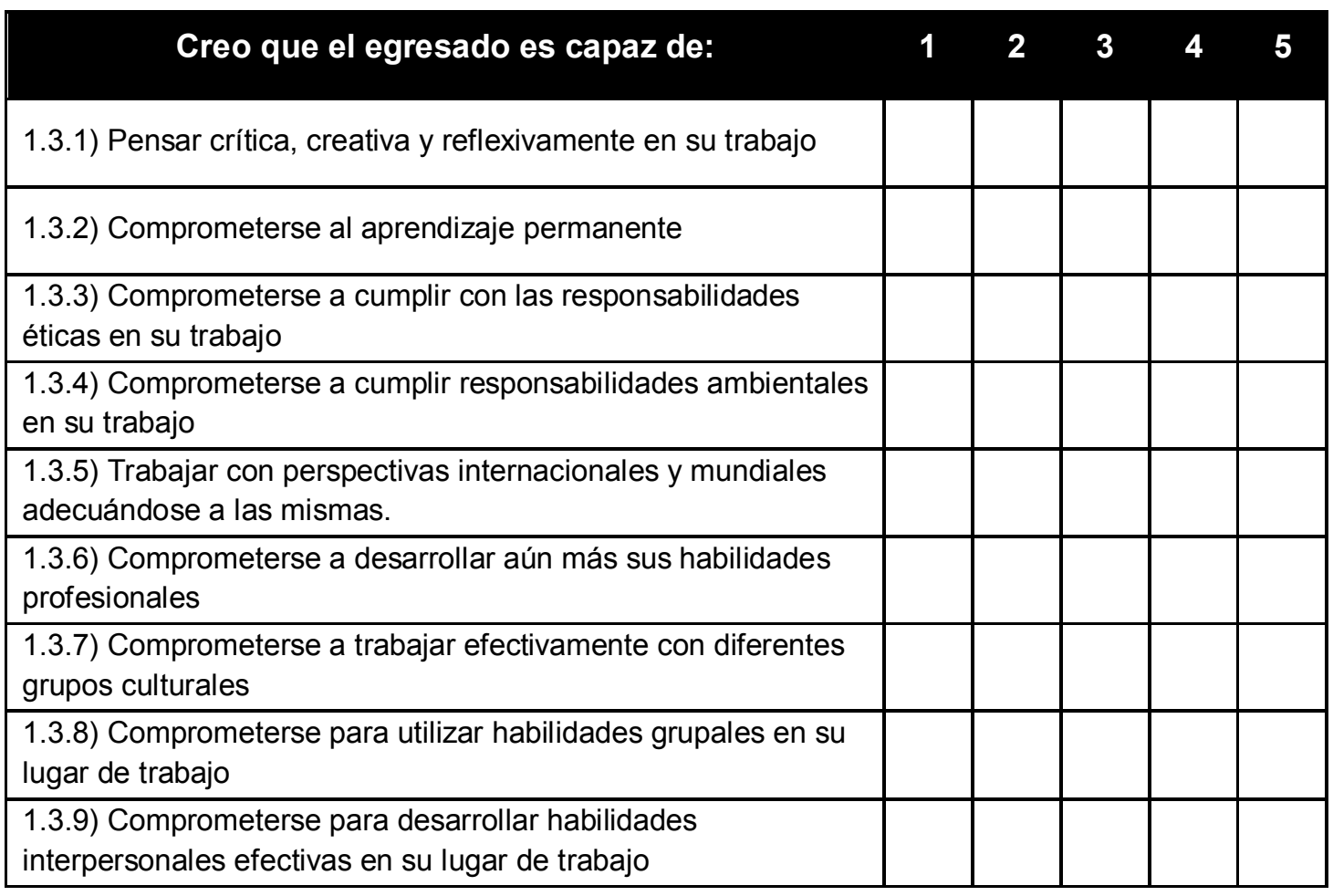

\section{Desempeño}

La performance fue evaluada a partir de dos preguntas relacionadas con la duración de las tareas solicitadas a los graduados y la calidad del trabajo realizado otorgando 5 opciones para responder cada una de ellas.

¿Cuál es la duración real de los trabajos realizados por el graduado?

\begin{tabular}{|c|c|c|c|c|}
\hline $\begin{array}{c}1 \text { = Mucho más } \\
\text { que lo } \\
\text { planificado }\end{array}$ & $\begin{array}{c}2 \text { = Más que lo } \\
\text { planificado }\end{array}$ & $\begin{array}{c}3=\text { Igual que lo } \\
\text { planificado }\end{array}$ & $\begin{array}{c}4=\text { Menos que } \\
\text { lo planificado }\end{array}$ & $\begin{array}{c}5=\text { Mucho } \\
\text { menos que lo } \\
\text { planificado }\end{array}$ \\
\hline
\end{tabular}

¿Cuál es la calidad de los trabajos realizados por el graduado?

\begin{tabular}{|c|c|c|c|c|}
\hline $\begin{array}{c}1=\text { Mucho } \\
\text { menos que lo } \\
\text { planificado }\end{array}$ & $\begin{array}{c}2=\text { Menos que } \\
\text { lo planificado }\end{array}$ & $\begin{array}{c}3=\text { Igual que lo } \\
\text { planificado }\end{array}$ & $\begin{array}{c}4=\text { Más que lo } \\
\text { planificado }\end{array}$ & $\begin{array}{c}5=\text { Mucho más } \\
\text { que lo } \\
\text { planificado }\end{array}$ \\
\hline
\end{tabular}




\section{Satisfacción}

Se evaluó mediante una pregunta la satisfacción con los resultados del trabajo o proyecto realizado por el graduado. La respuesta estaba acotada a una de las siguientes opciones:

\begin{tabular}{|c|c|c|c|c|}
\hline $\begin{array}{c}1=\text { Muy } \\
\text { insatisfecho }\end{array}$ & 2 = Insatisfecho & $\begin{array}{c}3=\text { No podría } \\
\text { precisarlo }\end{array}$ & $4=$ Satisfecho & $\begin{array}{c}5=\text { Muy } \\
\text { satisfecho }\end{array}$ \\
\hline
\end{tabular}

\section{Expectativas}

Las expectativas fueron medidas a partir de la elaboración de un ranking por parte del encuestado. Al igual que con las competencias, se ha divido las expectativas en 3 grupos: conocimientos, habilidades y actitudes.

Se le solicitó a cada persona encuestada que otorgue un orden jerárquico de 1 a 9 las competencias (en cada uno de los 3 grupos) que espera que los graduados demuestren cuando realizan su trabajo. El número 1 indica que le fue asignado como altamente significativo al atributo evaluado.

(en páginas siguientes: cuadros de Evaluación de conocimientos, Evaluación de habilidades $y$ Evaluación sobre actitudes) 


\subsection{Conocimiento}

\section{El graduado debe:}

4.1.1) entender los principios y conceptos relacionados con su carrera

4.1.2) entender la ciencia básica y principios fundamentales de su carrera

4.1.3) comprender en profundidad el proceso técnico en al menos una disciplina de ciencias económicas

4.1.4) lograr identificación de problemas, formulación y desarrollo de la solución 4.1.5) comprender cómo utilizar un enfoque de sistemas a diseño y desempeño operativo

4.1.6) Entiende los principios de diseño y desarrollo económico sostenibles relacionados con su carrera

4.1.7) entender las leyes, reglamentos y normas relacionadas con su carrera 4.1.8) entender los principios de gestión y negocios relacionados con ciencias económicas

4.1.9) comprender otras disciplinas relacionadas con su carrera

\subsection{Habilidades}

\begin{tabular}{|l|l|}
\hline \multicolumn{1}{|c|}{ El graduado debe: } & \\
\hline $\begin{array}{l}\text { 4.2.1) aplicar conocimientos técnicos en profundidad en al menos una disciplina de } \\
\text { ciencias económicas }\end{array}$ & \\
\hline 4.2.2) usar las tecnologías apropiadamente & \\
\hline 4.2.3) acceder, evaluar y sintetizar información & \\
\hline t.2.4) comunicar efectivamente no sólo con los profesionales de económicas sino & \\
\hline 4.2.5) funcionar eficazmente como un individuo & \\
\hline 4.2.6) funcionar eficazmente en equipos multidisciplinarios o multiculturales & \\
\hline 4.2.7) funcionar eficazmente en equipos con capacidad de ser miembro más & \\
\hline 4.2.8) funcionar eficazmente en equipos con capacidad de ser un director & \\
\hline 4.2.9) funcionar eficazmente en equipos con la capacidad de ser un líder & \\
\hline
\end{tabular}




\subsection{Actitudes}

El graduado debería estar:

4.3.1) Capacitado para pensar críticamente, creativamente, reflexivamente en su trabajo

4.3.2) comprometido para llevar a cabo el aprendizaje permanente

4.3.3) comprometido con las responsabilidades éticas de reunión en su trabajo

4.3.4) comprometido a cumplir responsabilidades ambientales en su trabajo

4.3.5) Capacitado para trabajar con perspectivas internacionales y mundiales, adecuándose a las mismas

4.3.6) comprometido a desarrollar aún más sus habilidades profesionales

4.3.7) comprometido a trabajar efectivamente con diferentes grupos culturales

4.3.8) comprometido para utilizar habilidades grupales en su lugar de trabajo

4.3.9) comprometido para desarrollar habilidades interpersonales efectivas en su lugar de trabajo 


\section{7.- Análisis de los datos}

Los datos fueron analizados siguiendo un esquema de general a particular. Es decir, se comenzó estableciendo el nivel de satisfacción de "los clientes" para luego ir realizando un análisis más detallado que explicaron las razones de ese nivel de satisfacción.

Primero se hizo un análisis univariado de cada uno de los datos evaluados. Seguidamente se procedió a realizar un análisis bivariado para poder conocer la relación entre las variables y poder obtener una mejor evaluación de la calidad de los graduados.

\section{Estadística descriptiva univariada}

El análisis de la información se llevó a cabo luego de la confección de una base de datos. Los datos obtenidos en las encuestas fueron cargados a una matriz, donde cada campo representó cada pregunta de la encuesta. Las respuestas fueron codificadas numéricamente, para facilitar la carga.

Luego se calculó el "Saldo de respuesta"1 de cada pregunta realizada, en función de la fórmula siguiente:

$$
\text { Saldo de Re spuesta }=\frac{\sum_{i=1}^{n} F_{i} \cdot i}{\sum_{i=1}^{n} F_{i}}
$$

Donde:

$\mathrm{Fi}=$ Es la cantidad de respuestas (frecuencias) de cada ítem para cada valor de las opciones de respuesta

${ }^{1}$ El cálculo de ese promedio sigue idéntica metodología que la del Global Competitiveness Index del World Economic Forum para el procesamiento de la Executive Opinion Survey en que se pregunta sobre una serie de cuestiones y se solicita que se califique en un rango que va de 1 a 7 en que 1 es lo peor y 7 lo mejor y que luego se sintetiza a través de un promedio. Xavier Sala-i-Martin (Cabrera de Mar, Barcelona, España, 1963), es un economista de origen español y de nacionalidad estadounidense, articulista, catedrático de economía en la Universidad de Columbia y Asesor Jefe ("Chief Advisor") del World Economic Forum donde, además, es coautor del Global Competitiveness Report y el padre intelectual del Global Competitiveness Index que ordena a más de 140 países del mundo según su competitividad. 
$\mathrm{i}=$ Es el valor de cada uno de las opciones de respuesta

El cálculo consiste en multiplicar los componentes de las cantidades de respuestas (frecuencias) por el tipo de respuesta dado y luego sumar esos productos. Posteriormente a ese número se lo divide por la sumatoria de la cantidad de respuestas.

Dado que se utilizó la misma encuesta de la investigación "Stakeholders" satisfaction with Civil Engineering Graduates" y que esta no preveía la determinación de la brecha entre la expectativa y la percepción de calidad del graduado, fue necesario realizar dos transformaciones matemáticas.

La primera transformación tuvo que ver con que la percepción sobre las competencias de los graduados calificaba lo peor con 1 y lo mejor con 5; mientras que para las expectativas se calificaba con 1 lo mejor y con 9 lo peor, por lo cual se invirtió la escala para las percepciones.

Determinación de la ecuación de la recta de transformación en función de los ejes cartesianos de los extremos.

\begin{tabular}{|c|r|r|}
\hline Percepción & $\begin{array}{l}\text { Calificación } \\
\text { original }\end{array}$ & \multicolumn{2}{|c|}{$\begin{array}{c}\text { Nueva } \\
\text { calificación }\end{array}$} \\
\hline Lo peor & 1 & 5 \\
\hline Lo mejor & 5 & 1 \\
\hline
\end{tabular}

Los extremos conforman los pares siguientes:

$\left(x_{0} ; y_{0}\right)=(1 ; 5)$

$\left(\mathrm{x}_{1} ; \mathrm{y}_{1}\right)=(5 ; 1)$

De tal modo, la pendiente de la recta de transformación "m" es:

$m=\frac{\left(y_{1}-y_{0}\right)}{\left(x_{1}-x_{0}\right)}=\frac{(1-5)}{(5-1)}=-1$

Y la ordenada al origen "b" es: 


$$
b=-m \cdot x_{0}+y_{0}=-(-1) \cdot 1+5=6
$$

Y la ecuación de la recta de transformación es:

$$
y=m \cdot x+b=-1 \cdot x+6
$$

La segunda transformación refiere a que las expectativas iban en un rango de 1 a 9 por lo cual debía llevarse a uno que fuese de 1 a 5.

Determinación de la ecuación de la recta de transformación en función de los ejes cartesianos de los extremos.

\begin{tabular}{|c|c|c|}
\hline Percepción & $\begin{array}{c}\text { Calificación } \\
\text { original }\end{array}$ & $\begin{array}{c}\text { Nueva } \\
\text { calificación }\end{array}$ \\
\hline Lo mejor & 1 & 1 \\
\hline Lo peor & 9 & 5 \\
\hline
\end{tabular}

Los extremos conforman los pares siguientes:

$\left(\mathrm{x}_{0} ; \mathrm{y}_{0}\right)=(1 ; 1)$

$\left(\mathrm{x}_{1} ; \mathrm{y}_{1}\right)=(9 ; 5)$

De tal modo, la pendiente de la recta de transformación "m" es:

$m=\frac{\left(y_{1}-y_{0}\right)}{\left(x_{1}-x_{0}\right)}=\frac{(5-1)}{(9-1)}=0,5$

Y la ordenada al origen "b" es:

$b=-m \cdot x_{0}+y_{0}=-0,5 \cdot 1+1=0,5$

Y la ecuación de la recta de transformación es:

$y=m \cdot x+b=0,5 \cdot x+0,5=0,5 \cdot(x+1)$ 
Luego se calculó la frecuencia de la brecha de satisfacción de la calidad del graduado, como la diferencia entre las percepciones y las expectativas que tienen los empleadores.

La brecha de satisfacción de los empleadores es la resultante de la resta entre la calificación otorgada a la expectativa que un empleador tiene sobre un aspecto del graduado y la percepción respecto de la calidad ofrecida por el graduado.

El "árbol de posibilidades" está conformado por la tabla siguiente.

\begin{tabular}{|c|c|c|}
\hline Expectativa & Percepción & Brecha \\
\hline 1,0 & 5,0 & $-4,0$ \\
\hline$\overline{1,0}$ & $\overline{4,0}$ & $-3,0$ \\
\hline 1,0 & 3,0 & $-2,0$ \\
\hline 1,0 & 2,0 & $-1,0$ \\
\hline 1,0 & 1,0 & 0,0 \\
\hline 1,5 & 5,0 & $-3,5$ \\
\hline 1,5 & 4,0 & $-2,5$ \\
\hline 1,5 & 3,0 & $-1,5$ \\
\hline 1,5 & 2,0 & $-0,5$ \\
\hline 1,5 & 1,0 & 0,5 \\
\hline 2,0 & 5,0 & $-3,0$ \\
\hline 2,0 & 4,0 & $-2,0$ \\
\hline 2,0 & $\overline{3,0}$ & $\overline{-1,0}$ \\
\hline 2,0 & 2,0 & 0,0 \\
\hline$\overline{2,0}$ & 1,0 & $\overline{1,0}$ \\
\hline 2,5 & 5,0 & $-2,5$ \\
\hline 2,5 & 4,0 & $-1,5$ \\
\hline 2,5 & 3,0 & $-0,5$ \\
\hline 2,5 & 2,0 & 0,5 \\
\hline 2,5 & 1,0 & 1,5 \\
\hline 3,0 & 5,0 & $-2,0$ \\
\hline 3,0 & 4,0 & $-1,0$ \\
\hline$\overline{3,0}$ & 3,0 & 0,0 \\
\hline 3,0 & 2,0 & $\overline{1,0}$ \\
\hline 3,0 & 1,0 & 2,0 \\
\hline 3,5 & 5,0 & $-1,5$ \\
\hline 3,5 & 4,0 & $-0,5$ \\
\hline 3,5 & 3,0 & 0,5 \\
\hline
\end{tabular}




\begin{tabular}{|lll|}
\hline 3,5 & 2,0 & 1,5 \\
\hline 3,5 & 1,0 & 2,5 \\
\hline 4,0 & 5,0 & $-1,0$ \\
\hline 4,0 & 4,0 & 0,0 \\
\hline 4,0 & 3,0 & 1,0 \\
\hline 4,0 & 2,0 & 2,0 \\
\hline 4,0 & 1,0 & 3,0 \\
\hline 4,5 & 5,0 & $-0,5$ \\
\hline 4,5 & 4,0 & 0,5 \\
\hline 4,5 & 3,0 & 1,5 \\
\hline 4,5 & 2,0 & 2,5 \\
\hline 4,5 & 1,0 & 3,5 \\
\hline 5,0 & 5,0 & 0,0 \\
\hline 5,0 & 4,0 & 1,0 \\
\hline 5,0 & 3,0 & 2,0 \\
\hline 5,0 & 2,0 & 3,0 \\
\hline 5,0 & 1,0 & 4,0 \\
\hline
\end{tabular}

Fuente: Elaboración propia.

Y resumiendo sólo los casos únicos:

\begin{tabular}{|r|l|}
\hline Brechas & \multicolumn{1}{|c|}{$\begin{array}{c}\text { Estados posibles de } \\
\text { satisfacción }\end{array}$} \\
\hline$-4,0$ & Insatisfacción total \\
$-3,5$ & Muy insatisfecho \\
\hline$-2,0$ & Bastante insatisfecho \\
$-2,0$ & \\
\hline$-1,5$ & Algo insatisfecho \\
\hline$-1,0$ & \\
\hline$-0,5$ & \\
0,0 & Satisfecho \\
0,5 & \\
\hline 1,0 & Algo más que satisfecho \\
\hline 1,5 & \\
\hline 2,0 & Bastante más que satisfecho \\
\hline 2,5 & \\
\hline 3,0 & Mucho más que satisfecho \\
\hline 3,5 & \\
\hline 4,0 & Satisfacción total \\
\hline
\end{tabular}

Fuente: Elaboración propia. 


\section{Percepción y expectativas sobre conocimientos}

De las respuestas obtenidas respecto de la evaluación de conocimientos a partir de la encuesta 1.1 y de las repuestas sobre las expectativas a partir de la encuesta 4.1 surgen los siguientes resultados:

\section{1) Principios básicos y conceptos relacionados con su carrera}

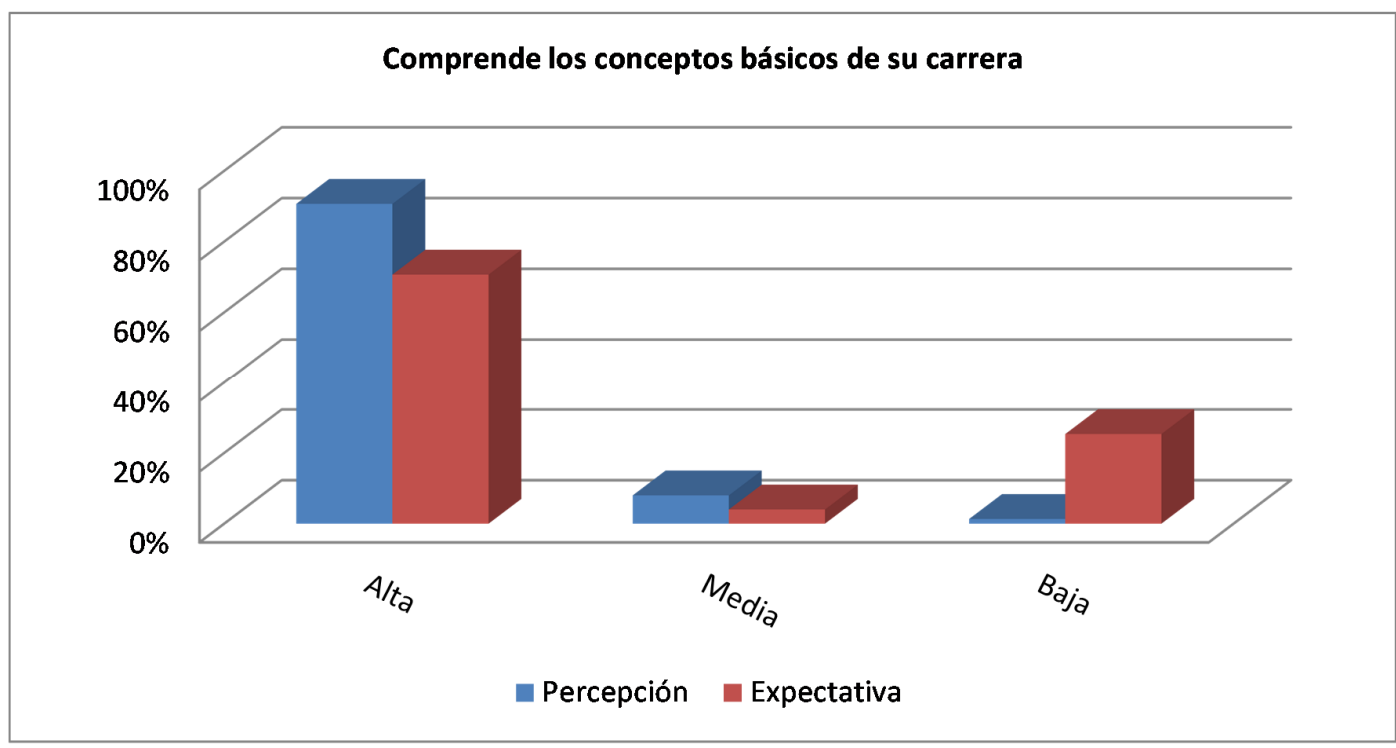

La percepción con un saldo de respuesta de 1,63 es superior a la expectativa, con un saldo de respuesta de 2,23. De las respuestas surge que más del $91 \%$ de los empleadores han evaluado como alta la comprensión de los graduados sobre los conceptos básicos de su carrera. 


\section{2) Fundamentos económicos de su carrera}

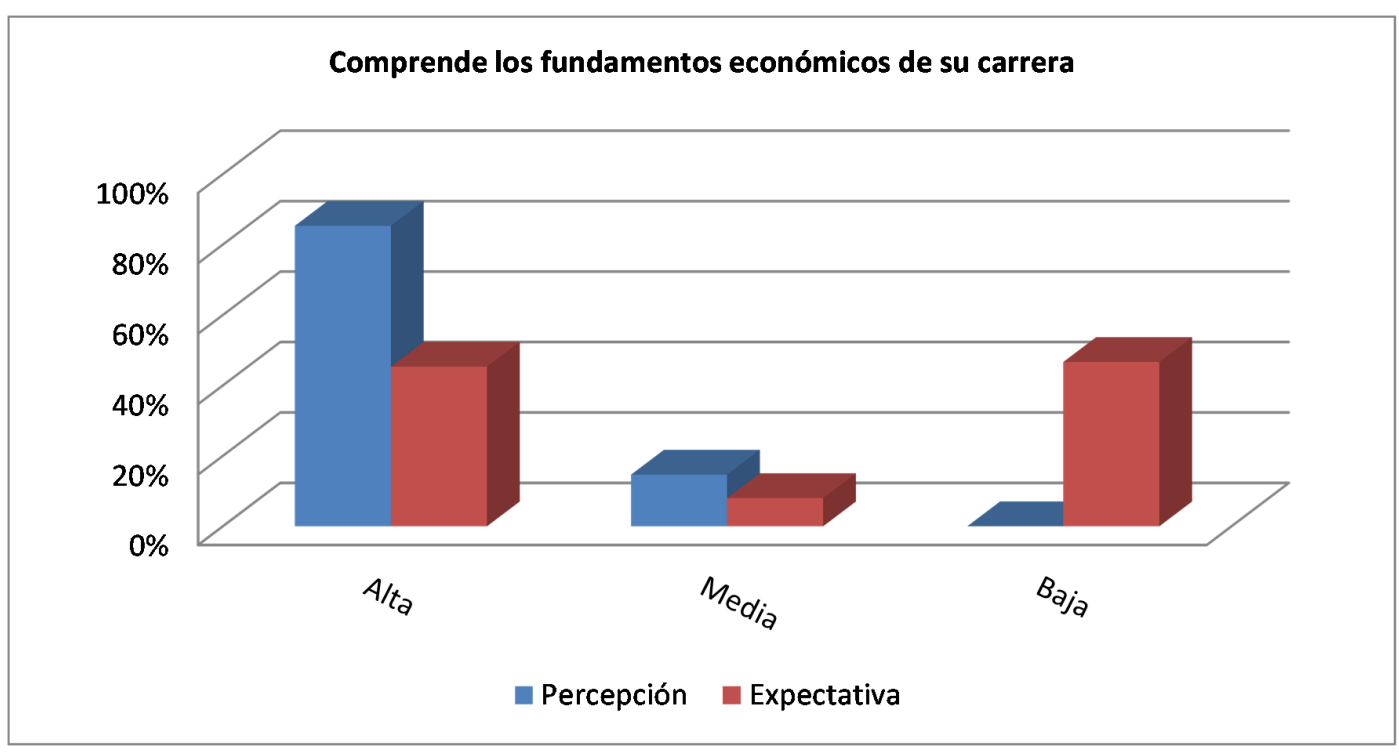

La percepción con un saldo de respuesta de 1,67 es superior a la expectativa, con un saldo de respuesta de 3,13 . De las respuestas surge que más del $85 \%$ de los empleadores ha evaluado como alta la comprensión de los graduados sobre los fundamentos económicos de su carrera.

\section{3) Procesos técnicos en al menos una disciplina de su carrera}

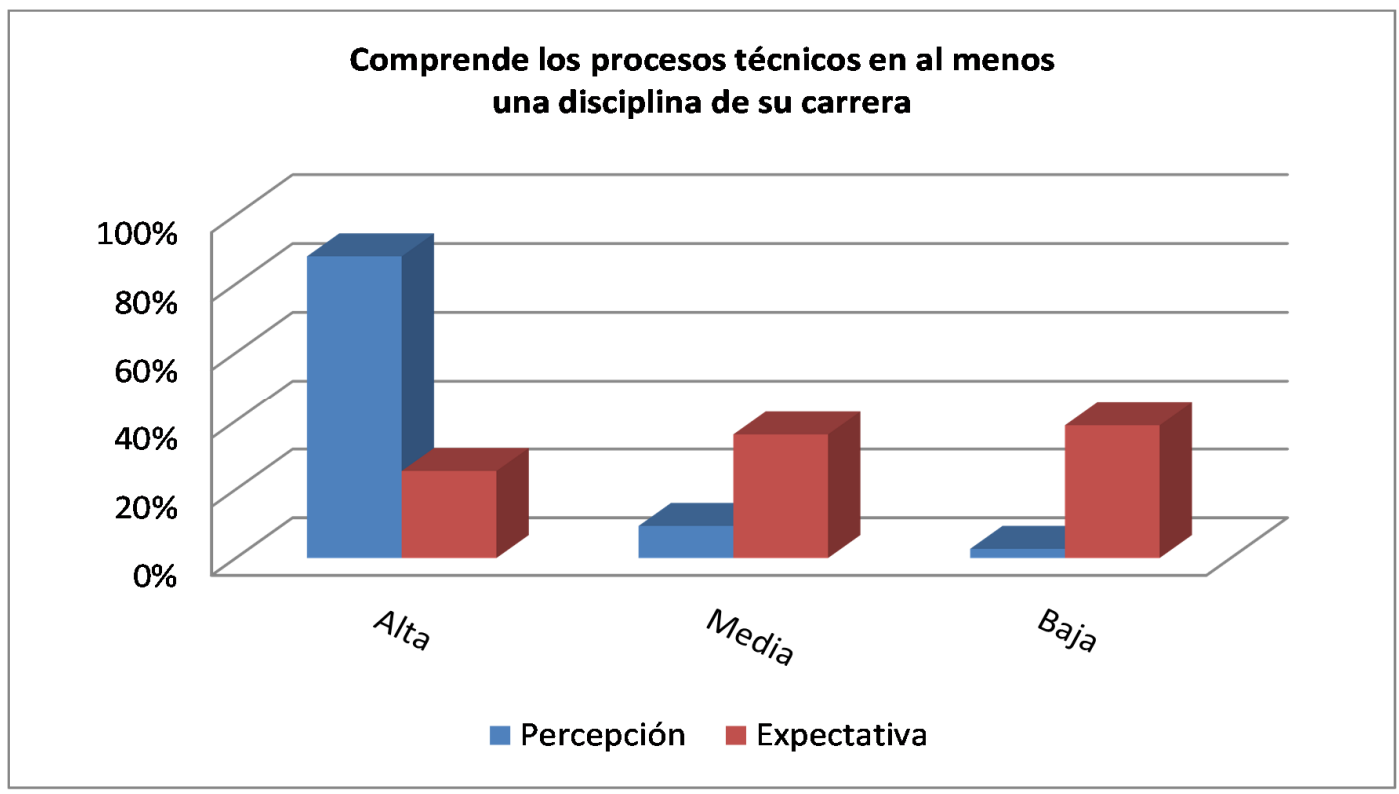

La percepción con un saldo de respuesta de 1,79 es superior a la expectativa, con un saldo de respuesta de 3,28 . De las respuestas surge que el $88 \%$ 
de los empleadores ha evaluado como alta la comprensión de los graduados sobre los procesos técnicos en al menos una disciplina de su carrera.

\section{4) Identificación de problemas, formulación y desarrollo de la solución}

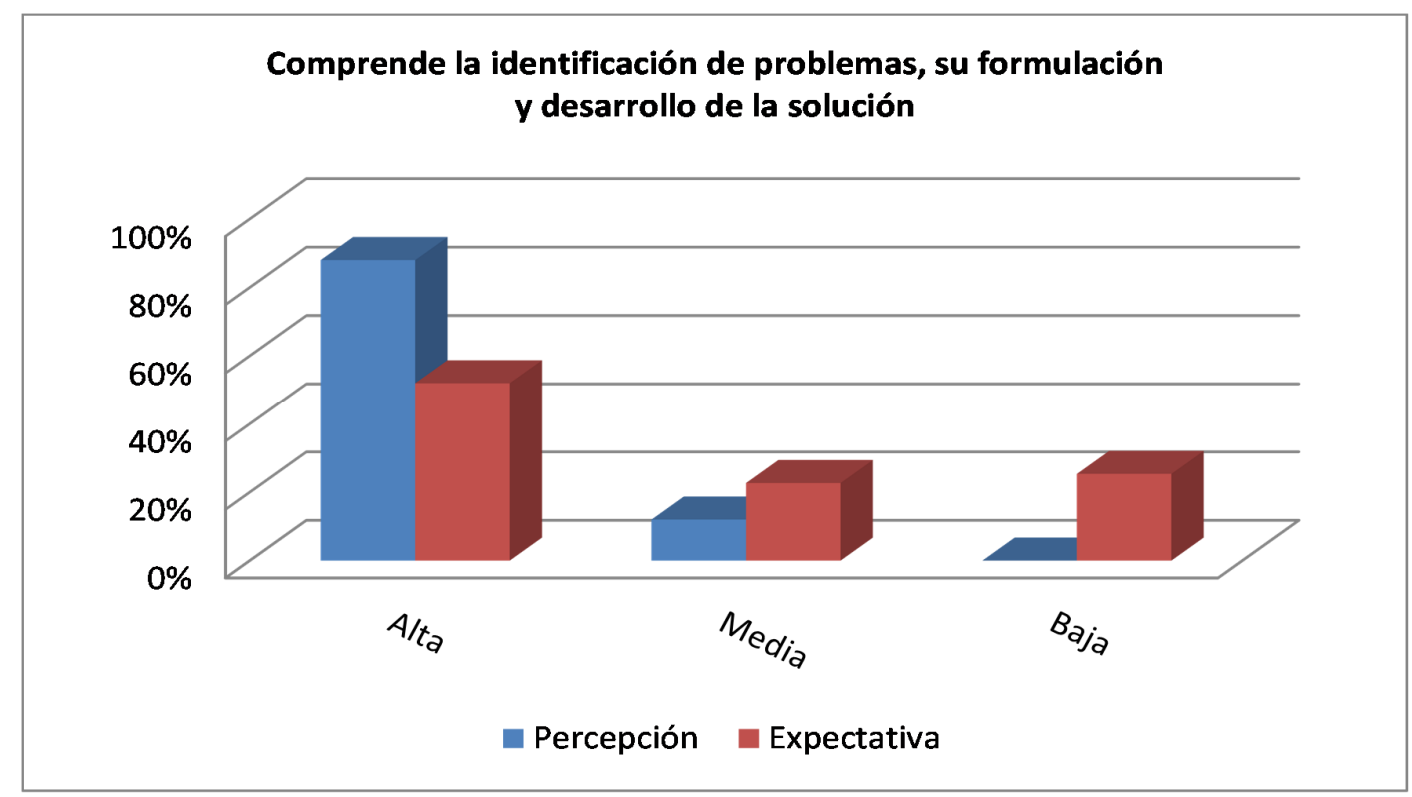

La percepción con un saldo de respuesta de 1,73 es superior a la expectativa, con un saldo de respuesta de 2,67. De las respuestas surge que el $88 \%$ de los empleadores ha evaluado como alta la comprensión de los graduados sobre la identificación de problemas, su formulación y desarrollo de su solución. 


\section{5) Utilización de un enfoque de sistema}

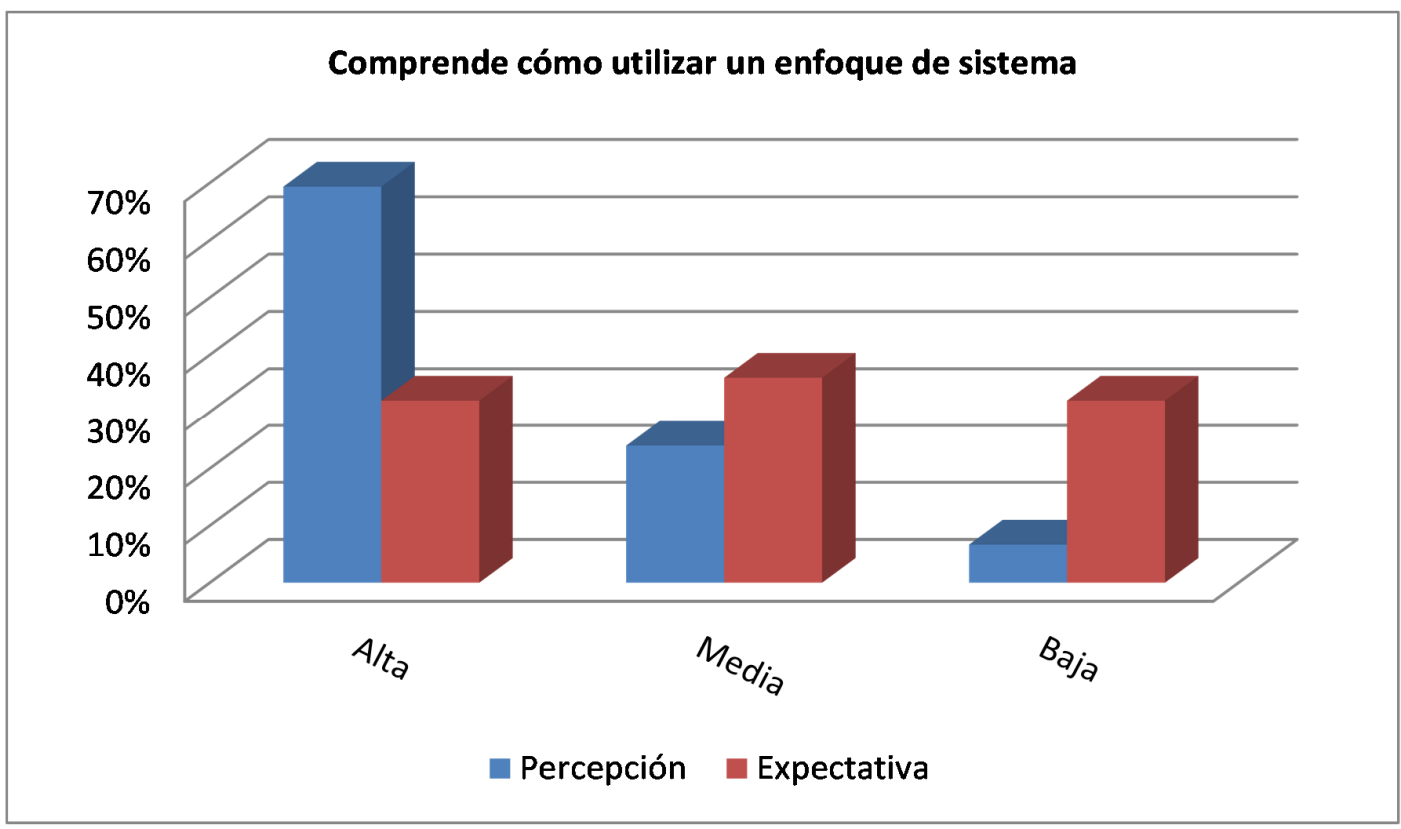

La percepción con un saldo de respuesta de 2,11 es superior a la expectativa, con un saldo de respuesta de 3,19. De las respuestas surge que el $69 \%$ de los empleadores ha evaluado como alta la comprensión de los graduados sobre la utilización de un enfoque de sistema.

\section{6) Desarrollo económico sostenible}

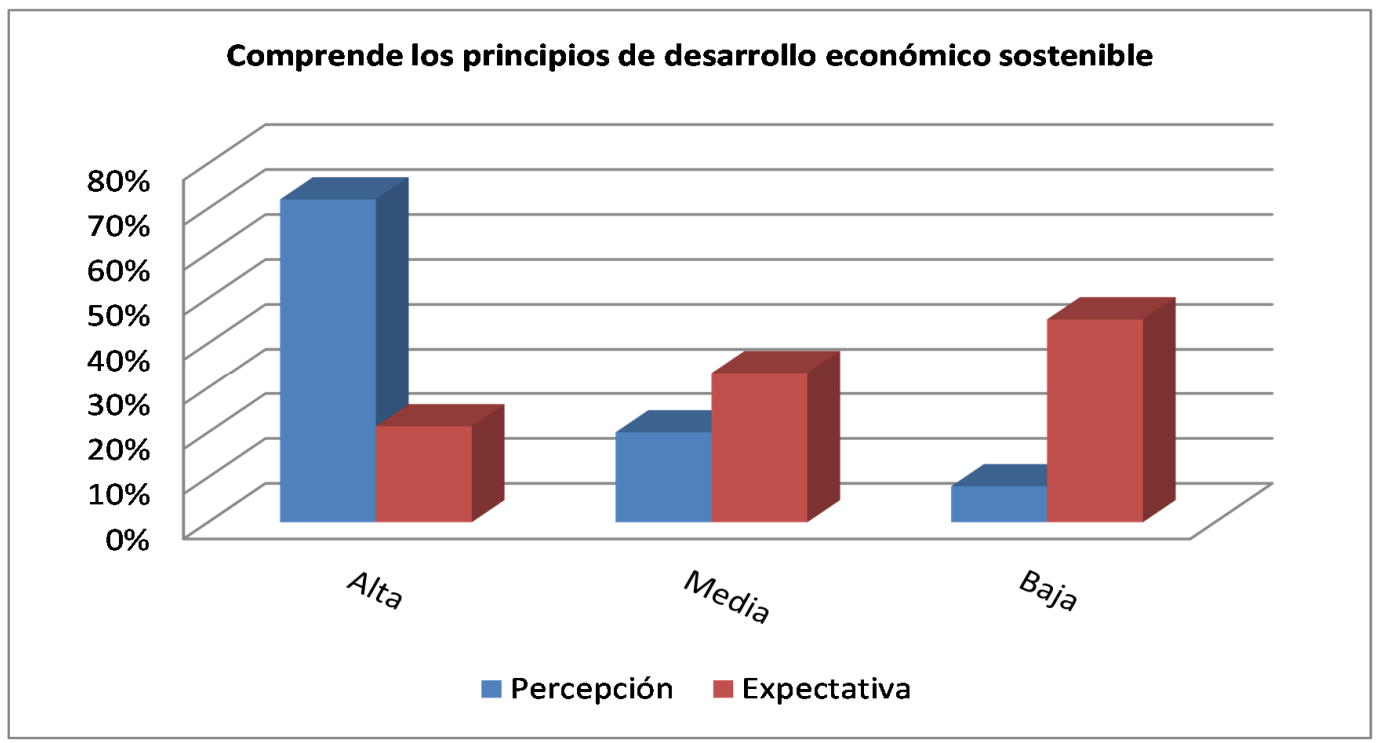


La percepción con un saldo de respuesta de 2,13 es superior a la expectativa, con un saldo de respuesta de 3,61. De las respuestas surge que más del $72 \%$ de los empleadores ha evaluado como alta la comprensión de los graduados sobre los principios de desarrollo sostenible.

\section{7) Leyes, reglamentos y normas}

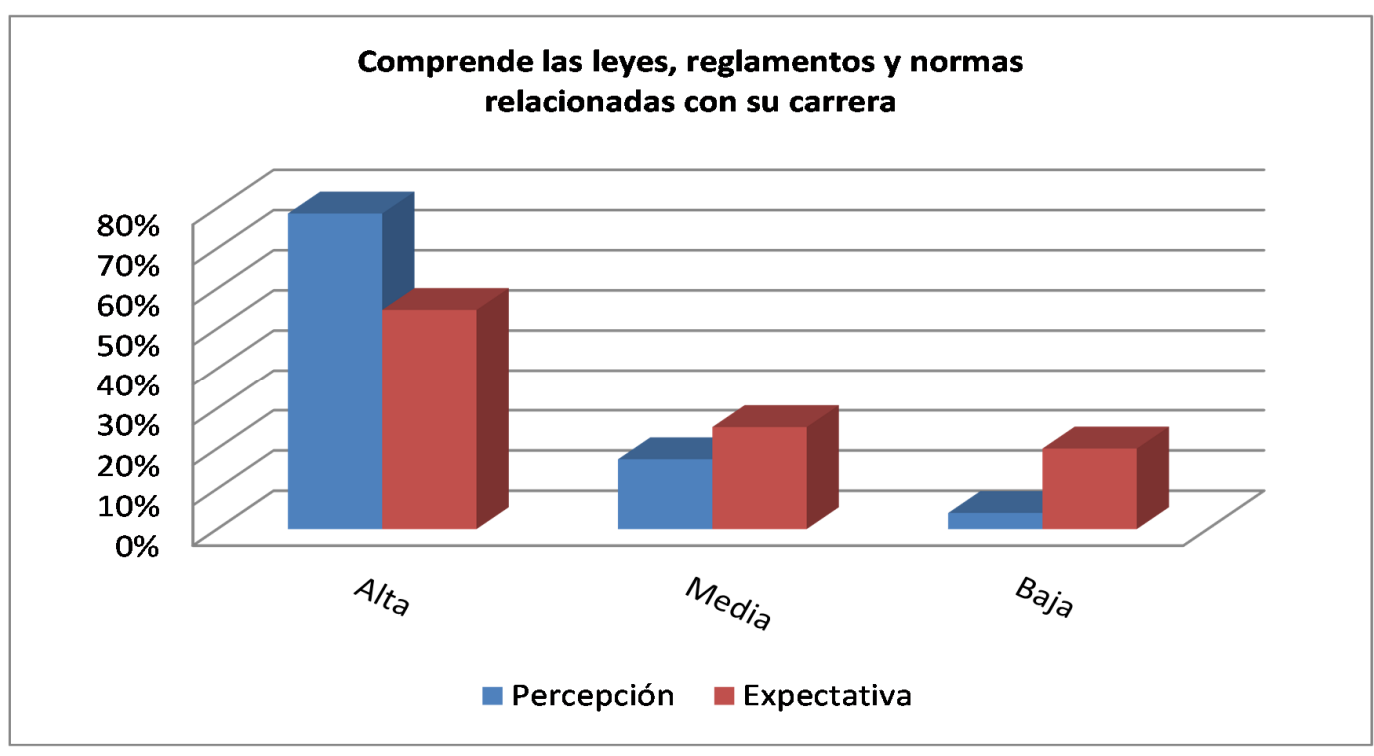

La percepción con un saldo de respuesta de 1,96 es superior a la expectativa, con un saldo de respuesta de 2,75 . De las respuestas surge que el $79 \%$ de los empleadores ha evaluado como alta la comprensión de los graduados sobre las leyes, reglamentos y normas relacionados con su carrera.

\section{8) Principios de gestión y negocios}

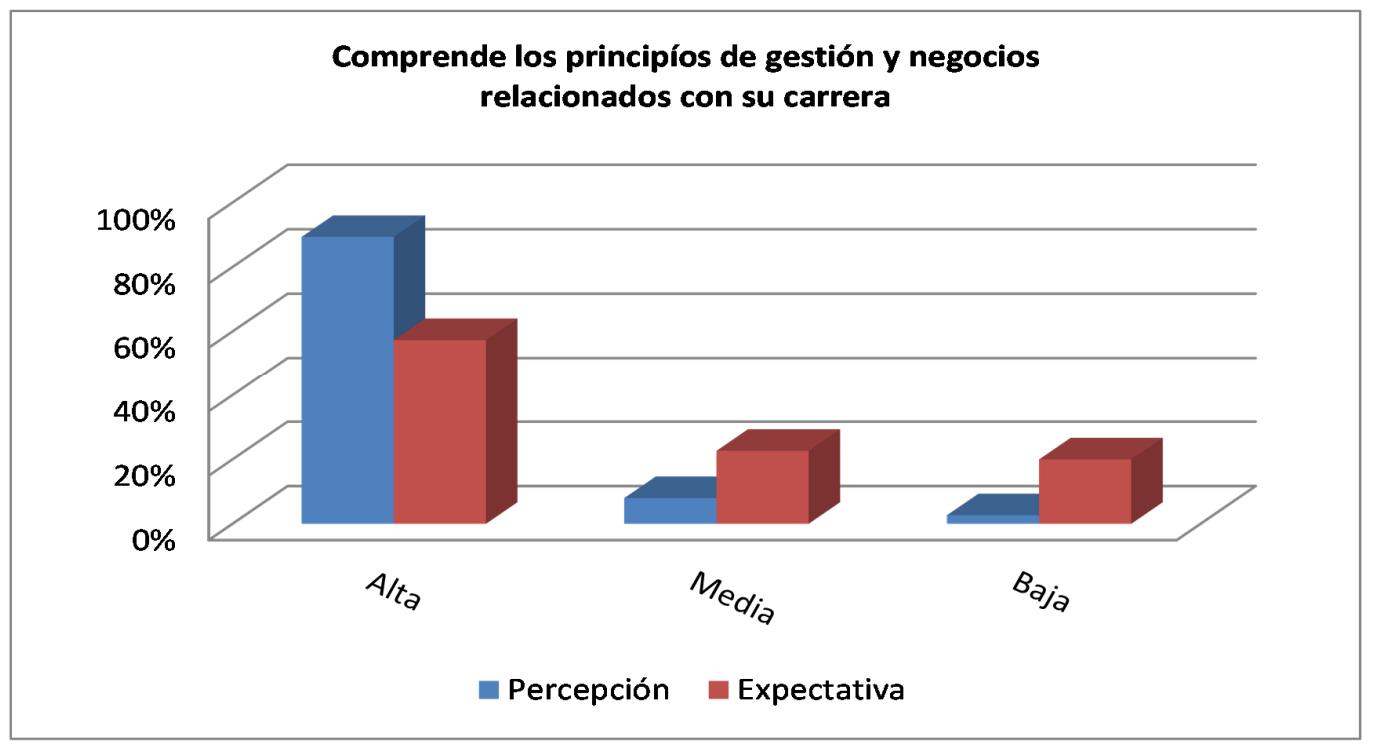


La percepción con un saldo de respuesta de 1,77 es superior a la expectativa, con un saldo de respuesta de 2,76. De las respuestas surge que más del $89 \%$ de los empleadores ha evaluado como alta la comprensión de los graduados sobre los principios de gestión y negocios relacionados con su carrera.

\section{9) Relación con otras disciplinas}

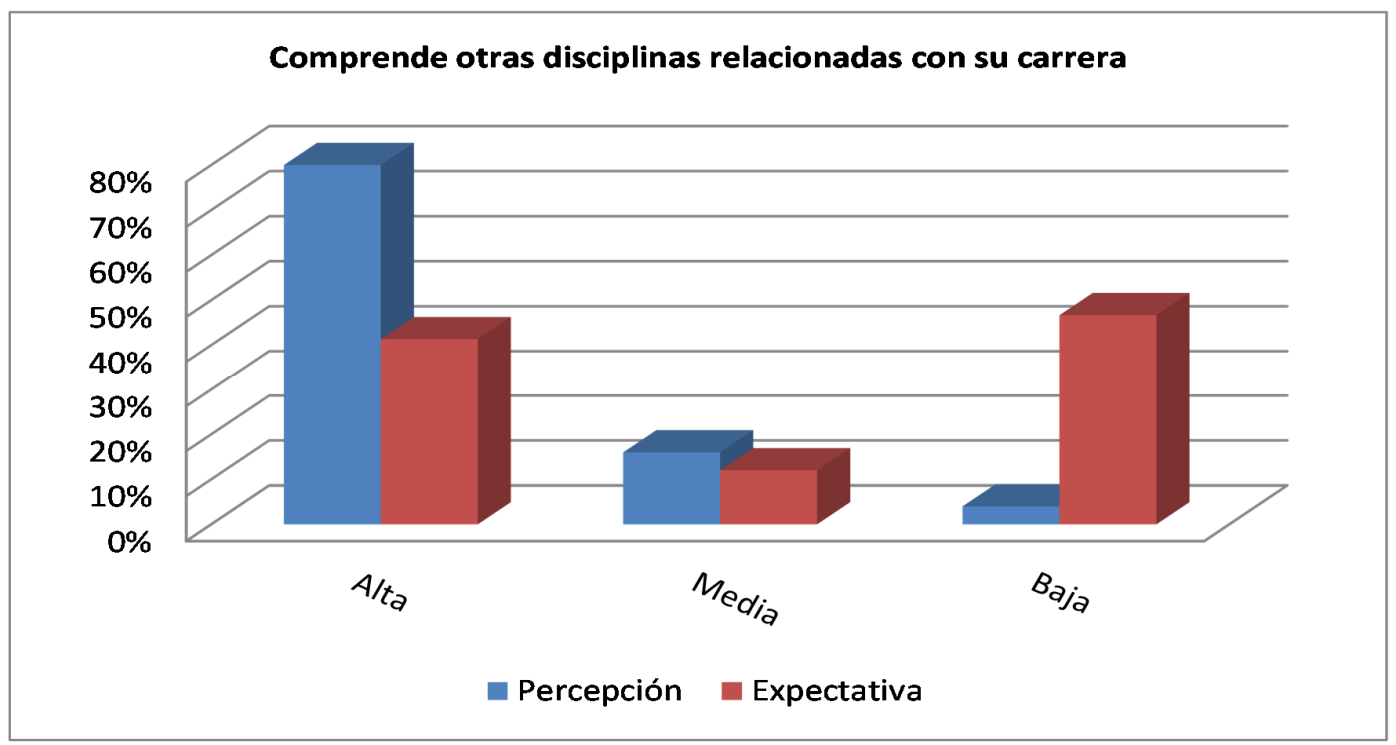

La percepción con un saldo de respuesta de 1,96 es superior a la expectativa, con un saldo de respuesta de 3,39. De las respuestas surge que más del $80 \%$ de los empleadores ha evaluado como alta la comprensión de los graduados sobre otras disciplinas relacionadas con su carrera.

Los resultados anteriormente expuestos muestran que en la mayoría de los casos considerados, la percepción ha superado las expectativas. Por lo tanto se podría concluir que los empleadores están satisfechos con el nivel de conocimiento evidenciado por los graduados.

Para confirmar la conclusión realizada en el párrafo anterior, luego de calcular y comparar las percepciones y las expectativas, se obtuvieron las brechas y se calcularon los saldos de respuesta para cada uno de los atributos considerados al evaluar el conocimiento de los graduados, obteniendo el siguiente resumen respecto del nivel de satisfacción de los empleadores. 


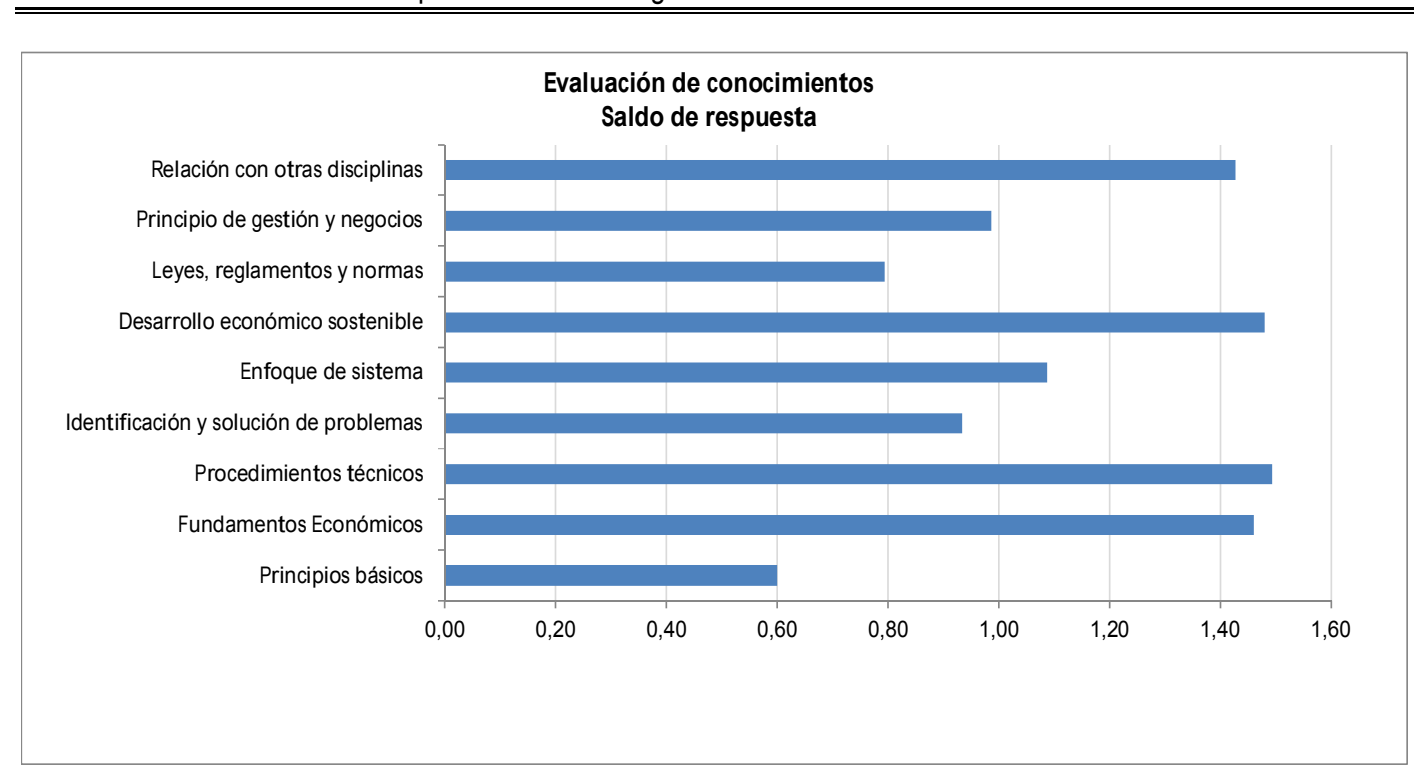

Efectivamente, los resultados confirman que los saldos de respuesta de las brechas se encuentran dentro de la zona de satisfacción, siendo desarrollo económico sostenible, los procedimientos técnicos, fundamentos económicos, la relación con otras disciplinas, el enfoque de sistema y principios de gestión y negocios, los atributos que más se destacan los graduados de la carrera de Contador. 


\section{Percepción y expectativas sobre habilidades}

De las respuestas obtenidas respecto de la evaluación de habilidades a partir de la encuesta 1.2 y de las repuestas sobre las expectativas a partir de la encuesta 4.2 surgen los siguientes resultados:

\section{1) Principios básicos y conceptos relacionados con su carrera}

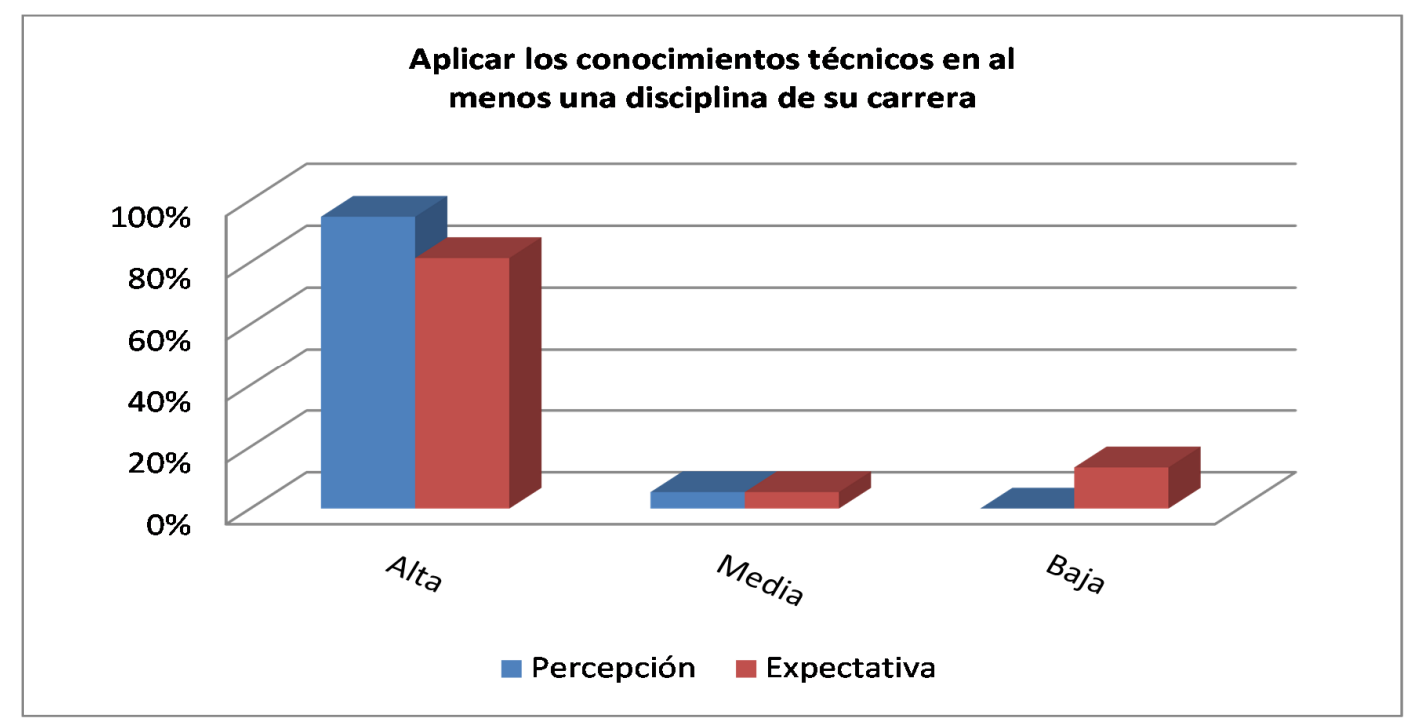

La percepción con un saldo de respuesta de 1,61 es superior a la expectativa, con un saldo de respuesta de 1,87. De las respuestas surge que la el $95 \%$ de los empleadores ha evaluado como alta la capacidad de los graduados de aplicar los conocimientos técnicos en al menos una disciplina de su carrera.

\section{2) Tecnologías disponibles}

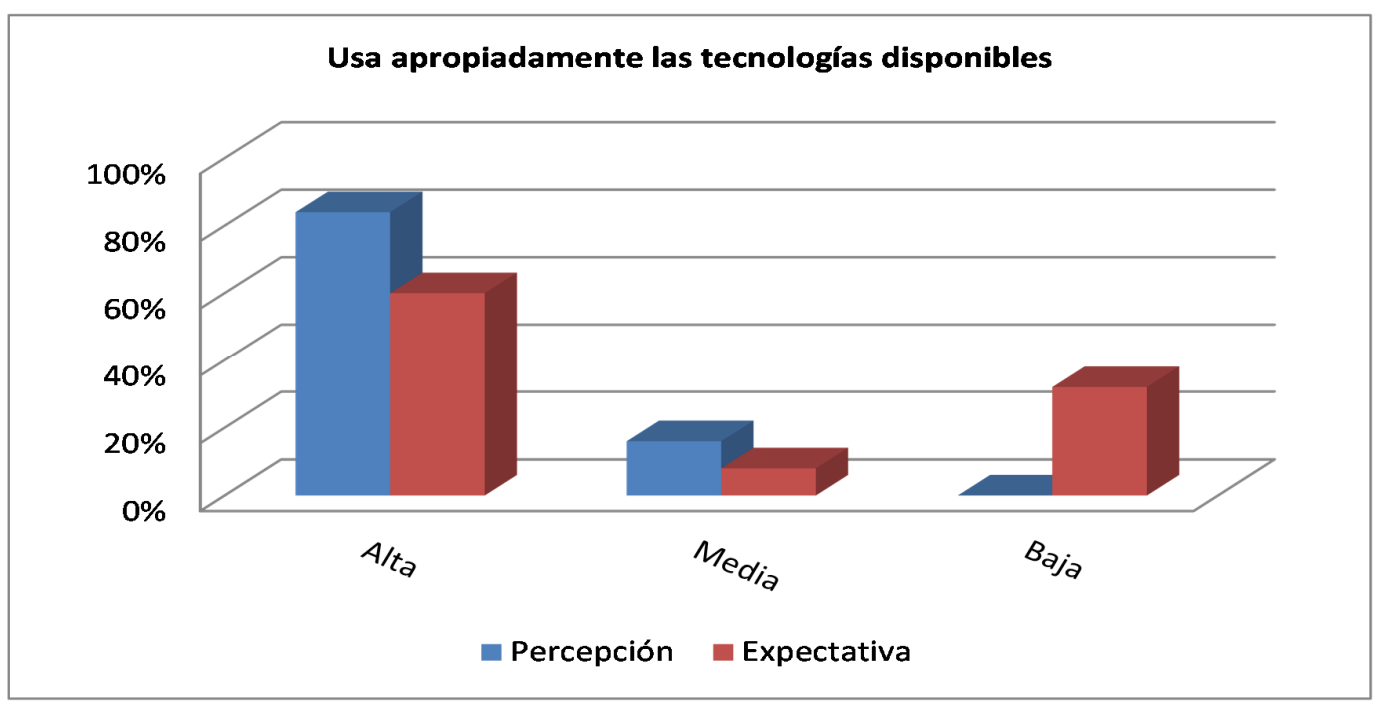


La percepción con un saldo de respuesta de 1,79 es superior a la expectativa, con un saldo de respuesta de 2,83 . De las respuestas surge que más del $84 \%$ de los empleadores ha evaluado como alta la capacidad de los graduados de usar apropiadamente las tecnologías disponibles.

\section{3) Acceder, evaluar y sintetizar información}

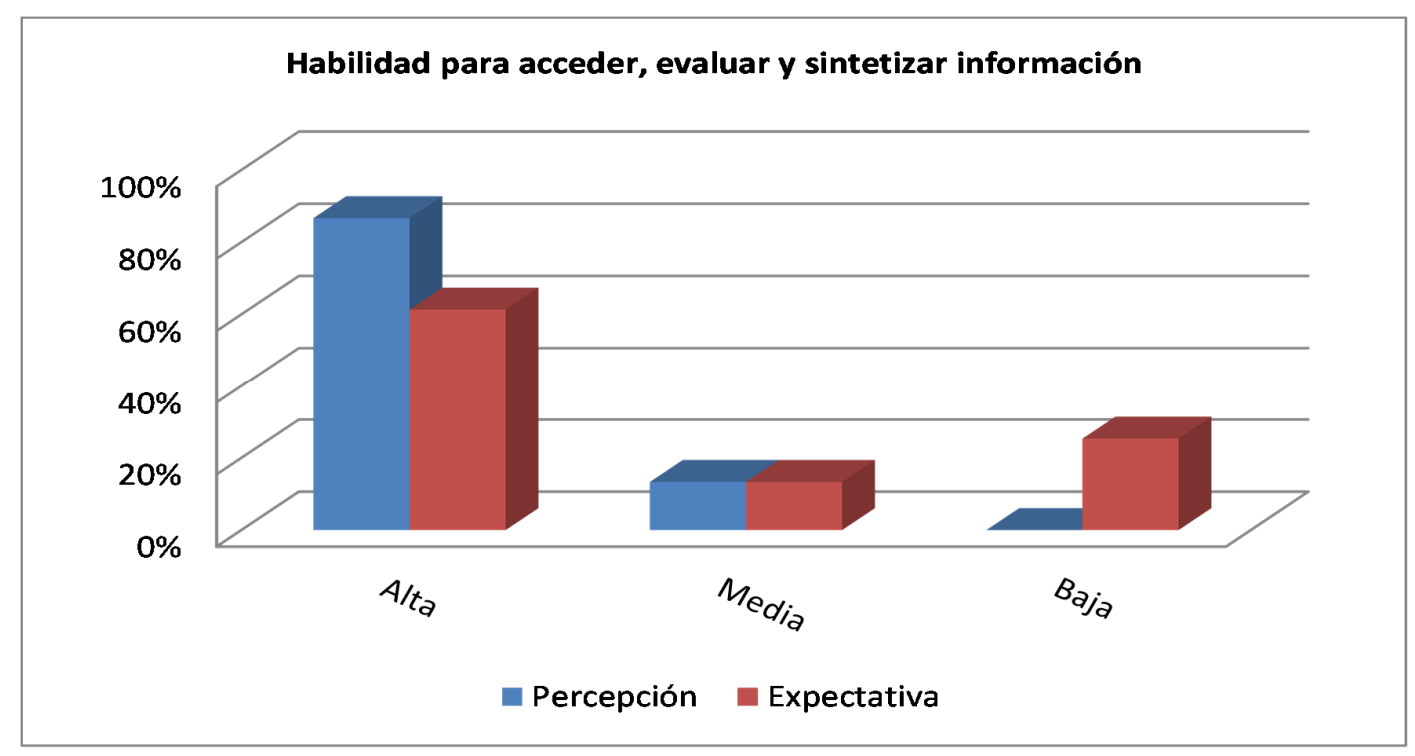

La percepción con un saldo de respuesta de 1,76 es superior a la expectativa, con un saldo de respuesta de 2,56. De las respuestas surge que más del $87 \%$ de los empleadores ha evaluado como alta la capacidad de los graduados de acceder, avaluar y sintetizar la información disponible. 
4) Comunicación con profesionales de otras disciplinas y la sociedad en general

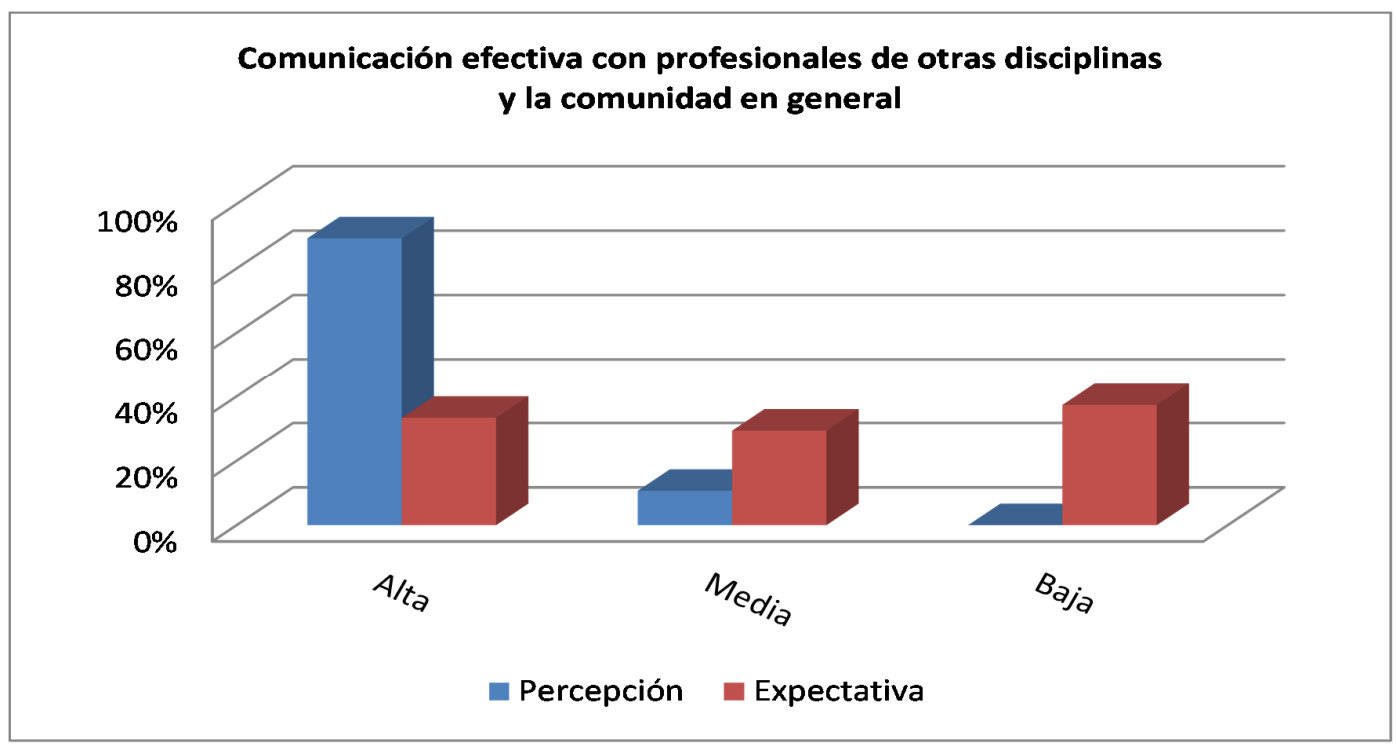

La percepción con un saldo de respuesta de 1,77 es superior a la expectativa, con un saldo de respuesta de 3,32. De las respuestas surge que el $89 \%$ de los empleadores encuestados ha evaluado como alta la capacidad de los graduados de comunicarse con profesionales de otras disciplinas y la sociedad en general.

\section{5) Funcionar eficazmente como individuo}

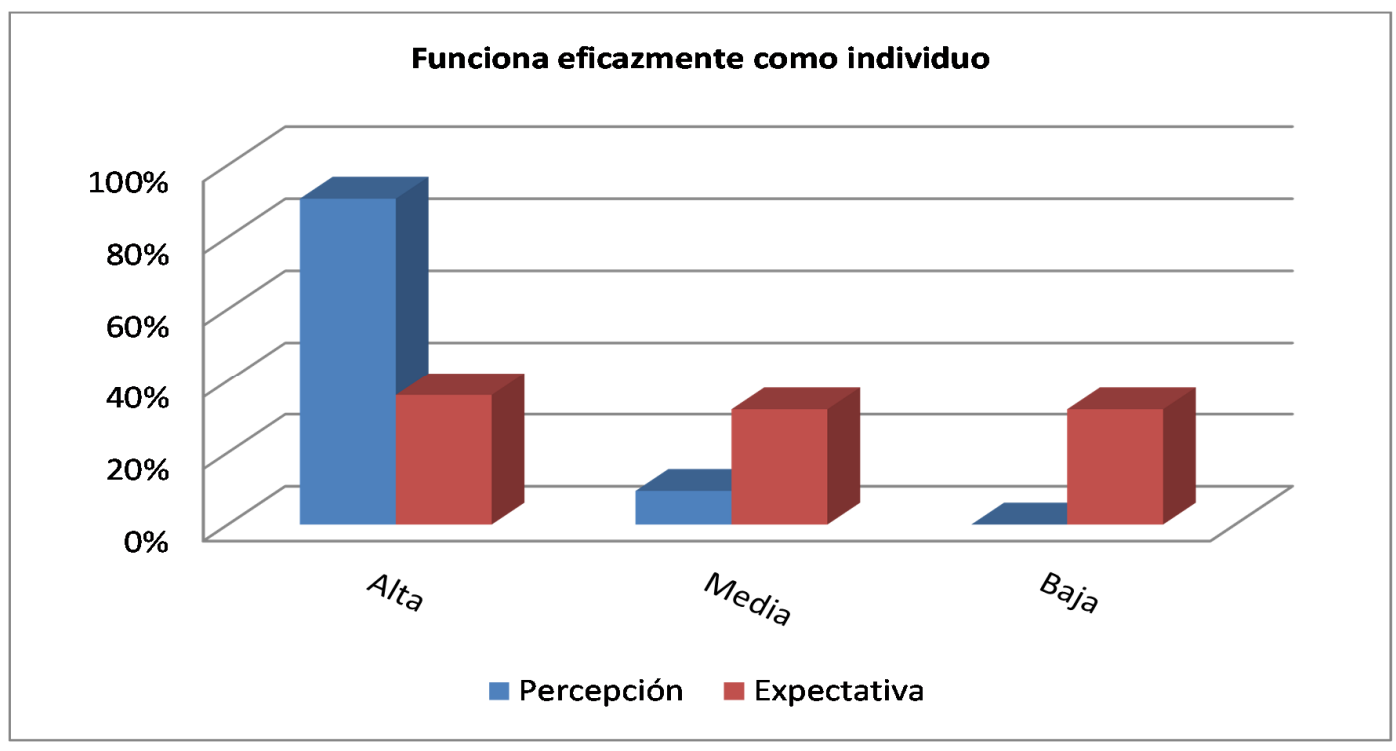

La percepción con un saldo de respuesta de 1,65 es superior a la expectativa, con un saldo de respuesta de 3,18. De las respuestas surge que más del 
91\% de los empleadores encuestados ha evaluado como alta la capacidad de los graduados de funcionar eficazmente como individuo.

\section{6) Funcionar eficazmente en equipos multidisciplinarios}

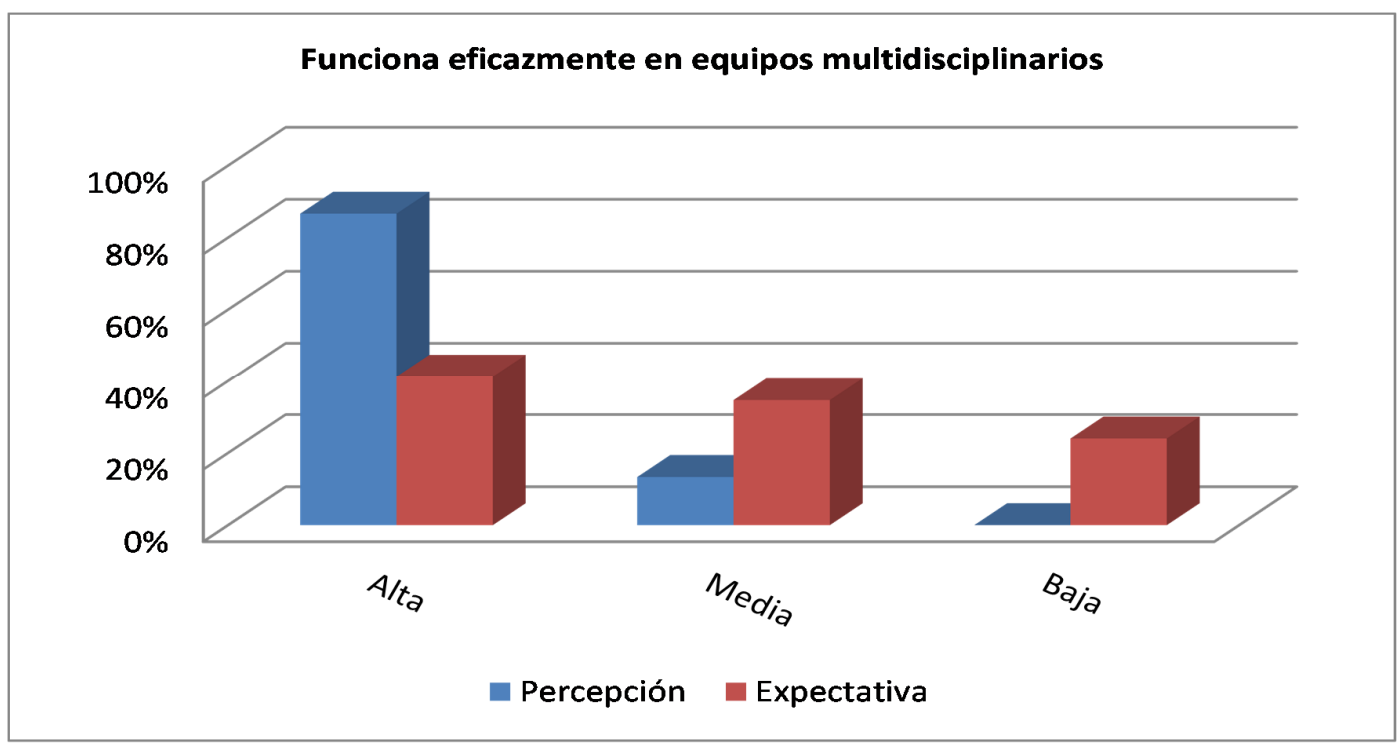

La percepción con un saldo de respuesta de 1,73 es superior a la expectativa, con un saldo de respuesta de 2,85 . De las respuestas surge que más del $87 \%$ de los empleadores encuestados ha evaluado como alta la capacidad de los graduados de funcionar eficazmente en equipos multidisciplinarios. 


\section{7) Funcionar eficazmente en equipos con capacidad de ser miembro}

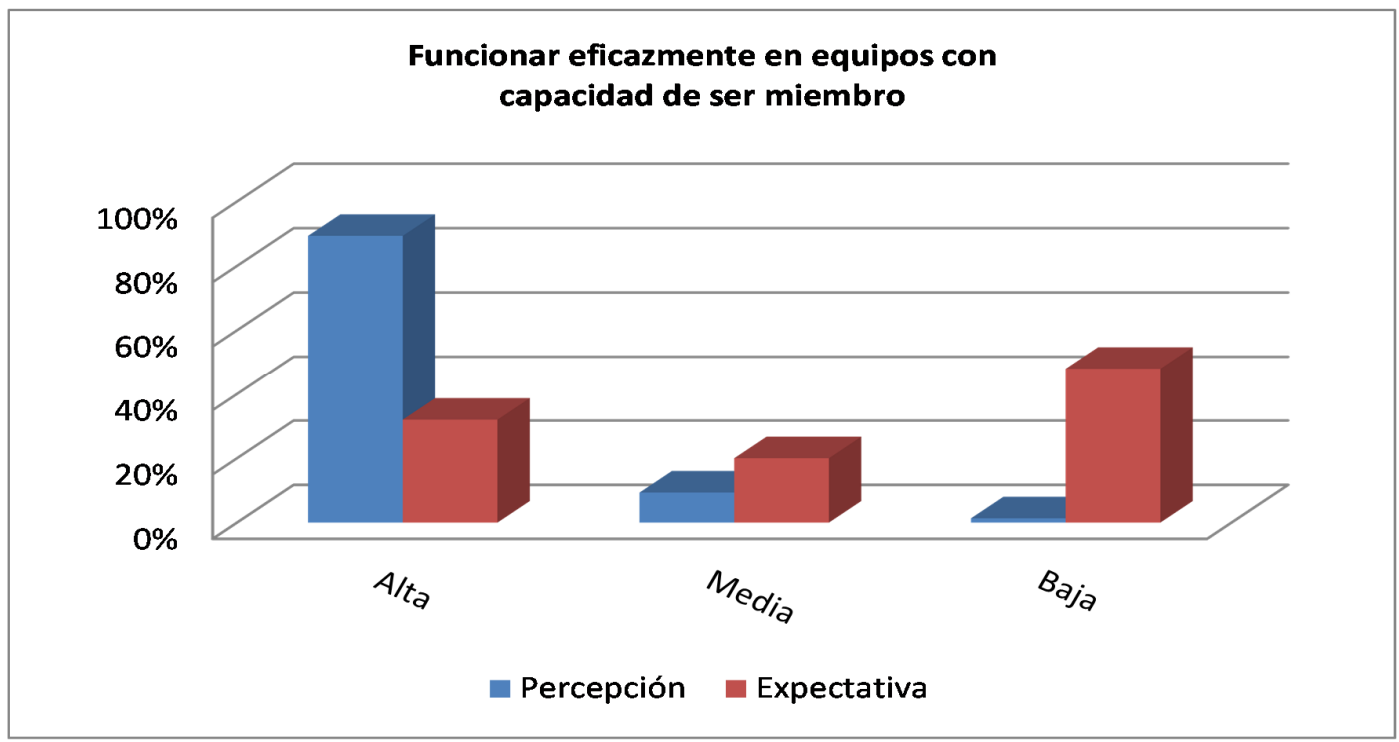

La percepción con un saldo de respuesta de 1,71 es superior a la expectativa, con un saldo de respuesta de 3,44. De las respuestas surge que más del $89 \%$ de los empleadores encuestados ha evaluado como alta la capacidad de los graduados de funcionar eficazmente en equipos con capacidad de ser miembro.

\section{8) Funcionar eficazmente en equipos con capacidad de ser director}

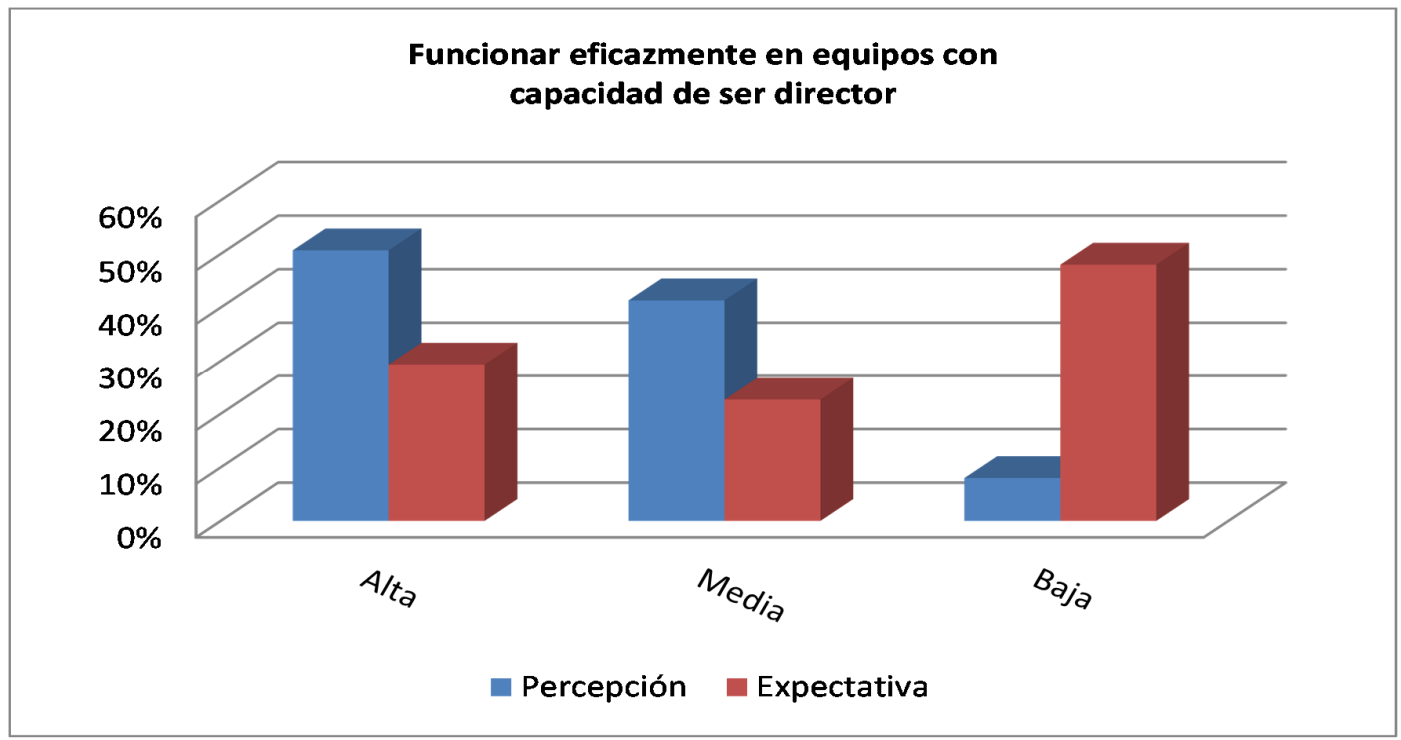

La percepción con un saldo de respuesta de 2,41 es superior a la expectativa, con un saldo de respuesta de 3,6. De las respuestas surge que más del 
$51 \%$ de los empleadores encuestados ha evaluado como alta la capacidad de los graduados de funcionar eficazmente en equipos con capacidad de ser director.

\section{9) Funcionar eficazmente en equipos con capacidad de ser líder}

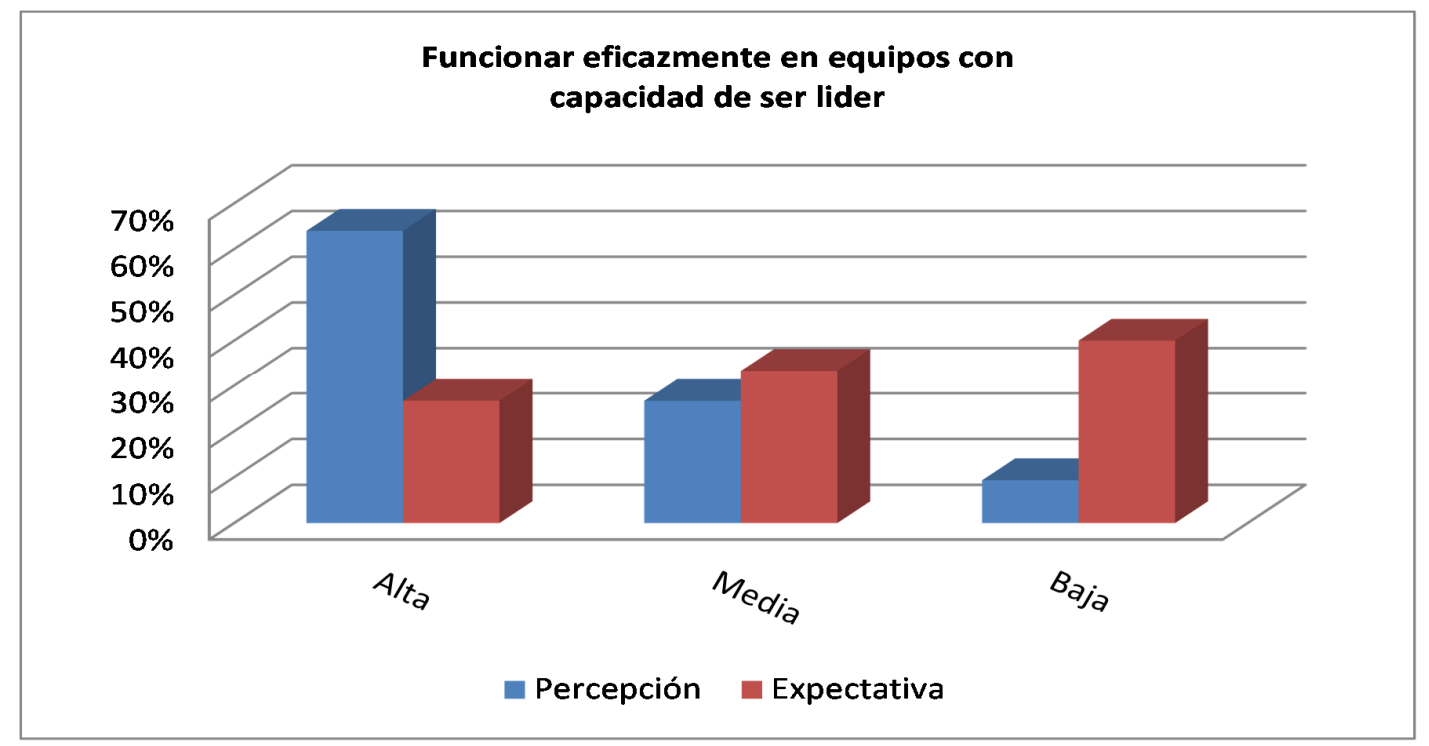

La percepción con un saldo de respuesta de 2,16 es superior a la expectativa, con un saldo de respuesta de 3,31. De las respuestas surge que más del $64 \%$ de los empleadores encuestados ha evaluado como alta la capacidad de los graduados de funcionar eficazmente en equipos con capacidad de ser líder.

Los resultados anteriormente expuestos muestran que en su mayoría la percepción ha superado las expectativas. Por lo tanto se podría concluir que los empleadores están satisfechos con el nivel de habilidades evidenciado por los graduados.

Para confirmar la conclusión realizada en el párrafo anterior, luego de calcular y comparar las percepciones y las expectativas, se obtuvieron las brechas y se calcularon los saldos de respuesta para cada uno de los atributos considerados al evaluar las habilidades de los graduados, obteniendo el siguiente resúmen respecto del nivel de satisfacción de los empleadores. 


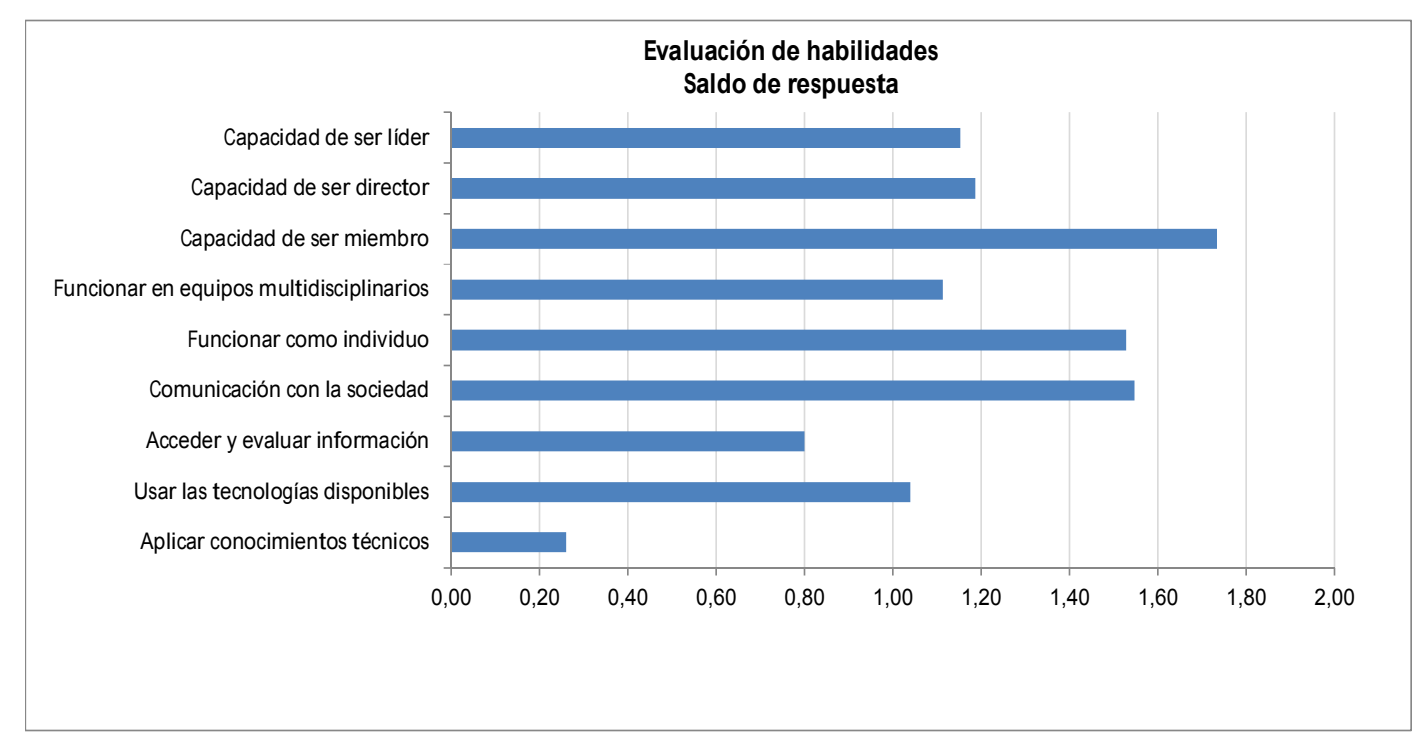

Efectivamente, los resultados confirman que los saldos de respuesta de las brechas se encuentran dentro de la zona de satisfacción, siendo la capacidad de ser miembro, la comunicación con la sociedad, funcionar como individuo, , capacidad de ser director, líder, así como funcionar en equipos multidisciplinarios los atributos en los cuales mayormente se destacan los graduados de la carrera de Contador. 


\section{Percepción y expectativas sobre actitudes}

De las respuestas obtenidas respecto de la evaluación de habilidades a partir de la encuesta.1.3 y de las repuestas sobre las expectativas a partir de la encuesta 4.3 surgen los siguientes resultados:

\section{1) Pensar crítica, creativa y reflexivamente}

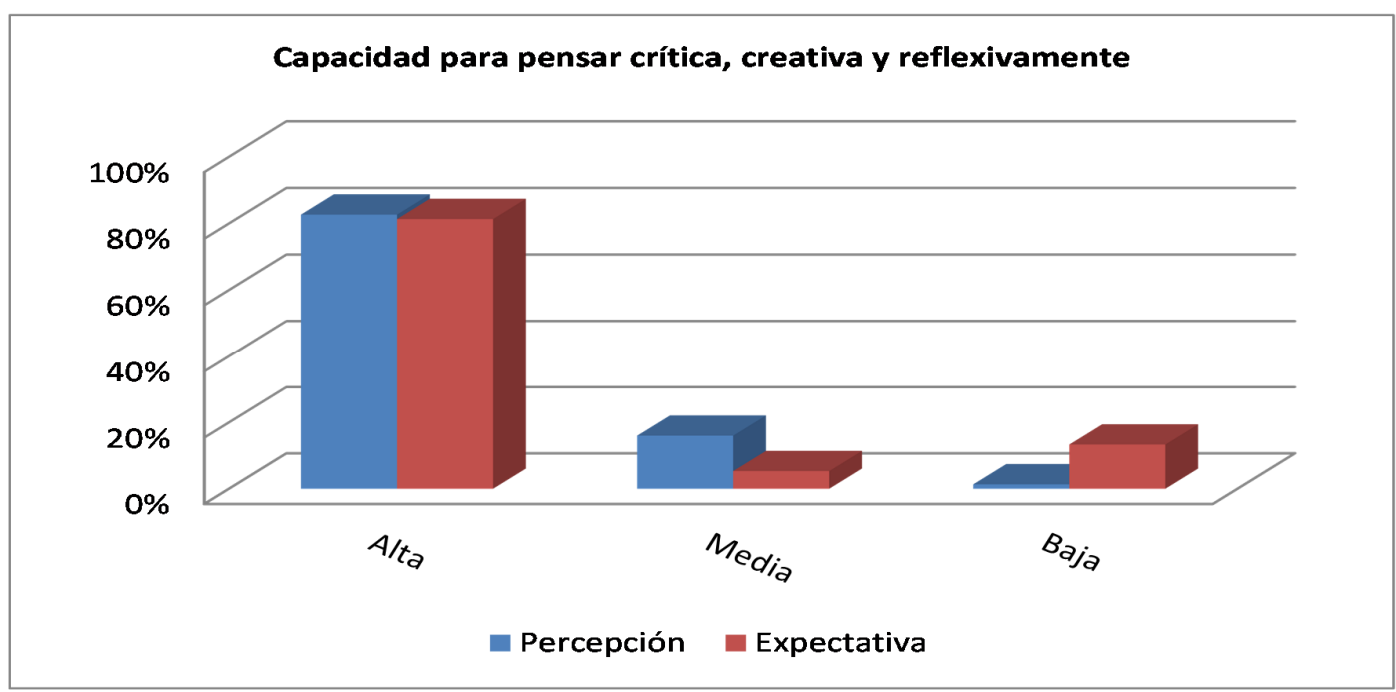

La percepción con un saldo de respuesta de 1,93 es menor a la expectativa, con un saldo de respuesta de 1,51. De las respuestas surge que más del $83 \%$ de los empleadores encuestados ha evaluado como alta la actitud de los graduados de pensar crítica, creativa y reflexivamente.

\section{2) Compromiso al aprendizaje permanente}

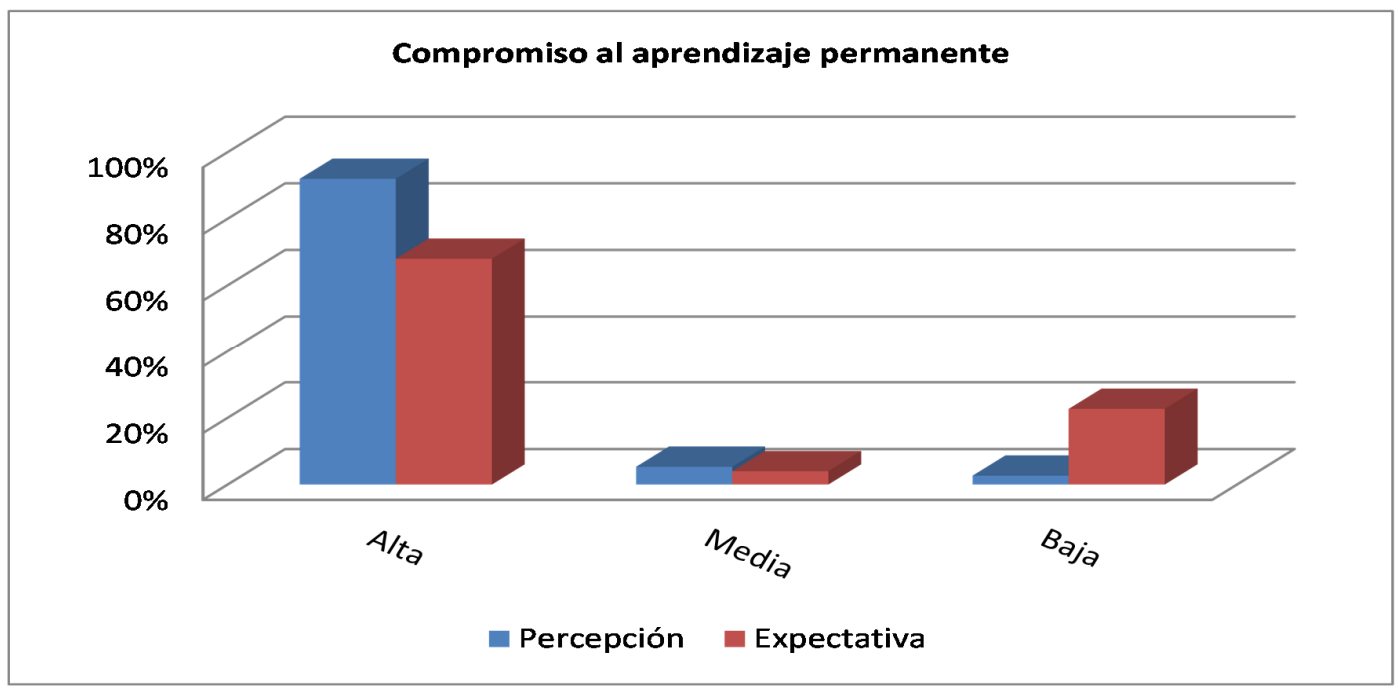


La percepción con un saldo de respuesta de 1,69 es mayor a la expectativa, con un saldo de respuesta de 2,42 . De las respuestas surge que el $92 \%$ de los empleadores encuestados ha evaluado como alta la actitud de los graduados de comprometerse a cumplir con su compromiso en el aprendizaje permanente.

\section{3) Compromiso a cumplir con responsabilidades éticas}

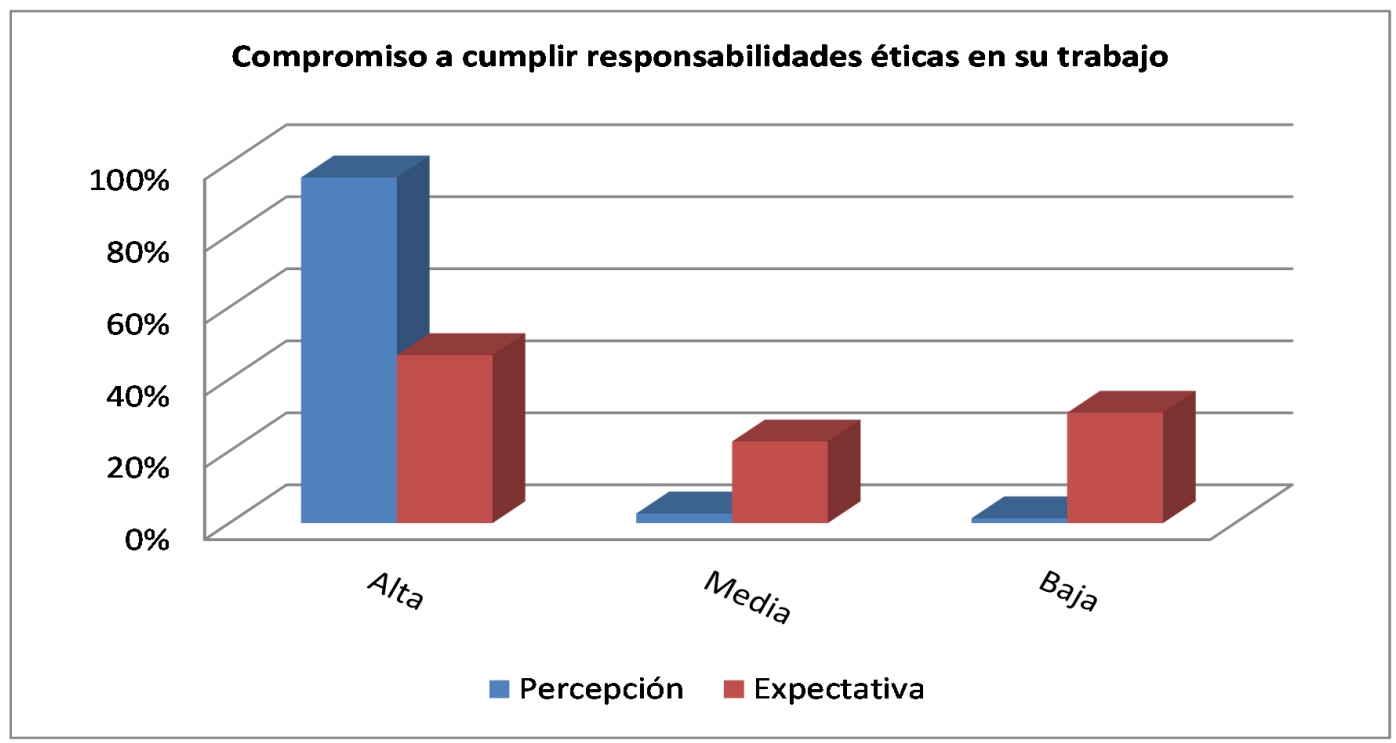

La percepción con un saldo de respuesta de 1,65 es mayor a la expectativa, con un saldo de respuesta de 2,8. De las respuestas surge que el $96 \%$ de los empleadores encuestados ha evaluado como alta la actitud de los graduados de comprometerse a cumplir con sus responsabilidades éticas en su trabajo.

\section{4) Compromiso a cumplir con responsabilidades ambientales}

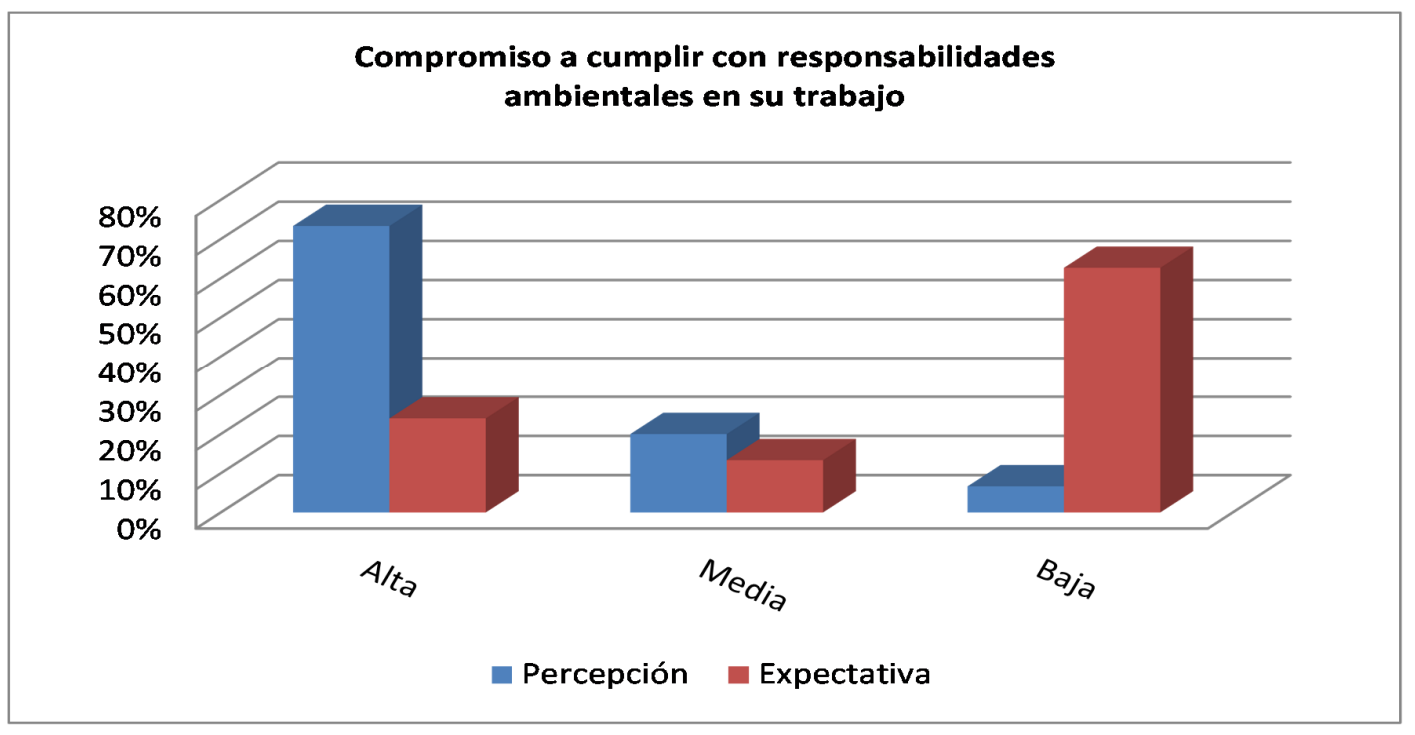


La percepción con un saldo de respuesta de 2,15 es mayor a la expectativa, con un saldo de respuesta de 3,81 . De las respuestas surge que más del $73 \%$ de los empleadores encuestados ha evaluado como alta la actitud de los graduados de comprometerse a cumplir con sus responsabilidades ambientales en su trabajo.

\section{5) Compromiso a trabajar con perspectivas internacionales}

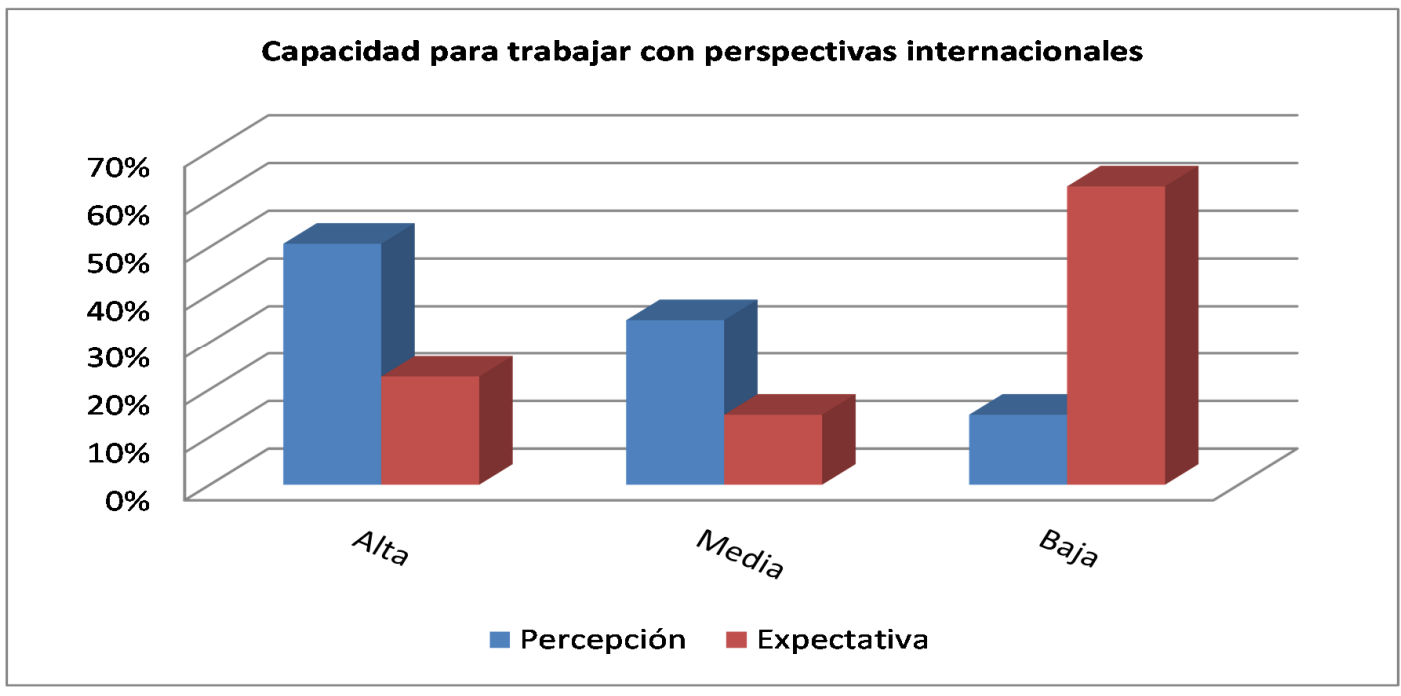

La percepción con un saldo de respuesta de 2,53 es mayor a la expectativa, con un saldo de respuesta de 3,76. De las respuestas surge que más del $51 \%$ de los empleadores encuestados ha evaluado como alta la actitud de los graduados de comprometerse a trabajar con perspectivas internacionales adecuándose a las mismas en su trabajo.

\section{6) Desarrollo de habilidades profesionales}

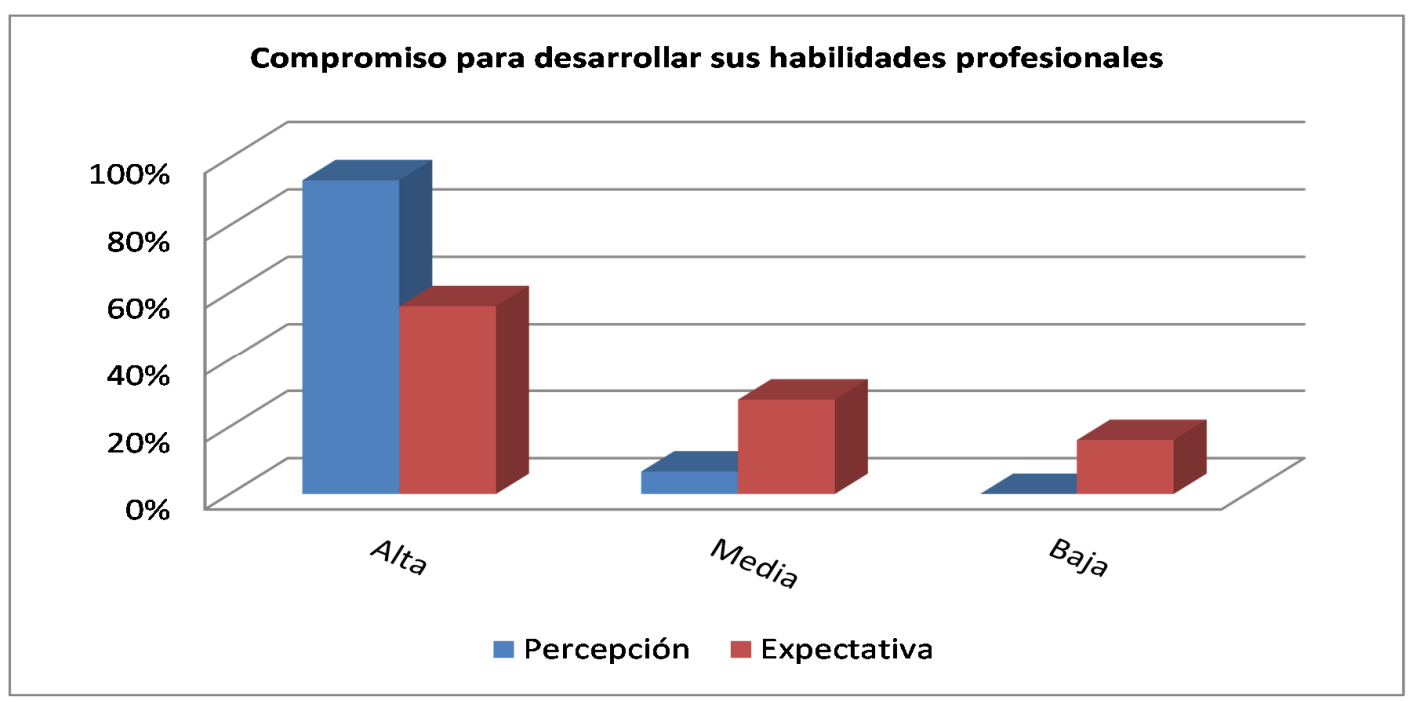


La percepción con un saldo de respuesta de 1,73 es mayor a la expectativa, con un saldo de respuesta de 2,75. De las respuestas surge que más del 93\% de los empleadores encuestados ha evaluado como alta la actitud de los graduados de comprometerse a desarrollar sus habilidades profesionales.

\section{7) Compromiso a trabajar con diferentes grupos culturales}

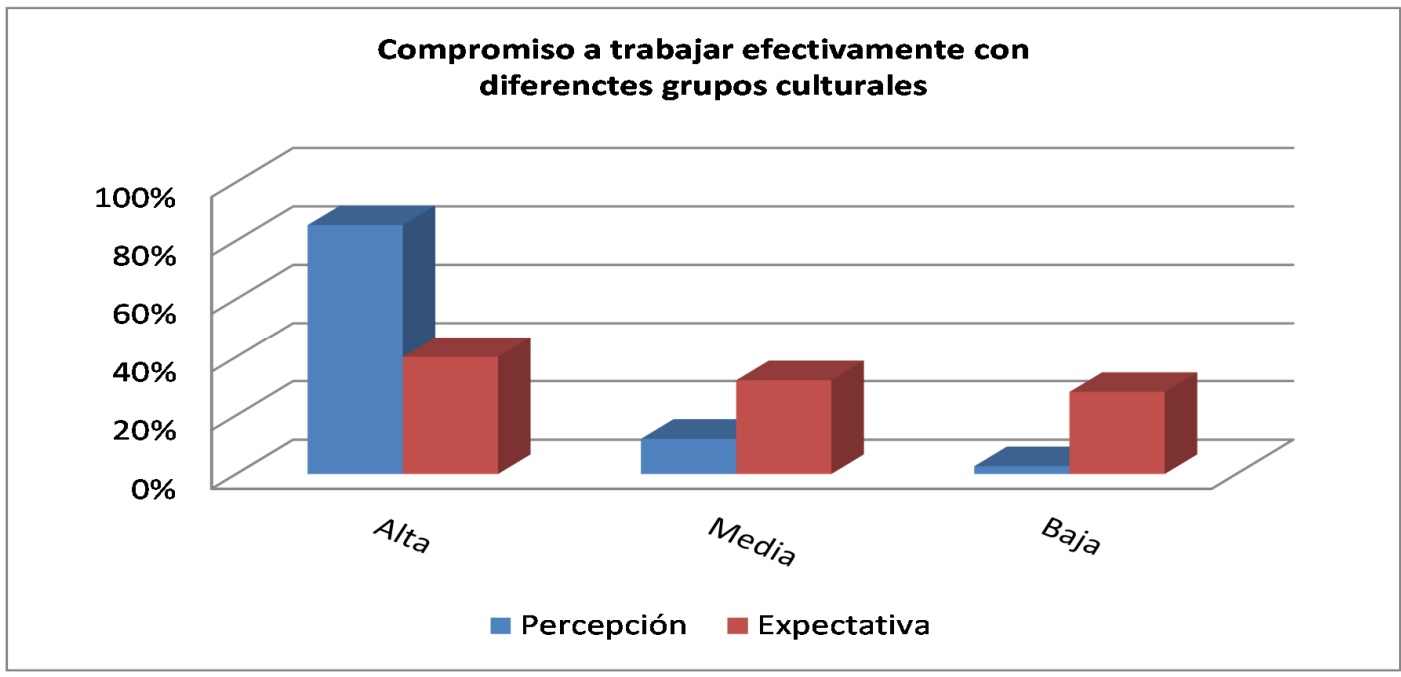

La percepción con un saldo de respuesta de 1,92 es mayor a la expectativa, con un saldo de respuesta de 3,06. De las respuestas surge que más del $85 \%$ de los empleadores encuestados ha evaluado como alta la actitud de los graduados de comprometerse a trabajar efectivamente con diferentes grupos culturales.

\section{8) Compromiso a utilizar habilidades grupales}

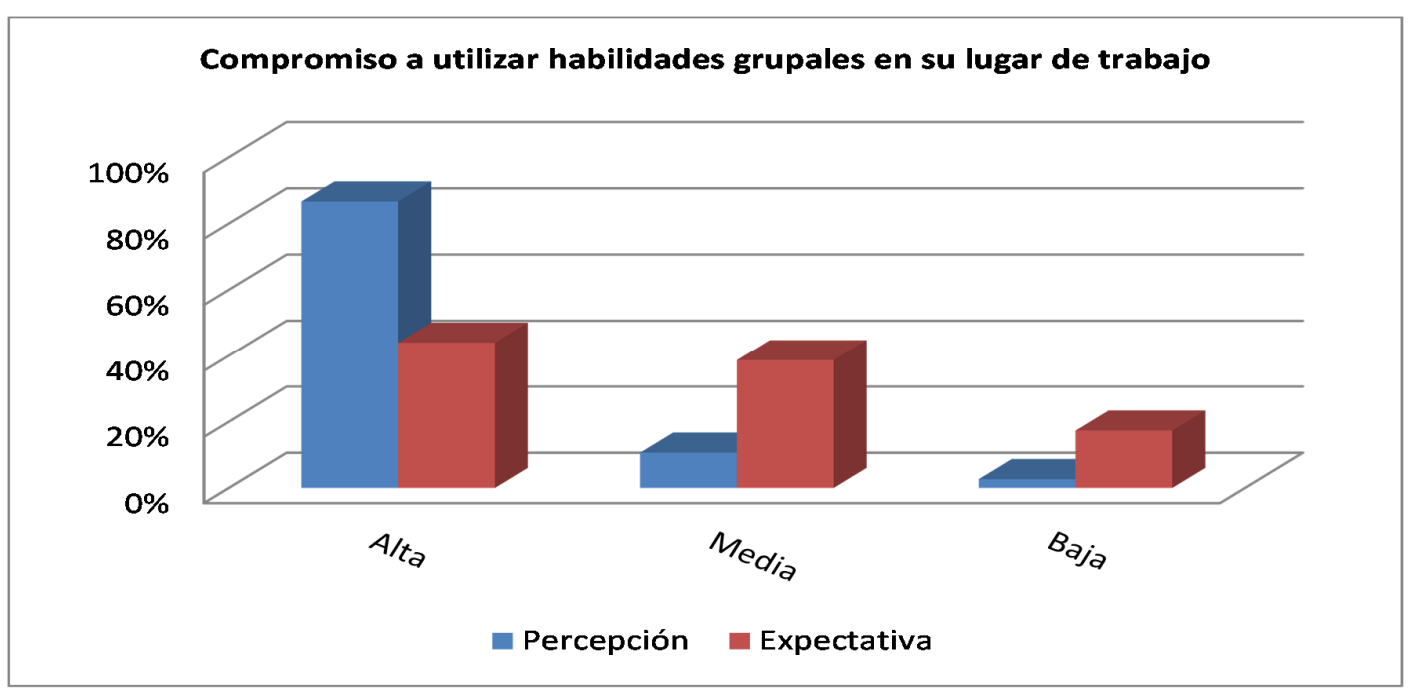


La percepción con un saldo de respuesta de 1,83 es mayor a la expectativa, con un saldo de respuesta de 2,96. De las respuestas surge que más del $87 \%$ de los empleadores encuestados ha evaluado como alta la actitud de los graduados de comprometerse a utilizar habilidades grupales en su lugar de trabajo.

\section{9) Compromiso a desarrollar habilidades interpersonales}

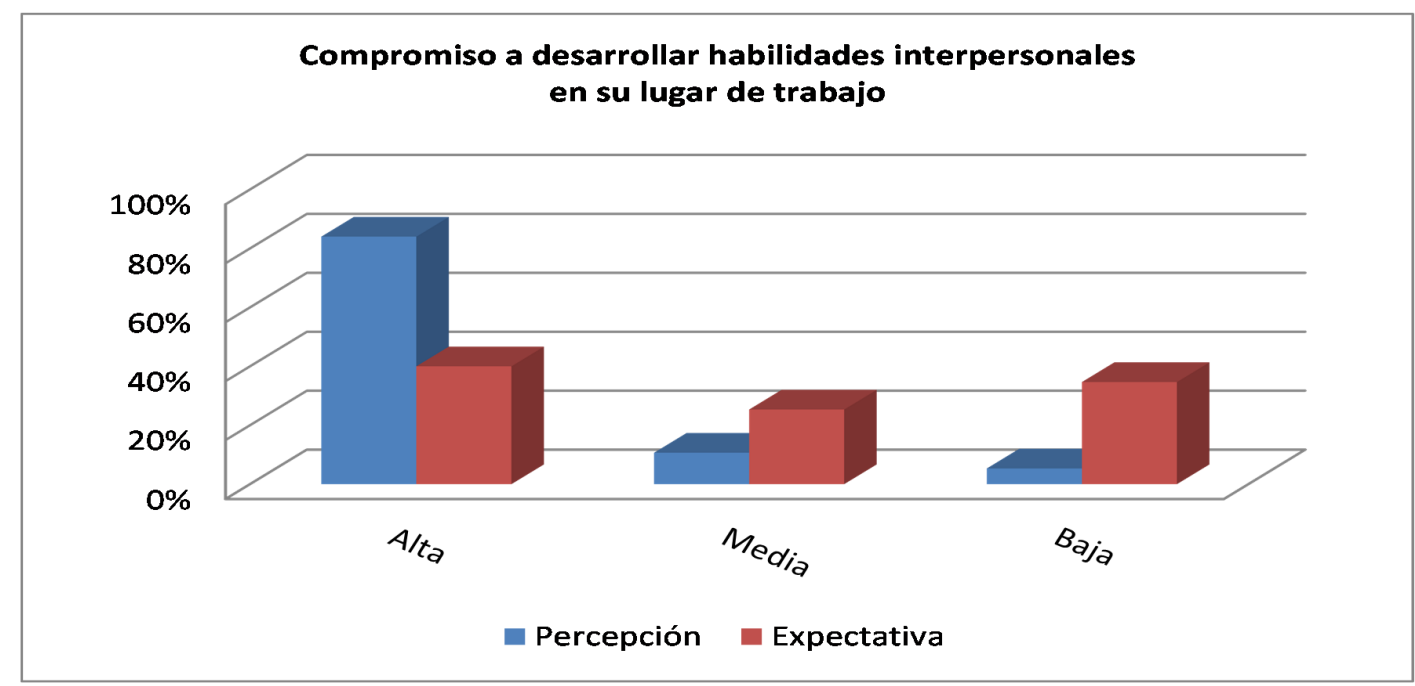

La percepción con un saldo de respuesta de 1,84 es mayor a la expectativa, con un saldo de respuesta de 2,98. De las respuestas surge que más del $84 \%$ de los empleadores encuestados ha evaluado como alta la actitud de los graduados de comprometerse a desarrollar habilidades interpersonales en su lugar de trabajo.

Los resultados anteriormente expuestos muestran que en su mayoría la percepción ha superado las expectativas. Por lo tanto se podría concluir que los empleadores están satisfechos con el nivel de actitudes evidenciadas por los graduados.

Para confirmar la conclusión realizada en el párrafo anterior, luego de calcular y comparar las percepciones y las expectativas, se obtuvieron las brechas y se calcularon los saldos de respuesta para cada uno de los atributos considerados al evaluar las actitudes de los graduados, obteniendo el siguiente resumen respecto del nivel de satisfacción de los empleadores. 


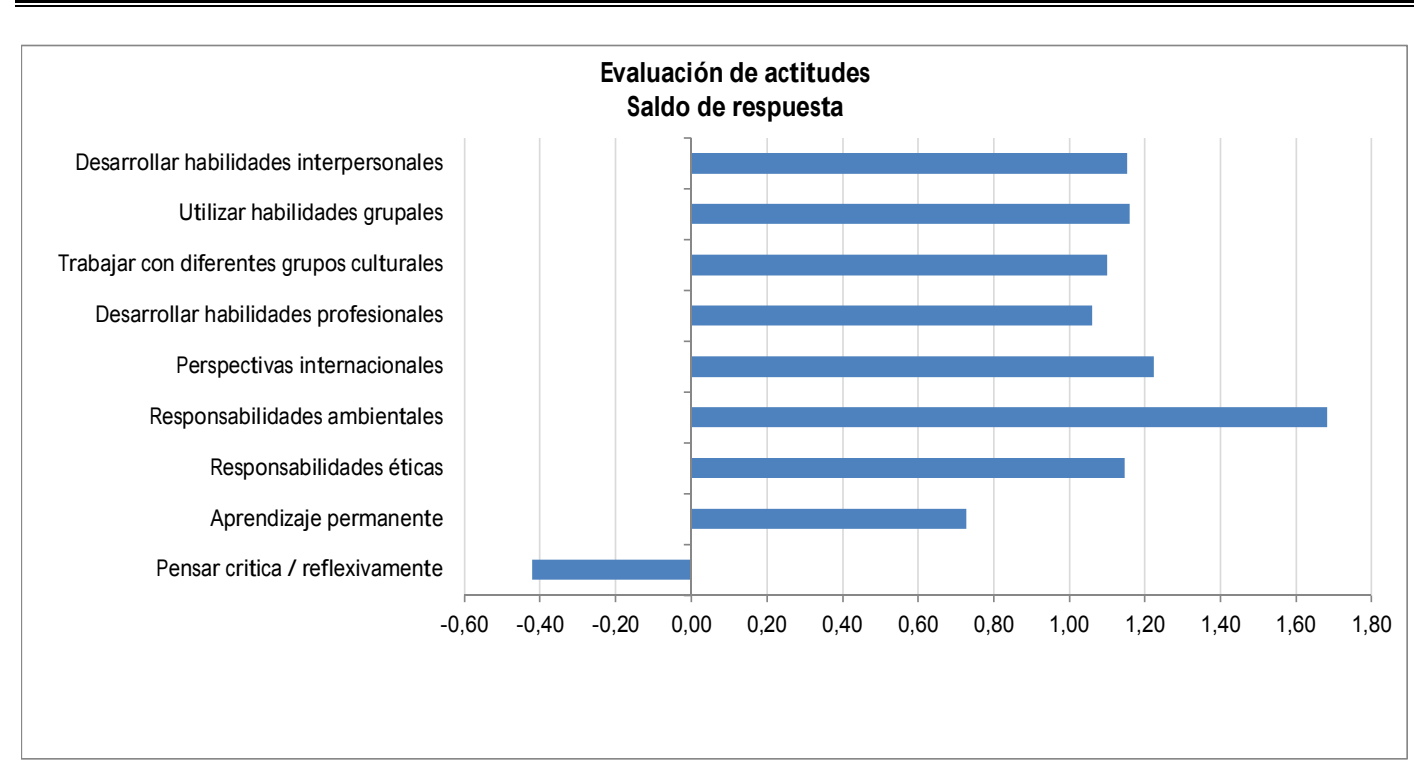

Efectivamente, los resultados confirman que los saldos de respuesta de las brechas se encuentran dentro de la zona de satisfacción, siendo las responsabilidades ambientales, perspectivas internacionales, desarrollar habilidades interpersonales, utilizar habilidades grupales, trabajar con diferentes grupos culturales y responsabilidades éticas, los atributos en los cuales mayormente se destacan los graduados de la carrera de Contador.

\section{Nivel de satisfacción}

De acuerdo con el análisis estadístico realizado, los valores obtenidos al evaluar la satisfacción con los trabajos realizados por los graduados fueron los siguientes:

\begin{tabular}{|c|c|}
\hline Media & 4,227 \\
\hline Mediana & 4,000 \\
\hline $\begin{array}{c}\text { Desvío } \\
\text { Estándar }\end{array}$ & 0,583 \\
\hline
\end{tabular}

Por lo tanto, de acuerdo con la evaluación general que se ha obtenido de la muestra, se puede inferir que en promedio "los clientes" están satisfechos respecto del nivel de los trabajos realizados por los graduados. 


\section{Nivel de desempeño}

Respecto de la duración real y de la calidad de los trabajos realizados por los graduados, la información obtenida de la muestra es la siguiente:

\begin{tabular}{|c|c|c|}
\hline & Duración & Calidad \\
\hline Media & 3,080 & 3,360 \\
\hline Mediana & 3,000 & 3,000 \\
\hline $\begin{array}{c}\text { Desvío } \\
\text { Estándar }\end{array}$ & 0,767 & 0,671 \\
\hline
\end{tabular}

Se puede concluir que, en promedio, tanto la duración real como la calidad de los trabajos realizados por los graduados son iguales a las esperadas por "el cliente". Sin embargo, la duración presenta un mayor desvío respecto de la media que la calidad del trabajo realizado, lo que implica que el desempeño en términos de duración puede presentar mayor diversidad entre los graduados.

\section{Análisis de correlación}

Con el objetivo de poder determinar si tanto la duración como la calidad influyen en la satisfacción respecto del trabajo realizado por los graduados, se procederá a realizar un análisis de correlación entra éstas variables.

En particular se analizará la relación entre:

1) La duración de los trabajos realizados por el graduado con la satisfacción del empleador respecto del resultado del trabajo realizado por el graduado.

2) La calidad de los trabajos realizados por el graduado con la satisfacción del empleador respecto del resultado del trabajo realizado por el graduado.

Los valores obtenidos de la muestra son los siguientes: (ver tabla en página siguiente) 


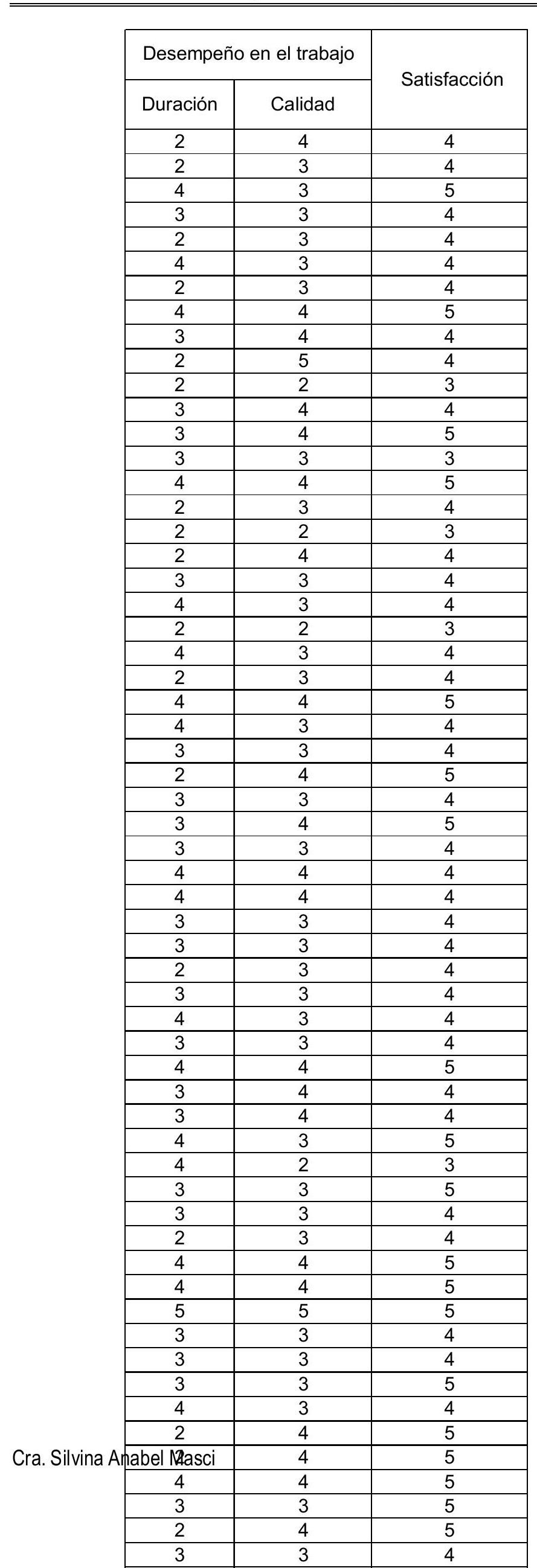


Luego, se encontró que el índice de correlación ${ }^{2}$ para la duración del trabajo realizado por los graduados y la satisfacción del empleador con el resultado del trabajo es igual a 0,29; mientras que el coeficiente de correlación para la calidad del trabajo realizado por el graduado y la satisfacción del empleador con el resultado obtenido es igual a 0,58 .

Los resultados anteriormente expuestos reflejan que si bien tanto la duración como la calidad influirían positivamente en la satisfacción de los empleadores, la calidad del trabajo realizado por el graduado lo haría en mayor medida que la duración en la realización de dicho trabajo a la hora de evaluar la satisfacción de los empleadores.

\section{Significación del coeficiente de correlación}

Una vez calculado el valor del coeficiente de correlación interesa determinar si tal valor obtenido muestra que las variables $X$ e $Y$ están relacionadas en realidad o tan sólo presentan dicha relación como consecuencia del azar. En otras palabras, corresponde establecer la significación de dicho coeficiente de correlación.

Los valores de $t$ encontrados para los coeficientes de correlación calculados anteriormente son los siguientes:

$$
\begin{aligned}
& t_{(\text {duración, satisfacción })}=1,926 \\
& t_{(\text {calidad, satisfacción) }}=4,544
\end{aligned}
$$

El valor obtenido a partir de la tabla de la distribución de $t$ de Student para un nivel de significación de 0,05 $(\alpha=0,05)$ y N-2 grados de libertad $(75-2=73)$ es igual a 1,9929 .

Al comparar los valores de t obtenidos se puede concluir que se rechaza la hipótesis nula planteada con un nivel de significación de 0,05 para el coeficiente de correlación entre la duración de las tareas de los graduados y la satisfacción de los empleadores ( $\mathrm{t}>\mathrm{t}$ (duración, satisfacción)) por lo tanto el coeficiente encontrado es significativo. Luego, las variables están relacionadas.

Asimismo, se rechaza la hipótesis nula con un nivel de significación de 0,05 para el coeficiente de correlación entre la calidad de las tareas realizadas por los

\footnotetext{
${ }^{2}$ Ver anexo A sobre la definición y forma de cálculo del coeficiente de correlación. 
graduados y la satisfacción de los empleadores ( $\mathrm{t}>\mathrm{t}$ (calidad, satisfacción)). En consecuencia el coeficiente encontrado es significativo. Luego, las variables están relacionadas.

\section{Correlación Satisfacción - Competencias}

Siguiendo con el análisis anteriormente realizado, se intentará establecer cuál de las 27 competencias evaluadas por los empleadores están correlacionadas con la satisfacción de los mismos.

Los resultados obtenidos para el coeficiente de correlación entre satisfacción y cada una de las competencias evaluadas se mostrarán a continuación.

De la misma manera que se consideró para la duración y la calidad de las tareas desarrolladas por los graduados, se realizará una prueba de hipótesis para determinar la significatividad de las correlaciones encontradas. Los valores del estadístico t para cada una de los atributos evaluados son las siguientes:

\begin{tabular}{|c|c|c|c|}
\hline Item & Coef de Correlación & T estadístico & Supera T C \\
\hline 5.1 .2 & $58,35 \%$ & 6,1388 & \multirow{11}{*}{$\begin{array}{c}\text { Correlación } \\
\text { moderada }\end{array}$} \\
\hline 4.3 .1 & $53,74 \%$ & 5,4444 & \\
\hline 4.1 .2 & $52,38 \%$ & 5,2537 & \\
\hline 4.3 .7 & $48,99 \%$ & 4,8007 & \\
\hline 4.1 .8 & $46,29 \%$ & 4,4614 & \\
\hline 4.1 .1 & $45,67 \%$ & 4,3858 & \\
\hline 4.3 .8 & $45,02 \%$ & 4,3080 & \\
\hline 4.3 .5 & $42,56 \%$ & 4,0187 & \\
\hline 4.3.6 & $42,03 \%$ & 3,9571 & \\
\hline 4.3.4 & $41,99 \%$ & 3,9525 & \\
\hline 4.3 .9 & $40,24 \%$ & 3,7556 & \\
\hline 4.1 .3 & $39,72 \%$ & 3,6981 & \multirow{18}{*}{$\begin{array}{c}\text { Correlación } \\
\text { débil }\end{array}$} \\
\hline 4.3 .2 & $39,20 \%$ & 3,6410 & \\
\hline 4.2 .6 & $38,84 \%$ & 3,6008 & \\
\hline 4.1 .6 & $38,48 \%$ & 3,5619 & \\
\hline 4.2.4 & $37,48 \%$ & 3,4540 & \\
\hline 4.1 .9 & $37,24 \%$ & 3,4282 & \\
\hline 4.2.1 & $37,02 \%$ & 3,4048 & \\
\hline 4.1 .5 & $36,44 \%$ & 3,3432 & \\
\hline 4.2 .5 & $36,21 \%$ & 3,3186 & \\
\hline 4.1 .7 & $34,62 \%$ & 3,1525 & \\
\hline 4.2 .7 & $33,49 \%$ & 3,0369 & \\
\hline 4.2 .9 & $33,16 \%$ & 3,0030 & \\
\hline 5.1 .1 & $29,14 \%$ & 2,6027 & \\
\hline 4.2 .2 & $27,61 \%$ & 2,4540 & \\
\hline 4.3 .3 & $27,28 \%$ & 2,4227 & \\
\hline 4.1.4 & $26,05 \%$ & 2,3055 & \\
\hline 4.2 .8 & $24,45 \%$ & 2,1547 & \\
\hline 4.2 .3 & $23,78 \%$ & 2,0916 & \\
\hline
\end{tabular}


Las variables cuyo valor del estadístico $t$ es mayor al $t$ crítico $(t=1,9929)$ que surge de la tabla son 5.1.2, 4.3.1, 4.1.2, 4.3.7, 4.1.8, 4.1.1, 4.3.8, 4.3.5, 4.3.6, 4.3.4, 4.3.9 representando ello una correlación moderada. Por lo tanto, éstas son las variables que cuya correlación es estadísticamente significativa. Luego, están correlacionadas con la satisfacción de los empleadores.

Con respecto a las variables $4.13,4.3 .2,4.2 .6,4.1 .6,4.2 .4,4.1 .9,4.2 .1$, $4.1 .5,4.2 .5,4.1 .7,4.2 .7,4.2 .9,5.1 .1,4.2 .2,4.3 .3,4.1 .4,4.2 .8,4.2 .3$ tienen una correlación débil. 


\section{Conclusiones}

\section{Percepción de los empleadores}

Los resultados muestran que los aspectos del conocimiento de los graduados que han sido evaluados con mejor puntaje, han sido la compresión de los principios básicos y conceptos relacionados con su carrera, los fundamentos económicos, así como el entendimiento de los procesos técnicos en al menos una disciplina de la misma, la identificación de problemas, formulación y desarrollo de soluciones y los principios de gestión y negocios. Mientras que los atributos de conocimiento peor evaluados han sido la la utilización de un enfoque de sistema y los principios de diseño y desarrollo económico sostenibles.

Al evaluar las habilidades, la percepción de los empleadores fue que los graduados tienen gran capacidad para aplicar conocimientos técnicos y comunicarse efectivamente no sólo con colegas sino también con profesionales de otras disciplinas y funcionar eficazmente como un individuo. Por otro lado, las habilidades que a criterio de los empleadores deben ser mejoradas por los graduados son la facultad para funcionar eficazmente en equipos ya sea con capacidad de ser líder, o director.

Respecto de las actitudes, las mejores calificadas por los empleadores fueron el compromiso al aprendizaje permanente y a cumplir con responsabilidades éticas en su trabajo. Por el contrario, las actitudes peores conceptuadas fueron el compromiso a trabajar con perspectivas internacionales.

En lo atinente a los estándares de satisfacción de los empleadores respecto de los profesionales para cada uno de los aspectos críticos considerados, se puede concluir que, en promedio y para la muestra analizada, los empleadores están satisfechos con el nivel de los graduados de Contador Público de la UNLP habiéndose obtenido un promedio de 4 (definido como "satisfecho" dentro de la escala de evaluación) para las respuestas referidas a la satisfacción con los resultados del trabajo realizado por los graduados. 


\section{Expectativas de los empleadores}

Las características más valoradas por los empleadores en cuanto al conocimiento fueron la comprensión de los principios básicos y conceptos relacionados con su carrera y entender la ciencia básica y los principios fundamentales de la carrera de Contador. Mientras que los atributos menos valorados fueron la comprensión del proceso técnico y los principios de diseño y desarrollo económico sostenibles relacionados con la carrera.

Al analizar las expectativas sobre las habilidades, los resultados muestran que los empleadores han puesto mayor énfasis en la capacidad la capacidad de aplicar los conocimientos técnicos en al menos una disciplina de la carrera de Contador Público y la utilización apropiada de tecnologías. Las habilidades cuyas expectativas fueron bajas han sido la posibilidad de funcionar eficazmente en equipos con capacidad de ser líder, director.

Finalmente, los resultados sobre las expectativas de las actitudes reflejan que los empleadores están interesados en que los graduados puedan pensar crítica, creativa y reflexivamente, que estén comprometidos al aprendizaje permanente. Por el contrario, las expectativas de los empleadores fueron bajas respecto del compromiso de los graduados a cumplir con responsabilidades ambientales, de la capacidad para trabajar con perspectivas internacionales.

\section{Brecha entre expectativas y percepciones de los empleadores}

Un aspecto importante a tener en cuenta al analizar la brecha fue considerar no sólo la evaluación actual sino también la expectativa sobre el atributo bajo análisis. En tal sentido, una brecha amplia podría deberse tanto a una buena evaluación como a una baja expectativa.

Los resultados expuestos revelaron, en concordancia con el análisis respecto de la satisfacción general de los empleadores con los graduados de la Contador Público, que la totalidad de las brechas analizadas están dentro de la zona de satisfacción. 
Las brechas de las variables con mayor expectativa sobre las competencias de los graduados referidas a cada uno de los grupos definidos, es decir, la capacidad para relacionarse con otras disciplinas, comprender los procedimientos técnicos, fundamentos económicos, capacidad de ser miembro y funcionar como individuo así como cumplir con responsabilidades ambientales y desarrollar habilidades interpersonales si bien no alcanzan el nivel de satisfacción total, cumplen con las expectativas de los empleadores.

Adicionalmente, las brechas de las variables en las cuales los empleadores se han mostrado algo más que satisfechos fueron aquellas en las que las expectativas no eran demasiado altas al momento de realizar la encuesta. 


\section{Recomendaciones}

El resultado de esta investigación sirve de inicio para la elaboración de una propuesta superadora por parte de la Facultad de Ciencias Económicas que ayude a reducir las brechas encontradas en la formación de los graduados respecto de las expectativas de los empleadores.

Si bien se asume que no resulta necesario realizar una investigación complementaria al presente estudio, se destaca que el mismo se encuentra acotado al contexto en el cual fue realizado y por consiguiente, deberá ser actualizado en la medida que tanto el desempeño de los graduados como las expectativas de los empleadores necesariamente se irán modificando con el paso del tiempo. De lo contrario, se podría estar poniendo énfasis en desarrollar competencias que no sean valoradas por el mercado. 


\section{Anexo A: Coeficiente de correlación y prueba de hipótesis}

El coeficiente de correlación de Pearson, pensado para variables cuantitativas es un índice que mide el grado de covariación (es decir el grado de variación conjunta) entre distintas variables relacionadas linealmente.

El índice de correlación es un número que oscila en valores absolutos entre 0 y 1 . Los valores del índice se especifican en "valores absolutos" ya que en realidad si se contempla el signo el coeficiente de correlación de Pearson oscila entre -1 y +1 . No obstante ha de indicarse que la magnitud de la relación viene especificada por el valor numérico del coeficiente, reflejando el signo la dirección de tal valor. En este sentido, tan fuerte es una relación de +1 como de -1 . En el primer caso la relación es perfecta positiva y en el segundo perfecta negativa. Se dice que la correlación entre dos variables $\mathrm{X}$ e $\mathrm{Y}$ es perfecta positiva cuando exactamente en la medida que aumenta una de ellas aumenta la otra. Se dice que la relación es perfecta negativa cuando exactamente en la medida que aumenta una variable disminuye la otra. Cuando el índice es igual a 0 significa que no hay relación lineal entre las variables y por lo tanto la variación en una de las variables no influye en la variación de la otra.

El coeficiente de correlación se calcula en función de la siguiente fórmula:

$$
r_{x y}=\frac{\sum Z_{x} Z_{y}}{N}
$$

Siendo

$$
\begin{aligned}
& Z_{x}=\frac{X-\bar{X}}{S_{x}} \\
& Z_{y}=\frac{Y-\bar{Y}}{S_{y}}
\end{aligned}
$$

Donde:

$$
\begin{aligned}
& \mathrm{X}=\text { a los valores obsenvados de la variable } \mathrm{x} \\
& \bar{X}=\text { al promedio de los valores de la variable } \mathrm{x} \\
& \mathrm{S}_{\mathrm{x}}=\text { Desvío estándar de la variable } \mathrm{x}
\end{aligned}
$$




$$
\begin{aligned}
& \mathrm{Y}=\text { a los valores observados de la variable y } \\
& \frac{\mathrm{Y}}{\bar{Y}}=\text { al promedio de los valores de la variable y } \\
& \mathrm{S}_{\mathrm{y}}=\text { desvío estándar de la variable y } \\
& \mathrm{N}=\text { tamaño de la muestra }
\end{aligned}
$$

Un coeficiente de correlación se dice que es significativo si se puede afirmar, con una cierta probabilidad, que es diferente de cero. En términos estadísticos, preguntarse por la significación de un cierto coeficiente de correlación no es otra cosa que preguntarse por la probabilidad de que tal coeficiente proceda de una población cuyo valor sea de cero. A este respecto, como siempre, se tienen dos hipótesis posibles:

$$
\begin{aligned}
\mathrm{H}_{0}: \mathrm{r}_{x y}= & 0 \text {, el coeficiente de correlación procede de una población cuyo } \\
& \text { coeficiente de correlación es cero } \\
\mathrm{H}_{1}: \mathrm{r}_{\mathrm{xy}} \neq & 0 \text {, el coeficiente de correlación procede de una población cuyo } \\
& \text { coeficiente de correlación es distinto de cero. }
\end{aligned}
$$

Desde el supuesto de la Hipótesis nula se demuestra que la distribución muestral de correlaciones procedentes de una población caracterizada por una correlación igual a cero sigue una distribución de Student con N-2 grados de libertad:

$$
S_{r}=\sqrt{\frac{1-r_{x y}^{2}}{N-2}}
$$

En consecuencia, dado un cierto coeficiente de correlación $r_{x y}$ obtenido en una determinada muestra, se trata de comprobar si dicho coeficiente es posible que se encuentre dentro de la distribución muestral especificada por la Hipótesis nula. A efectos prácticos, se calcula el número de desviaciones tipo que se encuentra el coeficiente obtenido del centro de la distribución, según la siguiente fórmula:

$$
t=\frac{r_{x y}-0}{\sqrt{\frac{1-r_{x y}^{2}}{N-2}}}
$$

Luego se compara el valor obtenido con el existente en las tablas para un cierto nivel de significación a y N-2 grados de libertad $\left(\mathrm{t}_{(\alpha, \mathrm{N}-2)}\right)$, que marca el límite (baja probabilidad de ocurrencia, según la Hipótesis nula) de pertenencia de un cierto 
coeficiente $r_{x y}$ a la distribución muestral de correlaciones procedentes de una población con coeficiente de correlación igual a cero. De esta forma si:

$$
\begin{aligned}
\mathrm{t}>\mathrm{t}_{(\alpha, \mathrm{N}-2)}= & \text { se rechaza la hipótesis nula. La correlación obtenida no } \\
& \text { procede de una población cuyo coeficiente de correlación es } \\
& \text { igual a cero. Por lo tanto las variables están relacionadas. } \\
\mathrm{t}<\mathrm{t}_{(\alpha, \mathrm{N}-2)}= & \text { se acepta la hipótesis nula. La correlación obtenida procede } \\
& \text { de una población cuyo coeficiente de correlación es igual a } \\
& \text { cero. Por lo tanto las variables no están relacionadas. }
\end{aligned}
$$




\section{Anexo B: Encuesta para empleadores}

Favor de indicar su respuesta para cada pregunta, ya sea marcando una casilla o proporcionando detalles.

\section{1. - Información personal del encuestado}
1.1) Sexo
$1 \square$ hombre $2 \square$ mujer

1.2) Indicar la ciudad donde usted trabaja:

1.3) ¿Cuál es su relación con el graduado?

$1 \square$ empleador $\quad 2 \square$ Supervisor $\quad 3 \square$ Otros, especificar:

1.4) ¿Cuánto tiempo hace que está en este puesto?

$1 \square$ hasta 1 año $\quad 2 \square 2$ años $3 \square 3$ años $\quad 4 \square$ de más de 3 años

\section{2. - Información sobre el graduado}
2.1) Sexo
$1 \square$ hombre $2 \square$ mujer

2.2 El graduado está graduado de la carrera de:

2.3) Año en que el graduado completó sus estudios:

2.4) Si el graduado trabaja en una ciudad distinta de usted, indicar la ciudad donde trabaja el graduado:

2.5) ¿El graduado continuó con su perfeccionamiento profesional?
$1 \square \mathrm{Si}$
$2 \square$ No

En caso afirmativo, indicar el tipo de desarrollo profesional que ha emprendido el graduado: 
2.5) ¿Cuántos años de experiencia tiene el graduado en el trabajo?

2.6) ¿El graduado ha recibido capacitación en el lugar de trabajo para realizar sus tareas?
$1 \square \mathrm{Si}$
$2 \square$ No

En caso afirmativo, ¿cuánto tiempo ha durado la capacitación?

$1 \square$ Hasta 8 horas $2 \square 9-16$ horas $\quad 3 \square 17-24$ horas $4 \square$ Más de 24
horas

\section{3. - Detalles del trabajo del graduado}

3.1) ¿Cuál es la naturaleza del trabajo que desempeña el graduado?

$1 \square$ Gestión $\quad 2 \square$ Técnica $\quad 3 \square$ Otros, especificar

3.2) ¿Dónde se realiza mayoritariamente el trabajo?

$1 \square$ En una Oficina $2 \square$ En forma virtual $3 \square$ Otros, especificar

3.3) ¿Qué tipo de comunicación es más necesaria para el trabajo?

$1 \square$ Oral $\quad 2 \square$ Escrita $3 \square$ Mediante gráficos $\quad 4 \square$ Otra, especificar

\section{4. - Atributos existentes del graduado}

Las siguientes afirmaciones están destinadas a intentar identificar los atributos existentes del graduado objeto de esta encuesta. Por favor marque con una cruz el número de la respuesta que usted crea que representa sus creencias acerca de la afirmación.

\begin{tabular}{|c|c|c|c|c|}
\hline $\begin{array}{c}1 \text { = Totalmente } \\
\text { en desacuerdo }\end{array}$ & $\begin{array}{c}2 \text { = En } \\
\text { desacuerdo }\end{array}$ & $\begin{array}{c}3=\text { No está } \\
\text { seguro }\end{array}$ & $4=$ De acuerdo & $\begin{array}{c}5=\text { Muy de } \\
\text { acuerdo }\end{array}$ \\
\hline
\end{tabular}




\section{1.-Evaluación de conocimientos}

\begin{tabular}{|c|c|c|c|c|c|}
\hline Creo que el graduado: & 1 & 2 & 3 & 4 & 5 \\
\hline $\begin{array}{l}\text { 4.1.1) Entiende los principios básicos y conceptos } \\
\text { relacionados con su carrera }\end{array}$ & & & & & \\
\hline 4.1.2) Entiende los fundamentos económicos su carrera & & & & & \\
\hline $\begin{array}{l}\text { 4.1.3) Entiende en profundidad los procedimientos } \\
\text { técnicos en al menos una disciplina de su carrera }\end{array}$ & & & & & \\
\hline $\begin{array}{l}\text { 4.1.4) Entiende la identificación de problemas, su } \\
\text { formulación y el desarrollo de soluciones }\end{array}$ & & & & & \\
\hline 4.1.5) Entiende cómo utilizar un enfoque de sistema & & & & & \\
\hline $\begin{array}{l}\text { 4.1.6) Entiende los principios de diseño y desarrollo } \\
\text { económico sostenibles }\end{array}$ & & & & & \\
\hline $\begin{array}{l}\text { 4.1.7) Entiende las leyes, reglamentos y normas } \\
\text { relacionadas con su carrera }\end{array}$ & & & & & \\
\hline 4.1.8) Entiende los principios de gestión y negocios & & & & & \\
\hline $\begin{array}{l}\text { 4.1.9) Comprende otras disciplinas relacionadas con su } \\
\text { carrera (lógico-matemáticas, humanas y sociales) }\end{array}$ & & & & & \\
\hline
\end{tabular}

\section{2.-Evaluación de habilidades}

\begin{tabular}{|l|l|l|l|l|l|}
\hline \multicolumn{1}{|c|}{ Creo que el egresado es capaz de: } & 1 & 2 & 3 & 4 & 5 \\
\hline $\begin{array}{l}\text { 4.2.1) Aplicar perfectamente los conocimientos técnicos en } \\
\text { al menos una disciplina de su carrera }\end{array}$ & & & & \\
\hline $\begin{array}{l}\text { 4.2.2) Usar apropiadamente las tecnologías disponibles } \\
\text { 4.2.3) Acceder, evaluar y sintetizar información }\end{array}$ & & & & & \\
\hline $\begin{array}{l}\text { 4.2.4) Comunicarse efectivamente no sólo con sus } \\
\text { colegas sino también con los profesionales de otras } \\
\text { disciplinas y la comunidad en general. }\end{array}$ & & & & & \\
\hline $\begin{array}{l}\text { 4.2.5) Funcionar eficazmente como un individuo } \\
\text { 4.2.6) Funcionar eficazmente en equipos } \\
\text { multidisciplinarios o multiculturales }\end{array}$ & & & & & \\
\hline $\begin{array}{l}\text { 4.2.7) Funcionar eficazmente en equipos con capacidad } \\
\text { de ser miembro }\end{array}$ & & & & & \\
\hline $\begin{array}{l}\text { 4.2.8) Funcionar eficazmente en equipos con la capacidad } \\
\text { de ser un director }\end{array}$ & & & & & \\
\hline
\end{tabular}


4.2.9) Funcionar eficazmente en equipos con la capacidad para ser un líder

\section{3.-Evaluación sobre actitudes}

\begin{tabular}{|l|l|l|l|l|l|}
\hline \multicolumn{1}{|c|}{ Creo que el egresado es capaz de: } & 1 & 2 & 3 & 4 & 5 \\
\hline $\begin{array}{l}\text { 4.3.1) Pensar crítica, creativa y reflexivamente en su } \\
\text { trabajo }\end{array}$ & & & & & \\
\hline $\begin{array}{l}\text { 4.3.2) Comprometerse al aprendizaje permanente } \\
\text { éticas en su trabajo } \\
\text { é.3) Comprometerse a cumplir con las responsabilidades }\end{array}$ & & & & & \\
\hline $\begin{array}{l}\text { 4.3.4) Comprometerse a cumplir responsabilidades } \\
\text { ambientales en su trabajo }\end{array}$ & & & & & \\
\hline $\begin{array}{l}\text { 4.3.5) Trabajar con perspectivas internacionales y } \\
\text { mundiales adecuándose a las mismas. }\end{array}$ & & & & & \\
\hline $\begin{array}{l}\text { 4.3.6) Comprometerse a desarrollar aún más sus } \\
\text { habilidades profesionales }\end{array}$ & & & & & \\
\hline $\begin{array}{l}\text { 4.3.7) Comprometerse a trabajar efectivamente con } \\
\text { diferentes grupos culturales }\end{array}$ & & & & & \\
\hline $\begin{array}{l}\text { 4.3.8) Comprometerse para utilizar habilidades grupales } \\
\text { en su lugar de trabajo }\end{array}$ & & & & & \\
\hline $\begin{array}{l}\text { 4.3.9) Comprometerse para desarrollar habilidades } \\
\text { interpersonales efectivas en su lugar de trabajo }\end{array}$ & & & & & \\
\hline
\end{tabular}

\section{5. - Desempeño en el trabajo}

Las siguientes preguntas están asociadas con el desempeño del trabajo o proyecto emprendido por el graduado. Por favor marque con un círculo el número de la respuesta que exprese su apreciación sobre el graduado.

\section{1.-Evaluación sobre el desempeño de cualquier trabajo}

Por favor marque con un círculo el número de la respuesta que exprese su apreciación sobre el graduado.

5.1.1. ¿Cuál es la duración real de los trabajos realizados por el graduado? 


\begin{tabular}{|c|c|c|c|c|}
\hline $\begin{array}{c}1 \text { = Mucho más } \\
\text { que lo } \\
\text { planificado }\end{array}$ & $\begin{array}{c}2 \text { = Más que lo } \\
\text { planificado }\end{array}$ & $\begin{array}{c}3=\text { lgual que lo } \\
\text { planificado }\end{array}$ & $\begin{array}{c}4=\text { Menos que } \\
\text { lo planificado }\end{array}$ & $\begin{array}{c}5=\text { Mucho } \\
\text { menos que lo } \\
\text { planificado }\end{array}$ \\
\hline
\end{tabular}

5.1.2. ¿Cuál es la calidad de los trabajos realizados por el graduado?

\begin{tabular}{|c|c|c|c|c|}
\hline $\begin{array}{c}1=\text { Mucho } \\
\text { menos que lo } \\
\text { planificado }\end{array}$ & $\begin{array}{c}2=\text { Menos que } \\
\text { lo planificado }\end{array}$ & $\begin{array}{c}3=\text { Igual que lo } \\
\text { planificado }\end{array}$ & $\begin{array}{c}4=\text { Más que lo } \\
\text { planificado }\end{array}$ & $\begin{array}{c}5=\text { Mucho más } \\
\text { que lo } \\
\text { planificado }\end{array}$ \\
\hline
\end{tabular}

\section{6. - Satisfacción}

La siguiente pregunta está asociada a su satisfacción con los resultados del trabajo o proyecto realizado por el graduado. Por favor marque con un círculo el número de la respuesta que expresa su apreciación sobre el graduado.

\section{1.-Satisfacción con los resultados del trabajo, tarea o proyectos}

Por favor marque con un círculo el número de la respuesta que exprese su apreciación sobre el graduado.

6.1.1. ¿Qué tan satisfecho está usted con el resultado de los trabajos realizados por el graduado?

\begin{tabular}{|c|c|c|c|c|}
\hline $\begin{array}{c}1=\text { Muy } \\
\text { insatisfecho }\end{array}$ & 2 = Insatisfecho & $\begin{array}{c}3=\text { No podría } \\
\text { precisarlo }\end{array}$ & 4 = Satisfecho & $\begin{array}{c}5=\text { Muy } \\
\text { satisfecho }\end{array}$ \\
\hline
\end{tabular}

\section{7. - Expectativa}

Por favor, otorgue un orden jerárquico de 1 a 9 los atributos sobre el conocimiento que usted espera que el graduado demuestre cuando realiza su trabajo. El número 1 indica que usted asigna como altamente significativo al atributo conocimiento.

\section{1.-Conocimiento}

\begin{tabular}{|l|l|}
\hline \multicolumn{1}{|c|}{ El graduado debe: } & Rango \\
\hline 7.1.1) entender los principios y conceptos relacionados con su carrera & \\
\hline 7.1.2) entender la ciencia básica y principios fundamentales de su carrera & \\
\hline $\begin{array}{l}\text { 7.1.3) comprender en profundidad el proceso técnico en al menos una } \\
\text { disciplina de ciencias económicas }\end{array}$ & \\
\hline
\end{tabular}




\begin{tabular}{|l|l|}
$\begin{array}{l}\text { 7.1.4) lograr identificación de problemas, formulación y desarrollo de la } \\
\text { solución }\end{array}$ & \\
\hline $\begin{array}{l}\text { 7.1.5) comprender cómo utilizar un enfoque de sistemas a diseño y } \\
\text { desempeño operativo }\end{array}$ & \\
\hline $\begin{array}{l}\text { 7.1.6) Entiende los principios de diseño y desarrollo económico sostenibles } \\
\text { relacionados con su carrera }\end{array}$ & \\
\hline $\begin{array}{l}\text { 7.1.7) entender las leyes, reglamentos y normas relacionadas con su carrera } \\
\text { 7.1.8) entender los principios de gestión y negocios relacionados con ciencias }\end{array}$ & \\
\hline económicas & \\
\hline 7.1.9) comprender otras disciplinas relacionadas con su carrera & \\
\hline
\end{tabular}

Por favor, otorgue un orden jerárquico de 1 a 9 los siguientes atributos de habilidad, que usted espera que los graduados demuestren cuando realizan su trabajo. El número 1 indica que usted asigna como altamente significativo al atributo habilidad.

\section{2.-Habilidades}

\begin{tabular}{|l|l|}
\hline \multicolumn{1}{|c|}{ El graduado debería ser capaz de: } & Rango \\
\hline $\begin{array}{l}\text { 7.2.1) aplicar conocimientos técnicos en profundidad en al menos una } \\
\text { disciplina de ciencias económicas }\end{array}$ & \\
\hline 7.2.2) usar las tecnologías apropiadamente & \\
\hline 7.2.3) acceder, evaluar y sintetizar información & \\
\hline $\begin{array}{l}\text { 7.2.4) comunicar efectivamente no sólo con los profesionales de económicas } \\
\text { sino también con la comunidad en general }\end{array}$ & \\
\hline $\begin{array}{l}\text { 7.2.5) funcionar eficazmente como un individuo } \\
\text { 7.2.6) funcionar eficazmente en equipos multidisciplinarios o multiculturales }\end{array}$ & \\
\hline 7.2.7) funcionar eficazmente en equipos con capacidad de ser miembro más & \\
\hline 7.2.8) funcionar eficazmente en equipos con capacidad de ser un director & \\
\hline 7.2.9) funcionar eficazmente en equipos con la capacidad de ser un líder & \\
\hline
\end{tabular}

Por favor, otorgue un orden jerárquico de 1 a 9 los siguientes atributos de actitud, que usted espera que los graduados demuestren cuando realizan su trabajo. El número 1 indica que usted asigna como altamente significativo al atributo actitud. 


\section{3.-Actitudes}

\begin{tabular}{|l|l|}
\hline \multicolumn{1}{|c|}{ El graduado debería estar: } & Rango \\
\hline $\begin{array}{l}\text { 7.3.1) Capacitado para pensar críticamente, creativamente, reflexivamente en } \\
\text { su trabajo }\end{array}$ & \\
\hline 7.3.2) comprometido para llevar a cabo el aprendizaje permanente & \\
\hline $\begin{array}{l}\text { 7.3.3) comprometido con las responsabilidades éticas de reunión en su } \\
\text { trabajo }\end{array}$ & \\
\hline $\begin{array}{l}\text { 7.3.4) comprometido a cumplir responsabilidades ambientales en su trabajo } \\
\text { adecuándose a las mismas }\end{array}$ & \\
\hline $\begin{array}{l}\text { 7.3.6) comprometido a desarrollar aún más sus habilidades profesionales } \\
\text { 7.3.7) comprometido a trabajar efectivamente con diferentes grupos culturales }\end{array}$ & \\
\hline $\begin{array}{l}\text { 7.3.8) comprometido para utilizar habilidades grupales en su lugar de trabajo } \\
\text { 7.3.9) comprometido para desarrollar habilidades interpersonales efectivas en } \\
\text { su lugar de trabajo }\end{array}$ & \\
\hline
\end{tabular}

\section{8) Realice comentarios adicionales, si lo desea.}

Por favor, indique su dirección de correo electrónico si le interesaría que la información agregada resultante del procesamiento de este cuestionario se le haga llegar a usted: 


\section{2.- Bibliografía}

- Abdullah, F. (2006). "Measuring service quality in higher education: three instruments compared", International Journal of Research Method in Education, pp. 71-89.

- Albani M. (2009), "Stakeholders' Satisfaction with Civil Engineering Graduates", Curtin University of Technology

- Aldridge, S \& Rowley, J (1998), "Measuring customer satisfaction in higher education", Quality assurance in education, vol. 6, n4, pp. 197-204.

- Angur, M.G. (1998), "Service quality measurements in a developing economy: SERVQUAL versus SERVPERF", Journal of Customer Service in Marketing Management, Vol. 4 No. 3, pp. 47-60.

- Brunner, J. J. (1999). "Los nuevos desafíos de la Universidad”. Educyt. Revista Electrónica de Educación, Ciencia y Técnica de la Facultad de Ciencias Exactas y Naturales de la Universidad de Buenos Aires, (núm. 91).

- Carman, J. M. (1990). "Consumer perceptions of service quality: An assessment of the SERVQUAL dimensions". Joumal of Retailing, Volumen 66. Págs. $33-55$

- Crosby P. B. (1979), "Quality is free”, McGraw-Hill

- Deming, W. Edwards (1986). "Out of the Crisis", MIT Press

- Devlin, S.J., Dong, H.K. and Brown, M. (1993), "Selecting a scale for measuring quality", Marketing Research, Vol. 5 No. 3, pp. 12-17.

- Evans J. R. y Lindsay W. M. (2005). "Calidad total en las organizaciones", Universidad Nacional Autónoma de Honduras.

- Feigenbaum A. V. (1951), "Total Quality Control”, MIT Press

- Harvey, L. (1995), "Student satisfaction", The New Review of Academic Librarianship, Vol. 1, pp. 161-73.

- Hernández Sampieri R. (1997). “Metodología de la investigación”, Mc Graw Hill

- Hill, F.M. (1995), "Managing service quality in higher education: the role of the student as primary consumer", Quality Assurance in Education, Vol. 3 No. 3, pp. 10-21.

- Hoyer R.W. y Hoyer B.Y. (2001). “¿Qué es calidad?”, Revista Quality Progress. 
- Ishikawa K. (1985), “¿Qué es Control Total de la Calidad? El modelo japonés", Prentice Hall.

- Juran J. M. (1967) "Management of Quality Control”, McGraw-Hill.

- O'Neill, M.A. and Palmer, A. (2004). "Importance-performance analysis: a useful tool for directing continuous quality improvement in higher education", Quality Assurance in Education, 12, (1), 39-52.

- Parasuraman, A., Zeithaml, V.A. and Berry, L.L. (1988), "SERVQUAL: a multiple-item scale for measuring consumer perceptions of service quality", Journal of Retailing, Vol. 64 No. 1, pp. 12-24.

- Parasuraman, A., Zeithaml, V.A., Berry, L.L. (1985), “A conceptual model of service quality and its implications for future research", Journal of Marketing, 49, (8), 41-50.

- Russell, M. (2005). "Marketing education: A review of service quality perceptions among international students", International Journal of Contemporary Hospitality Management. 17, (1), 65-77.

- Tunnermann, C. (2000) "Calidad de la educación superior". UNESCO.

- Vistremundo A. C. (2003). "El concepto calidad en la educación universitaria: clave para el logro de la competitividad institucional", Revista Iberoamericana de Educación.

- Wright, C., O'Neill, M. (2002). "Service quality evaluation in the higher education sector: an empirical investigation of students' perceptions", Higher Education Research \& Development, 21, (1), 23-39.

- James P, Womack \& Daniel T. Jones, Lean Thinking. Como utilizar el pensamiento lean para eliminar los despilfarros y crear valor en la empresa. $2^{a}$ ed., Barcelona, España, Ediciones Gestión 2000, 2005.Pag 7 Góngora. 